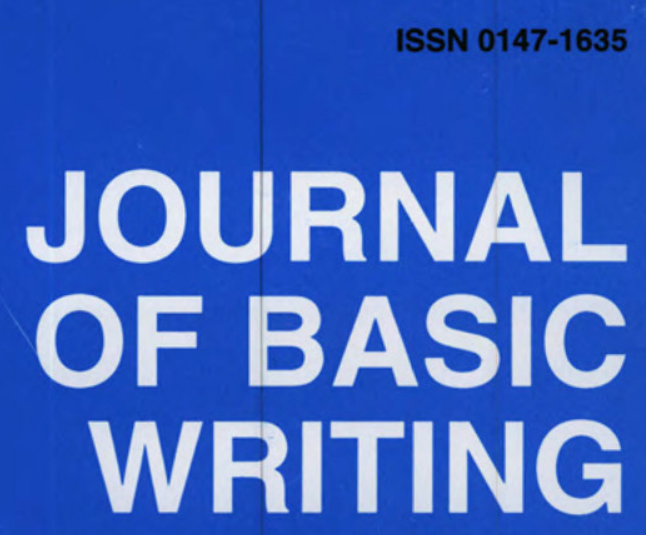

\title{
FALL 1996
}

VOLUME 15 NUMBER 2

A Full and Good World from Mina P. Shaughnessy: Her Life and Work Jane Maher

Revising the Political in Contemporary Basic Writing Scholarship Laura Gray-Rosendale

Narratives of Identity: Theorizing the Writer and the Nation Morris Young

The Hero's Performance and Students' Quests for Meaning and Identity: A Humanities and Writing Course Design

Rosemary Winslow and Monica Mische

The Importance of Expressive Language in Preparing Basic Writers for College Writing Jim Cody

A Basic Writer's Topoi for Timed Essay Tests Ann Kirch 


\section{St. Martin's Press}

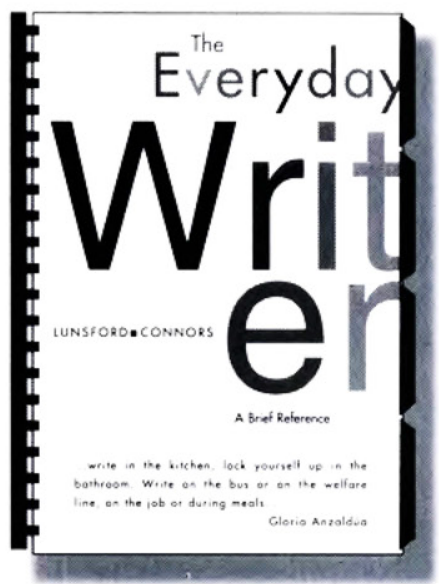

\section{Quick Simple Answers Students Want.}

THE EVERYDAY WRITER

A Brief Reference

INDREA LI ISFORD and ROBERT CONNORS

- Altention to evervday language in everyday language

- Best online coverage, including a special style from ilired Style

- I p-lo-date documentation models for Internet sources in VI. I. IP I. and C.BE styles

- Boxed editing tips help students work with their own writing

- Guidelines on most common errors

ISBN 0-312-09569-4 Just Published

Focuses Students on Their Own Writing.

WINDOWS ON WRITING Practice in Context

LAURIE G. KIRSTIER

STEPIIEN R. MANDELL.

"... This semester / am using W indows on IV riting. . I find that it provides effective instruction and examples. . . and more than adequate exercises... So far I am sery. impressed. . . It is turning out to be every. thing I had hoped it would be .

Paula Hillis, Idaho State I niversits

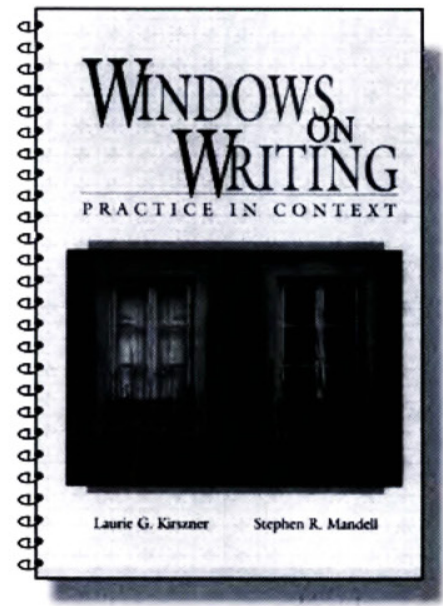

ISBN 0-312-07834-X

ISBN 0-312-14224-2 (with additional readings) 


\section{St. Martin's Press \\ COLLEGE D I VISION}

\section{More Choice}

Means Better Writing.

YOUR CHOICE

A Basic Writing Guide with Readings

KATE MANGELSDORF and EVELYN POSEY

"Your Choice has done much of the work for developmental composition teachers in a clear, practical, yet theoretically sound way."

- Helen Hogan, Salt Lake Community College

http: //wrww_smpcollege_com/Your_Choice/

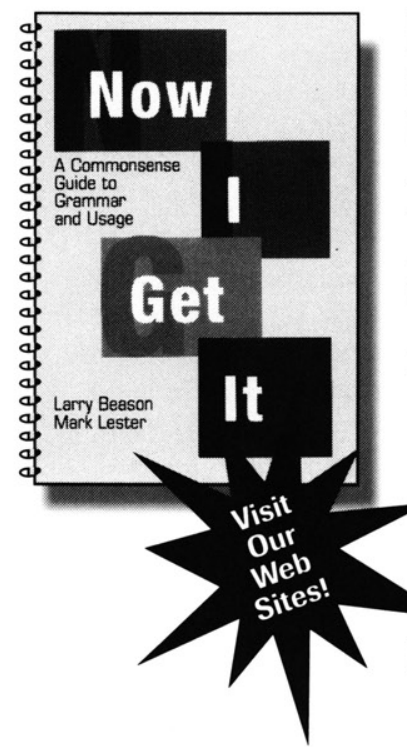

Practical Solutions

to Everyday Writing Problems.

\section{NOW I GET IT}

A Commonsense Guide to

Grammar and Usage

LARRY BEASON and MARK LESTER

"I am impressed by the authors' approach. Every error is broken down into clearly defined components and includes explanations, examples, and hands-on editing.... It is terrific!"

- Judith Funston, SUNY-Potsdam

http: //www.smpcollege.com/get_it/

345 Park Avenue South, New York, NY 10010

I. $800-446.8923$. F a x: (2 I 2) $686-9492$

email: facultyservices@sasmp.com 


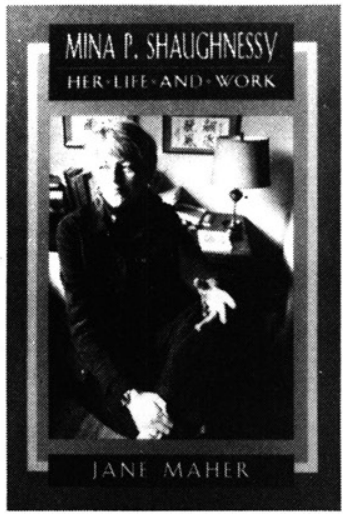

\title{
Mina P. Shaughnessy Her Life and Work
}

\author{
Jane Maher
}

"In addition to quietly telling the story of her subject's life, Nassau Community College professor Jane Maher judiciously excerpts eloquent remembrances from Shaughnessy's fellow dwellersin-the-trenches at the 1970s City University of New, York... giving a real sense of the time's climate."

\section{-Publishers Weekly}

March 24, 1997

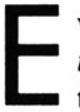

ven before the publication of her pioneering work, Errors and Expectations, Mina P. Shaughnessy was recognized as the leading figure in the field of basic writing and as a devoted advocate of Open Admissions. Her career at City College and the CUNY Instructional Resource Center spanned the turbulent years of Open Admissions, and throughout the late sixties and seventies she worked with a commitment and intensity to her students that was unparalleled. Author Jane Maher has recaptured that intensity in her account of Shaughnessy's remarkable personal and professional life. As a result of her work, Shaughnessy came to realize that "the open admissions experiment, wherever it has been seriously undertaken, has yielded a few truths that I . . w would walk the plank for-and one of them is that the young men and women we call remedial have the capacity (by now the proven capacity) to become competent writers and to do so, if everyone works very hard, even within the harsh limits imposed by the college timetable."

Although Shaughnessy's career was relatively brief - she died in 1978 at the age of 54 -her work as a teacher, a scholar, and an administrator has had a profound and permanent effect on basic writing as a discipline and on the education of underprepared students. From her roots in South Dakota to her professional life in New York City-expertly chronicled here by MaherShaughnessy won international recognition fighting for the rights of those students who had been denied for so many years the right to a college education; in addition, she helped teachers of basic writing realize that teaching these students to write well "is not only suitable but challenging work for those who would be teachers and scholars in a democracy." 331 pp. 1997. ISBN 0-8141-5029-2

No. 50292-4038 \$25.95 (nonmember) $\$ 18.95$ (member)

To order, call NCTE Headquarters toll free at 1-800-369-6283.

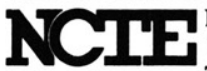


Thousands of languages and millions of words proliferate in the world.

Yet non-verbal communication sometimes drives home the most powerful message.

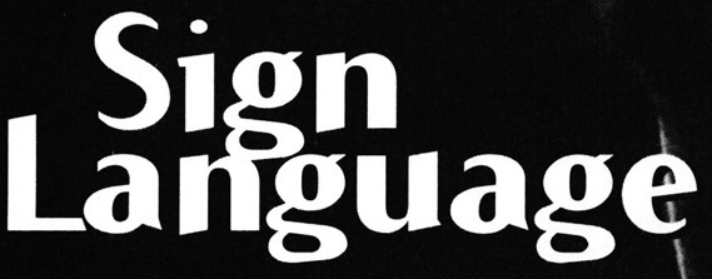

Knowing how to read the signs, both verbal and non-verbal, can make a difference in the international business deal. Or a cross cultural marriage. Or a multilateral treaty.

You'll find the keys in Linguistics and Language Behavior Abstracts (LLBA).

It's about word use and abuse. About the rapid evolution of language. And how communication shapes our lives.

In LLBA you'll find abstracts of scholarly articles and books as well as bibliographical entries for book and other media reviews and dissertations.

Think of LLBA as a sign of the times.

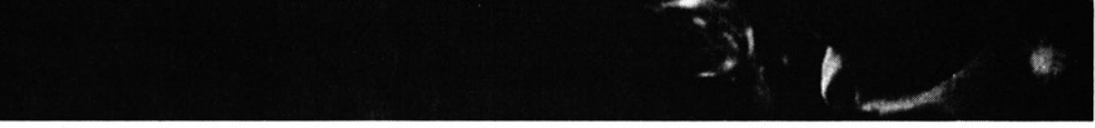

\section{LLBa}

Linguistics and Language Behavior Abstracts
P.O. Box 22206 San Diego, CA 92192-0206 619/695-8803 Fax: 695-0416 Internet socio@ cerfnet.com

LLBA is available in print; online from Knight-Ridder; on CD-ROM from SilverPlatter and NISC; on magnetic tape from LLBA direct. 


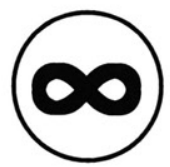

The paper used in this publication meets the minimum requirements of the American National Standard for Information Science -

Permanence of Paper for Printed Library Materials, ANSI Z39.48-1984.

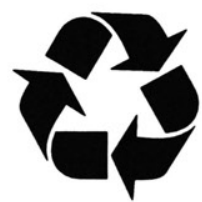

The text stock is also recycled.

This publication is available in microform from UMl.

Please send me information about the titles I've listed below:

Name

Title

Company/Institution

Address

City/State/Zip

Phone (_

\section{U.M.I}

A Bel I \& Howell Company 300 North Zeeb Road, Ann Arbor, M 48106 USA 800-521-0600 toll-free 313-761-4700 collect from Alaska and Michigan 800-343-5299 toll-free from Canada 


\title{
JOURNAL OF BASIC WRITING
}

VOLUME 15 NUMBER 2 FALL 1996

The Journal of Basic Writing publishes articles of theory, research, and teaching practices related to basic writing. Articles are refereed by members of the Editorial Board (see overleaf) and the Editors.

Trudy Smoke and George Otte Editors

\section{Linda Camarasana and Carl Whithaus Editorial Assistants}

\section{Mary E. Carney, Subscriptions}

The Journal of Basic Writing is published twice a year, in the spring and fall. We welcome unsolicited manuscripts and ask authors to consult the detailed "Call for Articles" in this issue. Subscriptions for individuals are $\$ 10.00$ for one year and $\$ 19.00$ for two years; subscriptions for institutions are $\$ 15.00$ for one year and $\$ 29.00$ for two years. Foreign postage is $\$ 5.00$ extra per year. ADDRESS:

\author{
Journal of Basic Writing \\ Instructional Resource Center \\ The City University of New York \\ 535 East 80th Street \\ New York, NY 10021
}




\section{JOURNAL OF BASIC WRITING}

\section{EDITORIAL BOARD}

Peter Dow Adams

Essex Community College, Baltimore

Akua Duku Anokye

University of Toledo

Chris M. Anson

University of Minnesota

David Bartholomae

University of Pittsburgh

Sarah Benesch

College of Staten Island, CUNY

Bill Bernhardt

College of Staten Island, CUNY

Patricia Bizzell

College of the Holy Cross

Lynn Z. Bloom

University of Connecticut, Storrs

Nancy Carriuolo

University of New Haven

Richard Courage

Westchester Community College,

SUNY

Donald Daiker

Miami University

Suellynn Duffey

Ohio University

Sarah Warshauer Freedman

University of California, Berkeley

Karen L. Greenberg

Hunter College, CUNY

Brenda M. Greene

Medgar Evers College, CUNY

Muriel Harris

Purdue University

Irvin Hashimoto

Whitman College

Warren Herendeen

Mercy College

Myra Kogen

Brooklyn College, CUNY
Patricia Ondek Laurence

City College, CUNY

Elaine 0 . Lees

Carlow Hill College

Andrea A. Lunsford

Ohio State University

Jane Maher

Nassau Community College

Peter Miller

College of Staten Island, CUNY

Susan Miller

University of Utah

Nathaniel Norment, Jr.

Temple University

Jerrold Nudelman

Queensborough Community

College, CUNY

Jane Peterson

Richland College, Dallas County

Community College Distnct

Nell Ann Pickett

Hinds Community College

Charles I. Schuster

University of Wisconsin, Milwaukee

Tony Silva

Purdue University

Lynn Quitman Troyka

Oueensborough Community

College, CUNY, ret.

Karen S. Uehling

Boise State University

Billie J. Wahlstrom

University of Minnesota

Evelyn E. Webb

Mississippi State Board for

Community and Junior Colleges

Harvey S. Wiener

Adelphi University 


\section{JOURNAL \\ OF BASIC WRITING}

VOLUME 15

NUMBER 2

FALL 1996

Editors' Column

A Full and Good World from Mina

P. Shaughnessy: Her Life and Work

Jane Maher

Revising the Political in

Basic Writing Scholarship

Laura Gray-Rosendale

Narratives of Identity: Theorizing

the Writer and the Nation

Morris Young

50

The Hero's Performance

and Students' Quests for Meaning

and Identity: A Humanities and

Writing Course Design

Rosemary Winslow \& Monica Mische

76

The Importance of Expressive

Language in Preparing Basic

Writers for College Writing

Jim Cody

95

A Basic Writer's Topoi for

Timed Essay Tests

Ann Kirch

News and Announcements 


\section{CALL FOR ARTICLES}

We welcome manuscripts of 10-20 pages on topics related to basic writing, broadly interpreted.

Manuscripts will be refereed anonymously. We require four copies of a manuscript and an abstract of about 100 words. To assure impartial review, give author information and a short biographical note for publication on the cover page only. Papers which are accepted will eventually have to supply camera-ready copy for all ancillary material (tables, charts, etc.). One copy of each manuscript not accepted for publication will be returned to the author, if we receive sufficient stamps (no meter strips) clipped to a self-addressed envelope. We require the MLA style (MLA Handbook for Writers of Research Papers, $4 r d$ ed., 1995). For further guidance, send a stamped letter-size, self-addressed envelope for our style sheet and for camera-ready specifications.

All manuscripts must focus clearly on basic writing and must add substantively to the existing literature. We seek manuscripts that are original, stimulating, well-grounded in theory, and clearly related to practice. Work that reiterates what is known or work previously published will not be considered.

We invite authors to write about such matters as classroom practices in relation to basic writing theory; cognitive and rhetorical theories and their relation to basic writing, social, psychological, and cultural implications of literacy; discourse theory, grammar, spelling, and error analysis; linguistics; computers and new technologies in basic writing; English as a second language; assessment and evaluation; writing center practices; teaching logs and the development of new methodologies; and cross-disciplinary studies combining basic writing with psychology, anthropology, journalism, and art. We publish observational studies as well as theoretical discussions on relationships between basic writing and reading, or the study of literature, or speech, or listening. The term "basic writer" is used with wide diversity today, sometimes referring to a student from a highly oral tradition with little experience in writing academic discourse, and sometimes referring to a student whose academic writing is fluent but otherwise deficient. To help readers therefore, authors should describe clearly the student population which they are discussing.

We particularly encourage a variety of manuscripts: speculative discussions which venture fresh interpretations; essays which draw heavily on student writing as supportive evidence for new observations; research reports, written in nontechnical language, which offer observations previously unknown or unsubstantiated; and collaborative writings which provocatively debate more than one side of a central controversy.

A "Mina P. Shaughnessy Writing Award" is given to the author of the best JBW article every two years (four issues). The prize is $\$ 500$, now courtesy of Lynn Quitman Troyka. The winner, to be selected by a jury of three scholars/teachers not on our editorial board, is announced in our pages and elsewhere. 


\section{EDITORS' COLUMN}

We begin this issue with the announcement that $J B W$ has a change in its editorship. Karen Greenberg stepped down from this position and has become once again a Consulting Reviewer for the journal. We are grateful for the enormous effort Karen put into $J B W$ and into the field of developmental writing over the past many years. She is an extraordinary scholar and teacher, and since it would be impossible to acknowledge the full extent of her contribution here, we will simply say how grateful we are to her. George Otte, known to many of you because of his basic writing scholarship and his hard work in our field, was able to join Trudy in time to help put this belated but otherwise impressive issue together.

In addition, we are delighted that we were able to hire two editorial assistants, Linda Camarasana and Carl Whithaus, who will be handling subscriptions, permissions, manuscript trafficking, and final production work on the journal. Linda and Carl are both doctoral students at the CUNY Graduate Center (where George is on the faculty) and each has experience in publishing and journal production, as well as knowledge about the field of basic writing. We are very fortunate to have such well-qualified and diligent individuals now working for the journal. With their assistance, we are sure that $J B W$ will be coming to you on time and in excellent shape. We must thank Vice Chancellor Elsa Nuñez for enabling us to hire Linda and Carl at this moment in $J B W$ 's history and we feel this support augurs well for $J B W$ s future.

Despite the pressures that resulted from these changes, we are extremely proud of this issue of $J B W$. It begins with the first chapter from Jane Maher's biography, Mina P. Shaughnessy: Her Life and Work, recently published by NCTE. As many of you know, Shaughnessy was not only in many senses the founder of our academic discipline, but she was also one of the founders of $J B W$, so it is especially appropriate that we are able to include the first chapter of the story of her remarkable life in this issue, particularly since Shaughnessy was the apotheosis of acute attention to students, and this first chapter gives acute attention to her as a student. In fact, acute attention to students might be the theme of this issue, and so it is doubly fitting that the next essay begin with Laura Gray-Rosendale's discussion of Shaughnessy's role in defining the Basic Writer. Gray-Rosendale questions the concept of definition itself and instead chooses to focus on the ways in which "those students whom we label 'Basic Writers' negotiat[e] their own identities as writers in our classes." Closely analyzing student discourse during a revision activity, Gray-Rosendale reveals how students' identities are constructed and reconstructed as they grapple with complex social and political issues:"

In his "Narratives of Identity: Theorizing the Writer and the Nation," Morris Young also includes his students' voices. He examines 
how the process of writing and revising texts helps a group of University of Hawai' $i$ students labeled "at risk" and "non-standard" deepen their understanding of their identities as writers and gain self-determination as Hawai'ians: Rosemary Winslow and Monica Mische also focus on helping their students gain self-awareness and a deeper understanding of their own identities and potential in society in the seminar course they created. In it, basic writers study the hero's quest; they are guided through an examination of the experiences of strong, courageous individuals from a variety of time periods. Through using readings, writing, and visits to such sites as monuments and museums, students learn how individuals make personal and moral decisions. This, in turn, enables the students' move beyond critical skills into "critical wisdom."

Jim Cody in the next essay explains why - though it may seem a paradox - an emphasis on expressive language helps basic writers to write academic discourse. Students enrolled in his workshop discovered the value of their voices as they wrote about their own experiences. By including his students' writing, Cody illustrates how this led them to better understand academic material and to fulfill college assignments. Cody's essay has an interesting complement in Ann Kirch's "A Basic Writer's Topoi for Timed Essay Tests." Kirch found that her basic writing students had difficulty drawing on their personal experiences when confronted with timed writing tests. She discovered that by introducing classical topoi to them, they could learn to create a framework that would allow them to draw from a broad array of ideologies. This not only led students to generate passing essays but also to become more aware of societal issues and problems.

If we have not adequately suggested to you what a substantial and engrossing series of articles is here assembled, we can only refer you to the articles themselves Again, we are extremely pleased with this issue and pledge our commitment to you to get our next issues to you on time. Thank you for your patience and continued support of JBW.

\section{-Trudy Smoke and George Otte}

Correction: In his essay on "Narrative Discourse and the Basic Writer" in the Fall 1995 issue of JBW, Norbert Elliot incorrectly attributed a quote to Patricia Laurence. The quotation on page 20 that begins with the words, "I think $L u$ and her supporters need to get real about the world I'm talking about...." was written by Peter Rondinone in the "Symposium on Basic Writing, Conflict and Struggle, and the Legacy of Mina Shaughnessy" in the December 1993 issue of College English (page 885), not by Patricia Laurence. Professor Rondinone should also have been included in the Works Cited list for Elliot's article. 


\section{A FULL AND GOOD WORLD}

This is the first chapter of Mina P. Shaughnessy: Her Life and Work, published in March, 1997 by The National Council of Teachers of English. Mina P. Shaughnessy was one of the founders of the Journal of Basic Writing; therefore the editors thought it would be fitting that an excerpt of her biography appear in these pages.

Mina Pendo Shaughnessy seemed to be the quintessential New Yorker: tall and beautiful, sophisticated, well spoken, well read, well dressed, interested in literature, art, music, and politics. One of Mina's colleagues at City College remembers thinking when he first met her in 1967 that she must have been teaching writing to disadvantaged students "out of a sense of noblesse oblige. She was a typical Upper East Sider, well dressed, stately, very well bred. One imagined that she left campus and went off to a dinner party with the most influential people, or to a theater opening. I was just flabbergasted when she told me she had been born and raised somewhere in the Midwest; I can't remember precisely where."

In fact, Mina Pendo Shaughnessy was born in Lead, South Dakota, to Ruby Alma Johnson Pendo and Albert Pendo on March 13, 1924. Her brother, George, her best friend throughout her childhood, had been born a year and five days earlier. Lead (rhymes with deed) was, at the time of Mina's birth (and still is), a gold mining town with a population of eight thousand, located about fifty miles west of Rapid City, less than three miles from its twin city, Deadwood, where Wild Bill Hickok was shot in a saloon in 1876, and less than ten miles from Spearfish, a town named by the Lakota Sioux Indians long before they were herded onto reservations. Dances With Wolves was filmed in the Black Hills that surround and rise majestically above these towns, and Native Americans live on the Pine Ridge Indian Reservation, the site

Jane Maher teaches basic writing at Nassau Community College, Garden City, New York, where she is an Associate Professor in the Basic Education Program. She has published two other biographies. Biography of Broken Fortunes is the story of Robertson and Garth Wilkinson James (the younger brothers of Henry and William). Seeing Language in Sign is the story of William C. Stokoe's twenty-year struggle at Gallaudet University to reverse the reigning critical assessment of American Sign Language. She is currently completing One Step More, the biography of Father Joseph C. Martin. In addition she is co-author of a textbook for basic writers, MOSAICS, to be published by Prentice Hall later this year. She is a member of the editorial board of the Journal of Basic Writing. 
of the Wounded Knee Massacre, located approximately sixty miles southeast of Lead. However, Mina's brother, George, recalls that while they were growing up, "we hadn't yet come to terms with the fact that we had taken away the Native Americans' lands, and we had little or no contact with them."

Lead is a classic mining town. The Homestake Mine, founded by William Randolph Hearst, employed more than one thousand miners at the time Mina was born, and it dominated every aspect of the townspeople's lives: they attended the Hearst Free Public School; borrowed books at the Hearst Free Library; shopped at the Hearst Mercantile Company, referred to by everyone as the company store. There were no labor unions in Lead; George Pendo recalls that the mere mention of the word could "cost a man his job." He recalls hearing, as a young child, of the time early in the century when the Homestake owners brought in strikebreakers from Missouri to quash an attempt to form a union-several men died, and there was a general animosity toward Missourians for many years after the incident.

Although one can see the magnificent Black Hills from anywhere in Lead, the town itself is an exquisite example of man-made ugliness. When the mine first began operation in 1876, it was not the practice to backfill mined out areas. As a result, large tracts of land began to cave in. By the late 1920s, the brick and stone buildings of Lead's commercial area, sitting on ground that was sinking as much as thirty-five feet, began to crack and heave. The situation became so serious that residences and commercial buildings had to be moved, leaving an enormous area that came to be known as the "subsidence zone." It was eventually converted into a public park that is known locally as the "Sinking Gardens." In addition, one of the mountains in the center of Lead proved to contain a particularly rich lode. In this case, surfacemining methods were used to extract more than forty million tons of gold from the mountain, leaving a deep oval-shaped open cut in the top of the mountain, as if a giant had taken a huge bite out of it. Brochures advertising tours of the mines try to make the best of this situation by noting that in 1916 a tightrope walker crossed the 4,500-foot wide, 960 -foot deep gouge, but the fact remains that gold mining, at least as it has always been practiced in Lead, South Dakota, wreaks havoc with the environment. The citizens of Lead were not concerned with the appearance of their surroundings, however. Without the mines, there would be no work. In Lead, everyone either worked in the mines or provided services to those who did.

Albert Pendo, Mina's father, was a miner. He was born in Lead in 1900, the third of eight children, two of whom died shortly after birth. His father, Rado Pendo, had emigrated to Lead from a town called Mocici in Croatia in 1887. Soon after he arrived, he established the Mule Deer Saloon, a particularly propitious choice of occupation, given 
the number of men who were "mucking" for gold in the mines more than a mile below ground all day. He met and fell in love with Elin Peyron, who had emigrated from Sweden with her family, but she refused to marry him unless he sold the saloon. He did as she wished but probably regretted it for the rest of his life as one job or enterprise after another failed: he worked in the mines, then in a mill, started a butcher shop, and later started a construction business building roads. (After his children were grown, he moved to Wyoming to raise his own cattle.) Rado Pendo was a devout Catholic, but his wife was an even more devout Lutheran, so the children (except for the oldest, Ralph, who remained a Catholic all of his life) were raised as Lutherans. Mina's father, Albert, completed the eighth grade, as required by law, but he had no further education when he began to work in the Homestake Mine at the age of seventeen.

Mina's mother, Ruby Johnson, was born in San Francisco in 1896. She was one of seven children born to Peter and Susanna Jane Peterson Johnson, both of whom had emigrated to the United States from Sweden and settled in California. The Johnsons moved from San Francisco, California to Douglas, Alaska in 1890 when gold was first discovered there, and Peter Johnson quickly rose to the position of foreman in the Treadwell Mine. However, the ocean broke through the mine, causing it to collapse (an event that made headlines throughout Alaska because of the loss of lives and the irreversible damage to the mine). As a result, Peter and Susanna Johnson and three of their children, including Ruby, moved to South Dakota in 1919, along with many other Treadwell mine families. Jobs were plentiful in the Homestake mine, so these men were able to find work immediately. Ruby had already completed a two-year teaching certificate program at the State Normal School in Bellingham, Washington in 1917 and had begun to teach grade school in Alaska before the move. Ruby's older brother, Charles, her favorite, had graduated from the University of Washington in Seattle with a degree in mining. Soon after the Johnson family arrived in Alaska, he met and married a woman named Mina (pronounced with a long i), a shortening of the name Wilhelmina, after Queen Wilhelmina of the Netherlands. When Charles contracted pneumonia and died, Ruby was devastated. After Charles's death, Ruby maintained close contact with her sister-in-law, even after she relocated to California and remarried. Thus, when Ruby's second child and first daughter was born in 1924, she named her Mina.

When the Johnsons arrived in Lead, South Dakota, they moved into the Swedish section of town. Lead was a town whose neighborhoods were determined by nationality and religion. Mina's brother, George, remembers that there was a Finnish Lutheran section of town, a Swedish Lutheran section of town that included Norwegians, an Italian Catholic section, a Yugoslavian section, and a Serbian section; there 
was even an area that was referred to by everyone as Slavonian Alley. The largest group of residents was comprised of the English Episcopalians. Many of these groups had their own clubs and churches. George remembers that as a child he overheard two women talking about a man who had recently died. When one of the women said she would have a Catholic mass said for the man, the other woman responded that she "might just as well pray for an old, dead cow." George also remembers that Albert Pendo thought it was important to describe himself as Austrian to further distinguish himself from the Yugoslavians, and he showed some annoyance when people assumed that his name was Italian. However, these distinctions did not prevent the children of Lead from mixing and socializing with each other, particularly in school.

Although the Johnsons adapted quickly to life in Lead, having come from another mining town and already knowing many of the miners and their families who had also traveled to South Dakota from Alaska, the "Treadwell miners" who took jobs at the Homestake were never fully accepted. Peter Johnson had been a foreman in the Alaskan mine, but because he was a latecomer, he was never able to rise above the position of shift boss at the Homestake. In fact, in 1929, after ten years of working at the Homestake, at the age of sixty, he decided to give up mining and start a chicken farm in Oregon. (Despite the Depression, he was able to eke out a living and at least be free of the brutal conditions in the mines. He was lucky to have escaped the fate of so many miners: silicosis, or miners' consumption, caused by silica dust constantly coating the lungs. Many miners did not live past the age of fifty.)

Albert Pendo and Peter Johnson, Ruby's father, worked side by side in the Homestake Mine as shift bosses. Ruby first became interested in Albert Pendo when her father came home from work one day and talked about "an awfully nice young man at the mine." They were married two years later, on June 21, 1922. While there were the inevitable strains of finances, raising children, differences in temperament (Albert was brusque, impatient, and hot tempered; George remembers that he would often utter the phrase, "Jesus suffering Christ," while Ruby was gentle and patient), it was a marriage that endured for more than fifty years until Ruby's death in 1975. The first strain may well have been the quick and close arrival of their two children: George was born in March 1923 and Mina was born in March 1924, but there were many other family members living close by to provide help and support.

A month before Mina was born, Albert Pendo wrote a note to his wife. It belies his eighth-grade education; despite the grammatical and spelling errors, it is clever and humorous, probably an intentional parody of the sermons he and Ruby heard every Sunday morning at 
the Augustana Lutheran Church. In addition, it reflects the playfulness and intimacy of the household where Mina and her brother George grew up.

Lead, S.D.

Feb. 7th, 1924

\section{My Dear Little Wife}

Since eating my supper last nite the thought come's back to me that two years ago, lacking a few months, we pledged ourselves to be as one always considerate of each other, it occurred to me that as time goes on we may become lax in certain of our duties which so far you have so nobly performed. Far be it from my intensions to reflect in any way upon your past performance of these duties but it behooves us all to be constantly on the lookout for little tasks which if neglected work discord while if willingly performed create \& maintain harmony which is issential to happiness. Not wishing in any way to impose upon you and making allowance for past favors there still remains one thing. Please when you put a hamburger sandwich in my lunch put an onion in it. Trusting you will take this in the right spirit. I remain your devoted husband.

Ruby Pendo so valued this note, printed in pencil in small, crowded letters on the back of a Homestake Mining Company time sheet the size of an index card, that she saved it with the family's birth and baptismal certificates.

Ruby also saved Mina's baby book recording "baby's first days" in which she made sporadic entries relating to Mina's first year. Both this book and her birth certificate indicate that Mina was actually named Ruby Mina Pendo. No one knows precisely when the transposition took place, but no one can recall her ever being referred to by any other name but Mina, and when she was enrolled in the Hearst Free Kindergarten in 1929, she was registered as Mina Ruby Pendo. The book contains a lock of Mina's blond hair, and in the entry for her first Christmas, Ruby wrote: "Part of the day was spent with Grandma and Granddad Johnson. Went to Grandma Pendo for dinner and received many useful gifts." The book provides a space to indicate the date on which baby began to crawl, but Ruby wrote above the space that Mina never crept, "she just slid around." Her first pair of shoes was purchased in November 1924 "at the Hearst," and Mina's behavior at her christening "was very good." One of Albert Pendo's sisters and one of Ruby Pendo's brothers were her godparents. Ruby Pendo also recorded Mina's first prayer, recited when she was two years old, along with a notation: "God bless Daddy, God bless Mamma, God bless Goggie (George), God bless everybody, make me good boy (as she always in- 
sisted on saying)." George recalls that Mina imitated everything he said and did, thus the male noun.

The Pendos bought a very small house at 308 Bleeker Street, a steep road near the center of town. (All of the roads were steep; Janet Emig once described Lead as "that astonishing perpendicular mining town.") While the house was modest by most standards - a narrow, wooden-framed two-story structure with a small porch and a tiny front yard-it was much like the other houses in town. Although Albert and Ruby were extremely thrifty by necessity, the children never felt deprived. George remembers that, even during the Depression, neither they nor the other townspeople suffered economically because the Homestake mine continued to operate. During Mina's childhood, the Pendos remodeled the second floor of their house and rented it to two English teachers from the Lead elementary school, Miss Amelia Perman and Miss Edith Johnson. The two women lived with the Pendos for fifteen years. They used the Pendo kitchen and joined them for most meals, and they would look after George and Mina when their parents were out. George remembers that they often played word games at the dinner table and corrected everyone's grammar. He and Mina were extremely fond of the two women. "They were almost like aunts to us," George recalls. "They loved us very much and we loved them."

Many years later, Mina would describe her childhood as one that was "filled with teachers whom I admired." She was referring not only to her mother and to these two women, but to two of her aunts as well. Two of Albert Pendo's sisters were teachers. Florence had completed her teacher training in South Dakota and taught in Rapid City. In 1940, she moved to California, and she would often write letters to Albert and his family, describing her favorite students. Esther taught in a one-room schoolhouse in the town of Belle Fourche, north of Spearfish. Although Ruby did not return to teaching until Mina and George were much older, she talked about her students in Alaska, and George and Mina often looked at a snapshot she had brought with her. She and her eleven students are standing outside a small schoolhouse in a fishing village called Chichagof on the coast of Alaska. The students ranged in age from five to eleven or twelve.

One of Mina's closest childhood friends, Georgia Jensen, remembers that "everybody knew everybody" in Lead, and because Lead was a town where people were generally aware of what others did for a living and what they earned; wealth and social status were simply not factors that were considered or discussed very often. The Pendos, Georgia Jensen recalls, were regarded as warm and friendly people, particularly Ruby. "She was a beautiful person, very giving, generous, and extremely intelligent. She was college educated; this was relatively rare in those days. Mina adored her and was proud of her. It 
was evident that they were best friends." Georgia recalls that before World War II, Ruby could not have taught even if she wanted to. Married women were simply not hired as teachers; they were expected to stay at home.

Mina and George grew up with their grandparents, aunts, uncles, and cousins nearby, and there were visits throughout their childhood to relatives in California and Alaska. During the late 1930s, their maternal grandparents moved to Oregon to raise chickens and their paternal grandparents moved to Wyoming to raise cattle. Neither enterprise was particularly successful, but the unspoiled, sparsely populated areas in which they settled were a welcome contrast to the many years spent in a dusty mining town. Mina and George would often spend several weeks during their summer vacations visiting their grandparents and, as George recalls, "being spoiled."

There were frequent visits from family members and neighbors, and George remembers that evenings were always spent reading and listening to the radio. Although Albert Pendo could read and write proficiently, he never read aloud to the children. When Ruby read to them each evening, however, he would sit and listen. George remembers that there seemed to be hundreds of books in the house, particularly books and magazines for children. Mina loved school, and she was an excellent student. Records from kindergarten through eighth grade indicate that she earned grades of A and B in every subject, with the exception of gym, in which she earned mostly Cs. George remembers that, although Mina received a plaque from the Girls' Athletic Association, "there were no athletic activities for girls in those days." He also remembers that Mina would read under the covers long after her parents had told them to turn the lights off. Among the papers that Ruby saved is a certificate of merit that Mina received from the World Book Look-it-up-Club. "We never say 'I don't know,', it reads, "we never guess; we look it up." George remembers that Mina started to take piano and cello lessons at the age of eleven, and she practiced regularly, without having to be told. (Although she played the cello in her high school orchestra, her love for the piano stayed with her for her entire life.)

George worked hard as well, but although he was a grade ahead of his sister, his teachers inevitably compared him with Mina and accused him of being lazy. Mina took great pity on George, and during the tenth grade she wrote many of his essays for him. "I got good grades that year," George recalls. George also remembers copying all of Mina's answers out of a workbook they were both assigned, but while she would receive As for her answers, he would get Cs.

Although George was a year older than Mina, she quickly surpassed him in height. By the time Mina was in the eighth grade, she was already as tall as her father, who was five feet eleven inches. As a 
result, she was terribly self conscious and often walked around with her knees bent. Mina was thin; she had large blue eyes, long, thick blond hair, and a radiant smile. She wore her hair parted on the side, falling in a silky pageboy around her shoulders. In her high school yearbook photograph, despite the eight-line description of activities that appears under her name, she seems out of place-she looks so much more mature and sophisticated than her peers. Although she was strikingly beautiful, however, her friends recall that she seemed utterly unaware of the effect her appearance had on others. Many years later, Mina told a friend that she used to hound her mother with the question, "Am I pretty?" Invariably, her mother would answer, "Now don't you worry, you're a fine looking girl." Mina was always more serious and mature than most girls her age, Georgia Jensen recalls. They talked about books a great deal and always knew that they would go to college. Although Mina was, according to Georgia, "perfectly comfortable with boys and loved to listen to music and dance," it was her brother and best friend, George, who took her to her junior prom.

Mina's high school course load was rigorous; in addition to the core subjects, she took vocal music, instrumental music, declamation, drama, dancing, French, Latin, and Spanish, and economics. She graduated fourth in her class of 124 and was given the "Goldenlode" award for character and personality, an honor just below that of valedictorian. George remembers that although Mina seemed to learn quickly and effortlessly, she always worked very hard and never fully appreciated or understood how impressive her accomplishments seemed to others.

However, it was outside of school, particularly during the summers, when George and Mina were happiest. In 1933, when George was ten and Mina was nine, the family drove for three days to visit the Chicago World's Fair. In 1935, Albert Pendo took a month-long vacation and traveled with Ruby and the children as far as San Diego to attend the exposition there, stopping at Denver and Las Vegas. At the end of the month, Albert returned home by train while Ruby and the children continued up the coast to Oregon, Washington, and Alaska to visit her brothers and sisters. Ruby saved a letter that she wrote to Albert, describing their route through Portland and Billings. The children were a little restless and cross, she noted, and they told all the other adults on the train that they missed their daddy "because he had to take another train." George remembers that he, Mina, and his mother were away from Albert for almost three months during that trip, a separation that was based as much on Ruby's need for some "peace and quiet and a respite from Albert's temper" as a desire to see her relatives. Despite these occasions, George recalls, his parents worked at their marriage and loved each other deeply. Divorce in the 1930s, 
particularly in South Dakota, simply was not an option that anyone considered. In fact, George cannot recall even hearing of a divorce in Lead during his childhood.

In 1939, the family drove to California and Seattle and then took a boat to Alaska to visit Ruby's relatives. George still remembers that he and Mina went panning with their Uncle John, but they found no gold that day. The family referred to these adventures for years afterward, recalling specific events, people they met, places they saw; George has saved scores of pictures from these trips. More than thirty years later, Mina recalled one of those trips in a Father's Day note she wrote to Albert from California, where she was attending a conference. "Being in California has somehow reminded me of our family trips to California, especially the year we went to Sawyer's Bar. Those days come back to me now so clearly. The world seemed to me then so secure. And you and Mom made it such a full and good world." And in a journal that Mina was required to keep for a college acting course, she wrote an account of one of the few times she had been on the ocean to satisfy an assignment describing an event when she could "see sound":

My contacts with the ocean have been rare, and since my ancestors have been rather earthy people, I have no instinct to aid me. I do remember one special time, however, where there was a good fog and all the trimmings. It was in Juneau, Alaska. We had been up on the damp, wooded parts of the island hunting for two days, and on our way back had run into a bad storm. We were all wet, hungry, and tired. By the time we reached Juneau, the weather had settled into its usual slow, penetrating rain, but by the time we had unloaded a heavy fog had settled. It reminded me of a blotter. When the fog horns would blow, it seemed that if you could watch the sound waves, they would travel like the ink when it touches a blotter. The lantern that one of the men held kept swinging, and I watched the weak light travel back and forth. When we bumped against the side of the tug, it sounded soft because the wood was soft from being soaked in water.

Religion played an important role in the family's life, and George believes that Mina was strongly influenced and affected by the religious training they received as children. They attended Lutheran services every Sunday. When they were in grade school, they attended classes before Sunday services, and when they were in high school, they attended mandatory confirmation classes every Saturday. George recalls that as a result of these classes they were "very familiar with and convinced of the value of the Bible and the Ten Commandments." Both Mina and George were confirmed, and many of the social events 
that the family attended were sponsored by the Lutheran Church. Mina loved to sing hymns and had, Georgia Jensen recalls, "a lovely contralto voice." Mina was deeply religious at this time, according to her brother, George, and at various periods throughout her life she would exhibit such a deep spirituality that it confounded her friends.

Stronger than religion, however, was the influence of their parents' values and behavior. Mina and George grew up in the house of a miner, in a mining town. As a result, they had a deeply ingrained consciousness of the earth and its formation. Along with the books and encyclopedias that Ruby provided for them, they were surrounded by geological maps and surveys. They knew that they lived near the center of the continent. Albert and his friends talked about lodes and veins and formations and shale. Each evening, he would tell his family how much muck had been "carried up" that day out of the Homestake. They understood the damage that water could do to an underground shaft, having heard the stories and seen the pictures of the destruction of the Treadwell Mine in Alaska.

Mina and George knew how hard the men worked, and under what conditions. They knew that their livelihood and the livelihood of most of their friends depended upon the amount of gold that was extracted from the Homestake Mine. They knew that, when they were infants, their father worked the night shift and that he would have to "muck his sixteen" in order to get paid. This expression, made famous by the song "Sixteen Tons," meant that each man had to fill sixteen one-ton ore cars by shoveling with a scoop, at depths of 2,400 feet, the material that had been loosened by blasting and drilling during the previous shift. They celebrated in 1929 when their father was promoted to mine foreman and would no longer be required to "muck" underground. They knew that during the winter months, while working the day shift, their father entered the mine when it was cold and dark and left when it was cold and dark.

As a result of this deep sense of the way the mine operated and its relationship to their well being, Mina and George were instilled with what George describes as an "appreciation of and respect for the resources nature gives us, along with the knowledge that you work for everything you have." More than anything else, George recalls, "we came to understand that the quality of the work we performed would most likely determine our future and our happiness. As a result, hard work was very important to us, possibly more important than our relationships. It was something we didn't mind doing. In fact, we enjoyed it."

On January 8, 1938, when Mina was fourteen, she wrote a letter to her parents, who had traveled to New Orleans for a (rare) vacation without the children. It reflects the activities she and George enjoyed, the habits of thrift and hard work that her parents were imbuing in her 
and her brother, and most important, the affection and security that Albert and Ruby provided for their children.

Dear Mother and Daddy,

I got my permanent today and like it very much. The girls sure like it.

I got that dress you sent away for today and it is a very nice one.

I decided to take Algebra, English, Science, and Occupation for High School. Miss Knowlton thought that would be best.

Aunt Helen asked me to go skating with her and Bob out at our cabin but then we decided not to go because it would be to [sic] far to walk.

I bet you are having a nice time.

Tomorrow we are going out with Gosses to the cabin to skate or maybe to some lake. They are very good to us.

We let Queen up tonight and I can hear her chewing a bone.

I took a bath last night. I am sleeping in your bedroom and it doesn't seem as skarry [sic]. I better close.

We have to get up tomorrow to go to Sunday School so I guess

Lots of love, Mina

P.S. George took the washing up.

After writing a row of Xs and Os, Mina wrote on the third side of the four-sided stationery, "Too bad I couldn't fill this page because I'm wasting some good paper." (Although Mina's mention of the arrival of her new dress seems to be an attempt to fill her letter with news of home, it is also an indication of a passion for beautiful clothes that remained with her for her entire life.)

The cabin to which Mina referred in her letter was a one-room, unheated shack with no indoor plumbing, located in Hannah (about ten miles from Lead), a town so small that it is not listed on maps of South Dakota. According to South Dakota law at the time, if an individual staked out and maintained a mining claim at least four feet deep, ten feet wide, and twelve feet long on federally owned land for five years, he or she could take possession of two acres of land surrounding the dig by paying five hundred dollars. More and more people, recognizing a loophole when they saw one, began to "mine" the area in and around Hannah, and hundreds of South Dakotans were able to build summer cabins on these plots of land. Albert always referred to the family's mining claim as "the Ruby Load." With the help of friends, he constructed a one-room cabin and eventually added indoor plumb- 
ing. There was no electricity, however, so they relied on kerosene lamps, used a coal and wood stove, and heated their water by running it through pipes connected to the stove and then channelling it into the water tank.

Ruby and Albert would take the children to the cabin as soon as school ended for the summer, and Albert would commute back and forth by car on weekends. George recalls that the "two aunt teachers," Edith Johnson and Amelia Perman, would often spend weekends at the cabin. It became a family tradition for Albert to set off a stick of dynamite early in the morning on the Fourth of July. Occasionally, Mina and George would invite friends from town (Georgia Jensen remembers "wonderful weekend visits when we spent the evenings playing big-band music on a wind-up phonograph"), but for the most part, they spent their summers together swimming, fishing, hiking in the hills, and horseback riding. The Pendos kept and cared for several horses, and George remembers that Mina practically "grew up on a horse. She was a fine and graceful rider. We rode horses more than we walked during the summers at the cabin."

The surroundings in which Mina and George spent their summers were magnificent. The Black Hills form a dome rising 4,000 to 7,000 feet above the surrounding northern Great Plains. The highest point has an elevation of 7,242 feet. Often the snow in the mountains did not melt until June, and Mina and George would "pile on sweaters" in the early mornings. George remembers that he and Mina could identify all of the trees that grew near the cabin: quaking aspen, ponderosa pine, lodgepole pine, white spruce, and mountain ash. They watched the flowering plants and bushes bloom in sequence as the summer progressed and would often pick flowers for their mother. They would pack a lunch and hike for hours, reaching elevations of 5,000 or 6,000 feet before heading back home. More than forty species of birds nested in the hills during the summer. Despite her familiarity with nature, however, Mina never overcame her aversion to snakes, particularly the garter snakes that inhabit the rocky soil.

The cabin was so isolated that there was no mail delivery, and George remembers that there was no official address. They simply told people they were located on Ward's Draw near Cyclone Hill and Horseshoe Curve. At the cabin, as at home, Mina and George were required to do chores and help with expenses. They earned money by locating and capturing lambs that had strayed from a nearby sheep camp. They earned five dollars per head, but it could often take an entire day to run down one lamb, and George remembers that on many occasions Ruby had to spend an entire evening removing wood ticks from Mina's thick, long hair.

Both at the cabin and at home, the Pendos had frequent visitors, some of them quite eccentric. Mina's favorite character was Old Johnny 
Perrit. He was very short, had an English accent, and wore a beard down to his waist. He was billed in local festivals and rodeos as the man who had found the biggest gold nugget in the South Dakota Hills. He often came to Sunday dinner and told fantastic tales about the Black Hills. In an attempt to reciprocate, he invited Mina and George to his cabin for breakfast. They went occasionally, but George remembers that Mina was never comfortable eating the food, because her father had once mentioned that Johnny would spit on the grill to determine if it was hot enough to make the pancakes.

In December of 1939, when Mina was a high school sophomore, she was chosen to represent her class at a regional "declamation contest" being held in Philip, South Dakota. She wrote a letter to her parents on Senechal Hotel stationery explaining how she felt about the contest. Despite her best efforts to mask her strong sense of competition, her desire to do well and to succeed - a desire that grew stronger throughout her life-is evident. It is almost painful to see her try to contain, or at least control, the struggle she was enduring. The first page of the three-page letter is missing, but one suspects that Ruby, who wrote Mina's name and the date on one of the surviving pages, kept only these pages because she was so moved by the determination reflected in the letter.

I am writing this before the Declamatory contest: I have just said my piece over and feel more self assured. fairly well.

If only I can keep calm through the piece I am sure I can do

I do want to win terribly bad.

I hope I can get a definite mood and hold the audience through that mood.

It is such a beautiful story, I hope the audience sees it the way I want them to. I will be so happy if I can go home victorious and if I don't I must remember I am only 15 years old and a sophomore. I still have time to do more. There have been others before me who have not won in these contests and as Miss Braum says it is not a life or death matter, but oh how I do want to win!

Perhaps Mina's conflicting emotions can be explained by the influences of the Midwest and of her Lutheran upbringing. In fact, there is even a Norwegian word for this ambivalence, janteloven: individuals are not supposed to think they are special or act as if they are more capable or more talented than anyone else. Mina carried this belief with her throughout her life, this sense that her accomplishments should not reflect on her talents or on her abilities, and it was most evident when she communicated with her parents, masking her ambition with a desire to please them and to repay them for all the things they had 
done for her. In one of the letters she wrote to them several years after graduating from college, she closed with the following paragraph: "You both have done so much for me-more than most parents it seems and it makes me want to please you and to work hard. I hope I never disappoint you too much." And in a letter written to her parents in 1954, after quoting a glowing recommendation she had received from a professor for whom she had done research, she wrote: "I'm just bragging to you. Don't tell any others about this, but I know you like to hear things like this and I always feel you are more responsible for whatever I have accomplished than I am."

No one can remember if Mina won that declamation contest in 1939 , but during her high school career, it was becoming evident to everyone that, in addition to her fine academic ability, she possessed great acting, speaking, and singing talent. Even as a sophomore, she was given the lead roles in the high school plays. Although they were school productions, drama was emphasized so strongly in Lead High School during this period that many people described the plays as the equivalent of regional theater productions. It was Mina's performances in these productions that would later earn her admission to Northwestern's prestigious and competitive theater and. speech department.

According to an entry in her high school yearbook in 1942, Mina earned first ranking in the poetry division of the Kiwanis Speech Derby while her friend Vivian Brown won for humorous prose. The yearbook entry continues, "Mina and Vivian earned the rank of superior, entitling them to go on to the divisional contest. At the divisional, Mina Pendo again was ranked superior, and represented this division at the state tournament." In addition, Georgia Jensen remembers that her mother drove Mina and her to a declamation competition in Chadron, Nebraska, during their senior year. Although Georgia Jensen no longer remembers precise details, she does recall that Mina had overcome any trace of nervousness by this time. "Mina never exhibited any competitiveness, but by then she knew what she was doing, she was self-assured, and she liked doing it."

Mina also earned the lead dramatic role in the high school senior play, a production of Three-Cornered Moon, and the choral lead in The Pirates of Penzance. It was almost unheard of for the same student to earn the lead roles in both senior productions. George remembers these productions as wonderful opportunities for the family, including aunts, uncles, and cousins, to get together. They were well attended, and they were an enormous source of pride and enjoyment for Ruby and Albert Pendo. People complimented them on Mina's performance for months afterward. Georgia Jensen remembers that Ruby "was as proud of Mina as modesty permitted." Mina is also pictured in the yearbook as a member of the yearbook staff and the camera club. (In both cases, 
she is in the back row - she was still one of the tallest students in the school.)

Although Mina graduated from Lead High School six months after the United States entered World War II, the war did not affect her college plans. Georgia Jensen remembers that there was never any question about whether she and Mina would attend college. Their mothers had attended college; they were both excellent students, and although neither family was wealthy, "they would find the money." It was common for those Lead High School graduates who planned to attend college to enroll in local schools: the girls attended Spearfish Normal (now Black Hills State University), and the boys (those who did not enlist) attended either the South Dakota School of Mines and Technology in Rapid City or the University of South Dakota in Vermilion. (George enrolled in the University of Nevada and later attended Washington University School of Dentistry in St. Louis, Missouri.) Most students who left the state usually attended the University of Minnesota or the University of Nebraska. Mina considered both of these schools because they had good drama and English departments. However, her acting talent was so extraordinary that Miss Braum, her drama teacher, encouraged her to "go east," and provided her with glowing recommendations. Mina applied to the School of Speech at Northwestern University in Evanston, Illinois. At the time, Alvina Krause was an assistant professor in the department, and she was famous not only for her rigorous training methods but for her valuable contacts with writers, directors, and producers. (Other graduates of this program include Charlton Heston, Cloris Leachman, and Patricia Neal.)

Mina's two-page application contains the usual information; however, in the space provided for parents' education, she indicated that her father, who had not attended school beyond the eighth grade, had completed four years of high school. In the spaces provided for "vocational preference," Mina indicated "stage" as her first choice, "radio" as her second choice, and "teaching" as her third choice.

Tuition at Northwestern for the 1942-43 academic year was three hundred dollars, a relatively huge sum for Albert Pendo who at the time was earning two thousand dollars a year. Fortunately, there was no tuition at the University of Nevada, where George was completing his undergraduate work, so Albert and Ruby had to pay only one tuition. George remembers that his mother would manage from time to time "to scrape together a very few dollars and send them to Mina for pocket money." Very few letters from this period have survived, but one indication of the financial strain the Pendos were under is evident in a note that Mina sent home in March 1943. "I've written three letters tonight," she explained to her parents, "and now I have to use another stamp." 
Mina enclosed in the letter a package of tiny picture postcards representing the various buildings of the campus, noting that she purchased them because they had cost only twenty-five cents. She made notations on the back of some of them, indicating, for example, that her English class was held in University Hall. In addition, she enclosed a snapshot of herself. In the photograph, she is walking toward the (unknown) photographer, smiling confidently, cradling newspapers and gloves in her arms, a purse slung over her shoulder. Her demeanor is relaxed; she is looking directly at the camera - still utterly unaware, it seems, of her remarkable beauty. These pictures were Ruby and Albert's only exposure to Northwestern until Mina's graduation. The train ride from Rapid City to Chicago took two days, and it was expensive.

During the first week of classes at Northwestern, each speech major was required to choose a sonnet and read it in front of an assembly of students and faculty. Shortly after the readings, Mina approached another first-year student, Priscilla Weaver, and told her that she had liked her reading very much. This meeting was the beginning of a lifelong friendship. Priscilla, and later her husband Alan Brandt, would become Mina's closest friends: when Mina got married, they held the wedding dinner in their home; when they had children, Mina was named their guardian; and when Mina died, Priscilla and Alan were with her.

Priscilla cannot even remember the name of the poem that she recited, much less the name of Mina's poem, but she does remember how unusual it was for someone to take the time to approach another student and pay her a compliment. Most speech and theater majors already knew, even on the first day of classes, that they would be competing with each other for roles and later for auditions in professional productions. And of course, Priscilla noticed Mina's appearance, "an unaffected Midwestern beauty that simply took you by surprise-a movie star with no make-up."

Priscilla had come to Northwestern from California, drawn as Mina had been by Alvina Krause's reputation. Mina and Priscilla roomed in the same dorm during their first two years at Northwestern. During their junior and senior years, tired of dorm life, they rented a room together in a private home, where Mina took piano lessons with the children who lived there. Mina pledged and was accepted into a sorority during her first year, but within weeks the workload in the School of Speech became so heavy that she dropped out.

The friendship between Mina and Priscilla continued to flourish; Priscilla remembers that she and Mina earned desperately needed spending money by performing for women's clubs. "We got a lot of bookings," Priscilla recalls. "We went as far as Peoria, doing scenes from I Remember Mama. Alvina Krause admired our ambition and re- 
minded us often of the value of performing in public - no matter how small the audience."

Mina's academic career at Northwestern was as successful as her high school career had been. She maintained a grade-point average of 3.7 or above during all four years, and for each of her last three years, she was awarded partial scholarships, including a particularly prestigious one known as the Edgar Bergen scholarship, based on merit. Many years later, when she was being asked to address larger and larger audiences on the issues of Open Admissions and basic writing, people were mesmerized by Mina's bearing and beauty, her voice, her diction, her carriage, her conviction. E. D. Hirsch described it as "that electrifying effect that Mina always had on those who heard her speak" (1). Some suspected that it was the result of her dedication to her students and to the cause of Open Admissions. Although it most certainly was, it was also the result of four years of rigorous training in articulation and projection at one of the most prestigious schools of speech in the country.

Most of Mina's required courses reflect her speech major and theater minor: in addition to more than thirty credits in literature (including a course that introduced her to Henry James, one of her lifelong literary passions), she took Training of Speaking Voice, Introduction to Theater, Public Speaking, Introduction to Radio, Acting, Interpretation of Drama, Theater Backgrounds, Creative Oral Interpretation, English Phonetics, and Persuasion. During her sophomore year, she was required to take one semester of physical education, and just as she had in high school, she received the lowest grade of her college career, a C.

Priscilla Brandt remembers the long hours that she and Mina spent in the library doing research; she remembers in particular a history course they took - they enjoyed reading and discussing (for hours) the works of Jonathan Edwards. Priscilla remembers that Mina would attend religious services "occasionally" while she was at Northwestern, but was put off by the "Evanston religious scene": she described it to Priscilla as a congregation of people who "practice religion with their fur coats on."

Among the documents that Ruby Pendo saved, there is a folder that Mina had labeled "Acting Notebook" for her course with Alvina Krause. Although it contains only forty handwritten pages, it provides a record of the thorough immersion in acting, speech, and theater that Mina received. There are "enunciation" exercises containing columns of words containing, for example, the " $\mathrm{A}$ as in palm" sound, definitions, passages from plays and poems, illustrations of "tactile" representation of the senses (for olfactory, Mina pasted into her notebook a picture of onions).

Mina was becoming aware of regional speech patterns - and how 
to avoid them. In a section entitled "Midwest Menace," she wrote the letter $R$ and listed the habits to avoid: The Midwest $R$ is "made in front of the mouth with the tip of the tongue"; one should "avoid a tense tongue and retracted tongue." Instead, one should "begin with 'ah' then make it 'dra'." One could practice by reciting the following verse:

Hark, hark, the merry hearted lark, Singing the song of the holy seven Aping the angels' harmonies On the golden harps of heaven.

One of the assignments was to visit a museum and observe carefully one exhibit. Mina chose the statue of an African female dancer and wrote a four-page description. The essay is highly descriptive and analytical, thus making the concluding paragraph seem inappropriate, even out of place. "I walked out feeling large and clumsy, but by the time I stood by those huge pillars at the entrance, I had dwindled considerably." Professor Krause gave the entire exercise a grade of Aand then wrote: "There is no need for you to feel large and clumsy! Improve your carriage and posture, stop slumping and you are the ideal figure."

One suspects that this folder was valuable to Mina because of the positive comments made by Professor Krause, whose reputation as a difficult and demanding teacher and coach was well known. "Good observations and appreciation," she wrote at the end of one of Mina's descriptions. "Good thinking" she wrote on another. And on a piece entitled "Art," a piece that Mina had revised, she wrote "Superior." The descriptions and memories of home and family that Mina recorded in this journal, however, provide an account of events and incidents that would otherwise remain unknown. In trying to justify her claim that art is not possible without three basic essentials, the artist, the medium, and the audience, Mina offered the following example. "Throughout my childhood, I listened to the simple melodies of Slavic songs sung by old 'Slavs' who usually congregated in some kitchen to sing songs and drink wine. I never thought of these songs as art until I heard a concert pianist play some of Mozart, whose themes are built around these melodies."

Mina drew on her summers at the cabin at Hannah and her visits to her grandparents in Oregon for an exercise she was required to write on "Tactual Response":

I guess I can only tell you of my tactual response by describing some of the things I remember. I think first of animals - the nose of a horse, soft and rather moist. I usually rub the palm of my hand against it although the tip of the fingers 
gives the most accurate account; chickens feel smooth and slippery, and there's something about a new, warm egg that makes you touch it lightly; the rough scaly skin of a pig's back covered with coarse stiff hairs makes even your fingers feel dry; a cow has a lovely skin if she's healthy - something like a horse only more mellow, and you can wrinkle it in your fingers; sheep have a soft but firm feeling like a thick mattress; squirrels have fine thin hairs that are almost too fine to feel. Then I remember the smoothly uneven rows of corn and the slight resistence [sic] when your finger presses a kernel; the gritty, flouncy feeling of chard right after it has been picked; the firm stiff head on cabbage as compared with the softer, leafier head on lettuce. I'm thinking now of a tactual response I get through my feet - when we irrigate, I feel the ground get soft and gradually give to my weight and creamy wet soil oozes around my feet and between my toes.

The typewriter keys are getting hard and slippery so I guess I'll stop.

One other reference to Lead in the journal described the night of Mina's high school graduation - a rite of passage that seems not to have changed very much since 1942. "On the night of my high school graduation," she wrote in a "Visual-Auditory response" to Strinberg's character, Anna Christie,

about four of the college kids decided to give us a party. Since they were much more informed upon the ways of the world, the entertainment was left to their discretion, and it took the form of alcohol in varying concentrations. I unfortunately got enough to make me act like a fool and still know it. I couldn't sleep much that night, and finally at 5:30 in the morning I got up, dressed, and started for a walk. By 6:30 I had gone outside the town, past the graveyard and stood on the edge of a road that looked down on rows and rows of hills. It was cool with just a slight breeze; the hills were a dark greenish black. Several pines close by were just barely wisping from the breeze. Then I felt something of what Anna must have felt. I felt healthy and clean.

During summer and holiday breaks, Mina usually returned home to Lead. George remembers that she did not seem to change very much from one visit to the next, or if she did, "she kept it from us. She was devoted to Mother and Father and never wanted to worry or displease them in any way." It was at about this time that Albert and Ruby Pendo purchased five acres of land in Spearfish, a tiny town surrounded 
by ranches approximately ten miles from Lead. Albert would not retire from the mine for another fourteen years, yet he was beginning to plan for the time when he would no longer have to live in town. Although the family continued to live in Lead, in the house on Bleeker Street, they visited what came to be called "the five acres" as often as they could. They hiked, hunted, and fished. They cleared the land and grew vegetables that Ruby would later preserve.

George had met a young woman named Norma, whom he married in 1945, and they purchased a home in Rapid City, where he had started a dental practice. Mina and Norma quickly established such a good relationship that George and Norma named their first daughter Mina.

During the summer between her junior and senior years, however, Mina did not return home. She had been invited by Alvina Krause to join an acting company that would travel to Eagles Mere, Pennsylvania. The actress Patricia Neal, who was a sophomore at the time, was also invited to join the troupe, along with Mina and Priscilla, and she wrote about that summer in her autobiography, As I Am. The tall "crazy" girl who did not want to go to New York to whom Neal refers is Mina.

For years Alvina Krause had nurtured a dream of starting a theater of her own. She found an old building standing empty near the mountain resort of Eagles Mere, Pennsylvania. The opening season's company would be limited. I was last in rank, but I knew Alvina liked my work. I was elated to see my name on the list.

That summer was fun. I spent a lot of time running around town getting furniture for props and making tuna casserole as a member of the kitchen team, but those duties did not keep me from acting. I worked like a dog to lose my southern accent for Noel Coward's Blithe Spirit.

Talent scouts found their way to Eagles Mere and flashed temptations of Hollywood, but I wanted only the real thing, the theater. I was more interested in an offer made to a girl in the company who was even taller than I was. She must have been about six feet. One of the scouts said he would suggest her name to the Theater Guild for Eugene O'Neill's A Moon for the Misbegotten. The main character was just her size, and there would be auditions soon. I couldn't believe it when she said she didn't want to go to New York. She had to be crazy. Wouldn't I love to show up for that audition in her place! (55)

Ultimately, Patricia Neal did get to try out for the part in O'Neill's play; Mina had decided that it was more important that she return to 
Northwestern to get her degree. During the summer season at Eagles Mere, however, she earned the lead role in Lillian Hellman's The Little Foxes, and her performance was spectacular. During the closing scene in which Regina withholds her husband's life-saving medication, Mina appeared on stage wearing a floor-length, low-cut black velvet gown and opera-length black gloves, her long blond hair pulled up on the back and top of her head in loose waves. Her carriage and beauty were so striking that members of the audience sensed that they were witnessing something very special. Mina had turned down an opportunity to perform on Broadway; instead, Priscilla recalls, she brought Broadway to Pennsylvania.

Although Mina had indicated on her college application that her first choice of a vocation was the theater, and although she and Priscilla decided to move to New York directly after graduation to pursue acting careers, Priscilla remembers that Mina remained surprisingly "unstagestruck." Perhaps her professors had also sensed this; in the letters of recommendation that Alvina Krause and James McBurney, the dean of the School of Speech, wrote, there is mention not only of Mina's acting ability but her scholastic achievements as well. "We think of her as one of our best products," McBurney noted. Krause, who perhaps knew her better than any other professor wrote:

I have known Mina Pendo for five years. In my own courses, she consistently ranked first in scholarship. As for general academic standing in the university, she was throughout her career here, the regular recipient of honor scholarship awards on the basis of outstanding scholarship and achievement. While her academic record here is superior, it does not indicate her creative ability, her wide range of interests, her unlimited capacity for work, her maturity and understanding. As a scholar and as an individual, she is held in high esteem by all who know her here at Northwestern.

Priscilla Brandt remembers that Mina had "other dimensions." Although she loved to laugh and have fun, and although she dated several men during college, she was also scholarly and serious. "While most aspiring actresses headed for New York determined to succeed on the Broadway stage no matter what it took," Priscilla recalled, "Mina seemed to already know that many other things could make her happy."

\section{Works Cited}

Hirsch, E.D. "Opening Remarks at an MLA Session in Memory of Mina Shaughnessy," San Francisco, December 1979.

Neal, Patricia. As I Am: An Autobiography. New York: Simon \& Schuster, 1988. 


\title{
Laura Gray-Rosendale
}

\section{REVISING THE POLITICAL IN BASIC WRITING SCHOLARSHIP}

\begin{abstract}
This paper traces our scholarly constructions of Basic Writers' identities. Arguing that we have relied too much on the question, "Who is the Basic Writer," the author instead asks, "What are those students who are labeled 'Basic Writers' accomplishing in their speech and writing in our classes?" Her text offers a speculative model for analyzing Basic Writing student discourse, uses that model to examine the language used in an actual Basic Writing classroom, and briefly reviews the implications of such work for reforming contemporary Basic Writing scholarship.
\end{abstract}

\section{From "Growth" to "Conflict": Challenging Our Scholarly Constructions of Basic Writing Student Identities}

Historically, Basic Writing teachers and scholars have been concerned with one compelling question: Who is the "Basic Writer"? Despite Mina Shaughnessy's repeated pleas to not let the term's meaning become an abstraction, in 1977 she did furnish our first definition of Basic Writers: "beginners ... who learn by making mistakes" (5) and "aliens ... unacquainted with the rules and rituals of college life" (40). Shaughnessy's discussion was wide-ranging and pictured the Basic Writer in both formalistic and psychological terms: as often displaying certain logical errors related to form, diction, and syntax as well as suffering from a characteristic lack of confidence. In subsequent years, however, the inclusiveness of Shaughnessy's definition began to strike Basic Writing scholars as problematic. In A Sourcebook for Basic Writers, Theresa Enos called attention to the perplexing nature of the term "Basic Writer" as it had developed, contending that it had "become so inclusive as to defy formal definitions" (v). Contributors to the volume tended to agree. Lynn Quitman Troyka, for example, traced the diversity of the terms "Basic Writer" and "basic writing," arguing that

Laura Gray-Rosendale is an Assistant Professor in the English Department at Northern Arizona University. Her dissertation, A Different Politics of Difference: Exploring Alternatives in Teaching Basic Writers, from which this article comes, is currently under revision for publication. Her other work in the rhetorics of feminist theory, cultural studies, and composition appears in Signs: A Journal of Women and Culture, Getting a Life: Everyday Uses of Autobiography, and Miss Grundy Doesn't Teach Here Anymore: How Popular Culture Has Changed the Composition Classroom. 
"basic writing has begun to lose its identity. The bandwagon effect seems to be taking over. The term basic writing is applied loosely to various populations of students" (13). By 1990, Andrea Lunsford and Patricia A. Sullivan pointed out in "Who Are Basic Writers?" that in the past "we simply held to a convenient, if indefensible circular definition: Basic Writers are those whom we place in basic writing classes. But this facile answer has never set well with scholars of basic writing, whose work over the last dozen years has consistently attempted more complete and richer definitions and answers to our title question" (18). Lunsford's and Sullivan's work aimed at identifying Basic Writers' backgrounds, strategies and processes, prose forms, and situations in the academy. Most recently, though, various contributions to the Journal of Basic Writing, perhaps the primary scholarly site where the identity of the Basic Writing student has been constituted, reshaped, and revised, have exposed the very problematic nature of the term "Basic Writing" (Lynn Bloom, 1995; Mary P. Sheridan-Rabideau and Gordon Brossell, 1995), questioning whether this category benefits or debilitates our students.

While an important concern, posing the question "Who is the Basic Writer?" has not come without its costs. This focus, which essentially poses as a problem of description or definition, may have led us to overlook the extent to which our scholarship also participates in the construction of student identities, often with dubious results. As Marguerite Helmers points out in her insightful 1994 text Writing Students: Composition Testimonials and Representations of Students, Basic Writing research has, in the process of trying to describe the key characteristics of the Basic Writer, inevitably also constructed certain problematic identities for them. Unfortunately, such student identities, which have included representations of the Basic Writer as Other, lacking, different, or excessive, may be more enfeebling to our actual students than anyone can have intended. Helmers' stunning examples reveal how Basic Writers have been depicted as natives, children, and animals: "unlike the popular representation of the adorable, innocent child, college beginners are [portrayed as] grotesque and deviant. They are stunted, undeveloped, young minds trapped in an aging body" (70). By depicting Basic Writers in terms of their deviances from the norm, our scholarship has tended to reinforce the norm, the pathology of the student writer, and the student's codependence upon the teacher.

While most representations of the Basic Writer are perhaps not so explicitly disconcerting as Helmers' work suggests, troubling features nevertheless continue to inhere in how we represent these students to ourselves. As Joseph Harris' Fall 1995 Journal of Basic Writing article "Negotiating the Contact Zone" reveals, the three main metaphors which have dominated our scholarship - growth, initiation, and conflict-have pictured Basic Writers as cognitively immature, out- 
siders to academic discourse, and signifiers of cultural marginality and resistance. The "growth" metaphor involved a shift of attention away from academic discourse, instead encouraging "teachers to respect and work with the skills students brought to the classroom" (29). Despite the positive connotation derived from the term, for Harris, it also tended to foster representations of the Basic Writer as "somehow stuck in an early stage of language development, their growth as language users stalled" (29). The "initiation" metaphor suggested that the "academy formed a kind of 'discourse community' with its own distinctive ways of using language" and the Basic Writing student needed to learn to assimilate or acculturate to a foreign linguistic system, one outside her/ his home language, which is implicitly denigrated. The most recent, the "conflict" metaphor, Harris contends, criticizes the two earlier metaphoric allegiances, claiming instead that the Basic Writer is a nexus of clashing cultural forces and relations of power within the classroom. Scholars partial to the "conflict" metaphor, writes Harris, hope to both respect cultural difference and to teach academically authorized language use, usually by foregrounding the ghettoization, disenfranchisement, and alienation that Basic Writers endure.

Not all of the results of these metaphoric investments have been negative (especially the recent turn to the "social" under the aegis of the conflict model), but I do concur with Helmers and Harris that our scholarship has constructed notions of Basic Writing student identity that share several discomfiting characteristics. First, in spite of very different rhetorical approaches and espoused political investments, our arguments incline towards delimiting the Basic Writer primarily as the site of a problem, be it cognitive, discursive or social, even if we see this problem as somehow outside the student's responsibility or control. Second, even when our scholarship professes to be motivated by a desire to decenter and deprivilege our classrooms, the teacher's heroic expertise and pedagogy, critical or otherwise, are always central to the answer provided to solve this "problem."

There is another, and, I argue, more basic problem with the metaphors for Basic Writers' situations that dominate our scholarship: they betoken a troublesome willingness to ignore the fact that the students we call "Basic Writers" seldom, if ever, think of themselves as such and that they rarely construe their tasks as writers in terms which accord closely with our preferred metaphors of "growth," "initiation," and "conflict." This does not mean, however, that our students fail to conceive of themselves as writers at all, but rather that their own ways of construing their identities as writers have been largely ignored. Certainly, some of the identities students take on as they struggle with writing tasks are as debilitating as the worst examples of our own attempts to classify them, but the fact remains that Basic Writing students themselves already concretely use discourse to alter, change, and 
constantly recreate their social circumstances and identities - often in resourceful and helpful ways that have been largely overshadowed by our scholarship's presumptions. If our focus on the question "Who is the Basic Writer?" has resulted in incapacitating representations of students so labeled, it might be instructive to at least momentarily suspend our focus on that question and to ask another one instead: "How are those students whom we label 'Basic Writers' negotiating their own identities as writers in our classes?"

Certain trends in Basic Writing scholarship have already justified such an approach. In particular, the current re-examination of the social and political dimensions of Basic Writers' situations has suggested the need to closely analyze the minutiae of classroom activities instead of simply applying broad cultural categories in an attempt to understand them. Mary Louise Pratt's important conception of the Basic Writing classroom as a "contact zone" where "cultures meet, clash, and grapple with each other, often in contexts of highly asymmetrical relations of power, such as colonialism, slavery, or their aftermaths" (Pratt 34), for example, has been justly criticized by Patricia Laurence, Barbara Gleason, Richard Miller, Francis Sullivan, and others. Their contention is that while the recent focus on the political dimension of Basic Writers' identities has been a great advance in Basic Writing scholarship, this turn to broad political identity categories can carry with it several potential dangers. The first of these has to do with what we might call the paradox of marginalization, the possibility that by focusing on one's "victim" status, one may unwittingly reproduce it. The second danger that has come under scrutiny of late, and the one that implicitly authorizes the argument that I am making, is that the very wide use of identity categories like race, class, and gender, which can represent such an important advance over purely "formal" criteria and definitions, can limit as well as open up our understanding of Basic Writers' situations. Scholars who think in terms of these political categories can make important contributions to our understanding of the social origins of Basic Writing, but these emphases may also relegate other contexts and metaphors for Basic Writers' situations to a kind of second-class status, less important, and implicitly less worth attention, than the "big" sociopolitical ones.

My purpose in this essay is to open an inquiry into other ways ot representing Basic Writers' student practices and identity formations by examining a brief interaction that I recently observed in a Basic Writing classroom. Drawing upon discourse analysis research in Speech Communications and Conversation Analysis, I wish to suggest one possible avenue for the exploration of how our Basic Writers' constantly participate in "co-creating and reproducing social identities, and thereby context, through their ways of speaking" (Buttny 162). Simply put, I will, in the pages that follow, demonstrate some of the 
insights that can be gained by observing the ways in which not Basic Writing theorists but Basic Writers themselves use verbal strategies and identity constructions in the writing classroom. Although considerations of space prevent a long discussion of key concepts in Conversation Analysis, it is necessary to highlight two that are of particular importance in the analysis that follows: "face wants" and "calls to account." Penelope Brown and Stephen Levinson point out in Politeness: Some Universals in Language Usage that, while negotiating considerations of race, class, and gender, and other things within social interaction, people also often seek to maintain each others' "face," or the public self-image of identity they want to create for themselves. "Face" includes 1) negative face, the basic rights to freedom of action and freedom from imposition, and 2) positive face, the basic desire that one's public self-image of identity be appreciated and approved. It should be self-evident that, when and if a student's desires to preserve face are impinged upon by other peer group members, for instance, communication can break down, and other students may readily shift their own identity constructions to compensate for these changes. At such moments, another phenomenon often occurs which can also evoke race, class, and gender conflict. This phrase, "calling another to account," involves creating talk designed to transform or challenge others' negative evaluations of one's identity.

Examining how Basic Writers in our classrooms continually use face-saving techniques and calling each other to account, one can view the sheer complexities that occur moment-to-moment in students' classroom interactions, and the important ways in which such considerations can add to our understanding of how constructs like race, class, and gender may actually come into play as our students approach writing and editing tasks. Basic Writers seem to co-create, reproduce, and intervene in various constructions of social identity contextually since each identity must be performed - continually updated and enacted through communication. When we open our analysis to such possibilities, we may be better able to witness exactly where and how Basic Writers may themselves uphold or subvert their institutional marginality through their talk, complicating our scholarly constructions of them as political subjects of one sort or another as well.

\section{Interaction in Action: Basic Writers Construct Dynamic Identities Within Peer Groups}

I turn now to the verbal peer group interaction of a particular group of Basic Writers. At Syracuse University, most "at risk" writers are "invited," sometimes as a prerequisite for their admission to a particular college, to participate in the Summer Institute run by Syracuse 
University's Center for Academic Achievement for six weeks in the late summer. As the Center's brochure elucidates,

the Summer Institute program is designed for ambitious students seeking to enrich their academic experience and ensure a smooth transition from high school to college .... Any student who is uncertain about facing the challenges of entering a college environment-academic, social and personal challenges - should seriously consider enrollment in the Summer Institute.(1)

The students who are part of this project include both the Summer Bridge Program and non-sponsored incoming freshmen. Characteristically, these students need particular support in composition which will prepare them for the Writing Program's curriculum. Though not explicitly labeled "Basic Writers," these are students who take special preparatory classes before being "mainstreamed" into other Composition courses. These students continue to gain credit for regular visits to the Writing Center. Interestingly, ethnic status alone comes to signify the need for supplemental instruction in the language of the program's brochure, which states that "all pre-freshmen who are African American, Asian American, Latino, Native American, and Mexican American are strongly urged to attend the Summer Bridge Program" (2). Perhaps as a result, this population of the summer programs is far more "diverse" than that which attends most credit-courses during the regular semester, hailing from small rural towns and urban metropolises, from exclusive, white neighborhoods and impoverished ghettos.

What follows is a brief interaction transcribed from one Basic Writing classroom designed to support such students at Syracuse University. I choose to limit my discussion to this particular piece of interaction for several reasons: 1) it represents a rather typical peer session among Basic Writers in this particular course; 2) it reveals moments in which the students are discussing politically charged issues, naturally opening themselves up to purely political analyses of their identities; and 3) it shows, in a relatively short exchange, how these Basic Writers are involved in reconstituting their relationships to identity constructions, institutional demands, and socio-cultural oppression. I center here upon their verbal compositions because often when we investigate how students construct themselves as writers and thinkers, verbal interactions are often overlooked in favor of investigations into students' written compositions.

These particular Basic Writing students, however, were not "mainstreamed" into typical Composition courses in the Fall. Instead, they participated in a three-year, grant-funded Writing Across the 
Curriculum project with Syracuse University's School of Information Studies. Since Information Studies wàs an alternate admission program, it attracted many incoming freshmen who needed additional support to improve their speaking and writing skills and confidence. In the Fall of 1994 these students took a unique Composition course, designed to help them further the writing and thinking goals of their home college. Their discussions were recorded throughout the semester and then transcribed for the purposes of analysis and discussion in class. Though several peer groups met simultaneously at many times during this course, the particular group I cite here volunteered to be tape-recorded to serve as our sample group throughout the semester for our conversations about peer review.

This specific peer group exchange involves four students (names have been changed) who describe themselves thus: John, an 18-yearold, African-American from Bronx, New York; Paulita, an 18-year-old Spanish-American from Queens; Kali, a 30 year old from Trinidad; and Teketa, an 18-year-old half-Portuguese, half-African-American. In this exchange, the students are discussing Paulita's first draft of her very politically-charged paper "My Tension with the term 'Latino.'" In this paper Paulita raises a critical question which has impacted her own identity, "What happened in order to come up with these names [Latino and Hispanic], and why has there not been a change in such a name which would better suit Spanish speaking people?" Though somewhat conflicted about how to put the draft together, Paulita argues very strongly in her paper that these terms are not useful labels for group identity which people can utilize in order to combat oppression since the first, "Latino," she contends, is a made-up word and seems to refer only to those people who have Latin American ancestry and the second, "Hispanic," was used for census purposes historically and doesn't fully designate the range of cultural backgrounds her people possess. Making the analogy with African-Americans' adoption of that same term to describe themselves and the political efficacy of such a choice, Paulita's paper advocates the use of a new term "Spanish American" because, for Paulita, it signals the allegiance of her people to be language-based. At this particular juncture, Paulita has just read her paper and the group begins to discuss it. While the politics of the content of Paulita's paper clearly impact the way in which this exchange unfolds, the exchange is also shaped by other important perspectives generated moment-to-moment by the students themselves, perspectives and positions which, as we shall see, are by no means fixed or unconflicted. Indeed, at the very moments in this exchange during which these Basic Writers are discussing issues of political identity, they simultaneously enact identities which appear to be far more complex.

In the sections that follow, short excerpts of transcripted conver- 
sation will be periodically interrupted by cursory analyses of the ways in which "face wants" and "calling to account" might be thought to operate in the particular exchange documented below. Read within this framework, seemingly minor utterances that usually pass completely unnoticed can take on significance undisclosed when our focus, as Basic Writing theorists, is trained either on just the formal elements of student writing or on the broad identity categories we often use to describe them and to probe the social nature of their writing "problems." None of the readings of the exchange that I offer are, of course, definitive, limited as they are by the relatively short list of analytic concepts I bring to bear. Often, my observations are necessarily speculative, since they represent an attempt to probe possible motives for particular uses of language: it is conceivable that widely varying readings might result from the application of different analytic emphases. It is nevertheless my hope that my analysis does demonstrate some of the insights that a similar but more extended approach to Basic Writers' interactions can yield.

\section{Stage One of Commentary and Response to Paulita's Paper}

John: [in a soft voice] I like it.

Paulita: Huh? What?

John: I like it.

Paulita: You do? Really?

John looks down and nods.

Kali: I follow you totally. I just want to argue with some of the points. [pause] I'm trying to be clear... The part where you talked about...you didn't show us why the terms were derogatory.

I. John: [in a soft voice] I like it.

Trying to establish his own identity in the exchange as a peer reviewer who will not make waves, John simultaneously attempts to construct a set of common knowledges amongst group members. This is a critical maneuver, made possibly in part because of the charged nature of the claims Paulita's paper offers. John then further indicates that he and Paulita share specific wants, values, and goals. He proceeds to satisfy Paulita's desires to be considered one who produces good writing and is likable.

John effectively begins to construct his identity in this exchange by impersonalizing himself and the paper in question. He accomplishes this not in the most obvious way, by offering seemingly objective statements which are devoid of the "you" and "I" pronouns. Instead John achieves this by slyly choosing not to go "on record" - or to be just questionably audible. This early shift in John's self-identity construc- 
tion is significant: John will later move from one who is willing to be a character in the exchange to one who is willing to be the originator of it. John's positive politeness is designed strategically to combat the tension their very momentary identity positions are producing.

\section{Paulita: Huh? What?}

Paulita, however, demands that John either overtly agree or disagree with her own conception of the peer review situation. There is a real attempt to define the terms of the situation for their own purposes. Implicitly John is being asked to position himself vis-a-vis the claim her paper makes as well. In doing so, Paulita forces John to dispense with certain aspects of impression management since if she determines that he has purposely not gone "on record" with his comment, she could reasonably perceive this as a personal and political affront. Paulita also forces John to articulate more thoroughly what he perceives his relationship to the other members of the group, and his appropriate identity, to be at this moment. The setting for the peer revision group as Paulita articulates it is one of agreement or disagreement, the audience is Paulita primarily (with the other members yet to articulate their own relationships to the setting), and John's role, according to Paulita's framework, is to champion what she has accomplished in the paper or to expose what she hasn't and risk confrontation. As she calls him to account, Paulita tacitly asks John to construct an identity in terms of these factors alone. Simultaneously, Paulita's decision to call John to account reaffirms her membership in the peer group.

Paulita chooses to respond by questioning the relatedness of what John has said. In other words, Paulita is demanding that John give an account of himself since John failed to fully respond to the context which Paulita's original prompt created. As suggested earlier, every call to account demands a reassertion of a previous identity construction or the rearticulation of a new one. Not fulfilling the commitment offered by Paulita's prompt immediately raises all sorts of questions which Paulita forces John to answer when she calls him to account (i.e., What are his motives, intentions, and beliefs in not going on record? Did he do this because he didn't want to insult her, didn't want to incriminate himself, or didn't want to appear to support her work? In short, what is the provisional identity he is willing to adopt here?)

\section{John: I like it.}

By merely raising his voice in answer, John asserts his willingness to adhere to the tacit rules of peer exchange as well as his intention not to insult Paulita. Implicitly he also indicates an allegiance to Paulita's claim as well and to its political statement. Through this very action of giving an account, John newly constructs his identity for the 
group: he is an overt advocate of Paulita's political position. John's identity vis-a-vis the group's perceptions has altered substantially. $\mathrm{He}$ is not undermining Paulita's framing of the peer review group's activity. John answered softly only because of an oversight. This also confirms John's position to Paulita, enabling another verbal sequence to occur rather than continuing the task of trying to establish what John's provisional identity is within the exchange. Though John was perhaps audible enough to hear, Paulita interestingly demands that he go on record, appearing openly accepting of her and what she has done within her paper. John's identity is newly constructed as supportive of group membership, establishing a common ground, and in support of members' face wants.

\section{Paulita: You do? Really?}

John looks down and nods.

Paulita's response continues in the same vein of establishing an alliance with John, recasting the situation in such a way as to maintain the peer group's function as she wants it to operate. Her further insistence that she know definitively whether John is attempting to satisfy her positive face wants or not indicates that Paulita wishes to have her perspective of the peer group situation and its logics established as the valid one which will determine all further actions within the exchange. It also signals Paulita desire to solidify, fix, and maintain the identities she and John have now constructed. Their alliance is not formed merely on their joint willingness to accept the claim her paper makes or their social positions. It also comes from a joint willingness to accept provisionally each other's present identity constructions and perceptions of the scene of verbal exchange. As a result, Paulita's own identity can also be made less tentative: she is a writer who produces good work (i.e., "likable" work) that has a valid political purpose. Here John and Paulita's language intervenes in the potential institutional construction of Paulita as a Basic Writer who is somehow lacking, whose work is sub par.

V. Kali: I follow you totally. I just want to argue with some of the points. [pause] I'm trying to be clear... The part where you talked about...you didn't show us why the terms were derogatory.

Kali's involvement shifts this interaction radically, though. Suddenly Kali refigures the frame in which the activity is taking place (the frame which heretofore has been about whether the paper was "liked" or not) and her claim politically valid or not. Instead, Kali proposes that the very purpose of the peer group interaction itself must be reinterpreted: it should be about clarifying particular points within Paulita's paper. Kali also challenges Paulita's conception of her own cultural framework: why are these terms necessarily derogatory in the first 
place?

In doing this, Kali effectively throws Paulita's and John's contingently constructed identities into a tailspin because they have been constituted around certain cultural allegiances as well as agreements about the social setting of the exchange itself. Casually, Kali calls upon Paulita to account for her own actions within her paper, not within her verbal interaction. Here Kali also very much adopts the role of a teacher, giving her an established social identity to hide behind for the time being. She asserts the possibility of a hierarchy, a hierarchy in which she reigns as authority. Kali's adoption of this identity also signals her unwillingness to satisfy Paulita's face wants simply or easily. Kali's use of an institutionally sanctioned role is significant since it allows her to alter the frame of the activity with less disruption from the other group members. By assuming this new identity, Kali momentarily forces the group exchange to involve reconceptualizing the situation at hand rather than debating the social and cultural differences between the group members. Kali is able to effect this change partially because she is older than the other group members.

\section{Stage Two of Commentary and Response to Paulita's Paper}

\section{Paulita: Okay.}

Kali: It may just be me, but I never considered these terms derogatory, "Hispanic" or "Latino." When you talk about "Latino," aren't you talking about coming from a Latin American country? You are not talking about people who come from Central America are you? Are you pro-Spanish? There seem to be all these countries and ideas going on...

Paulita: You have to...

They talk over each other.

Kali: But, at home we had Spanish-speaking people...

\section{Paulita: Okay.}

Rather than answering Kali's many questions, Paulita claims a common ground with her, simply by seeking to avoid disagreement. This is a relatively new tactic for Paulita when dealing with group members, suggesting that she may have taken her cue from John's tactic several seconds before. By doing this, Paulita defers to Kali as authority rather than answer or dispute the import of her questions. We see Paulita adopting an identity which admits to the possibility of Kali's authority.

II. Kali: It may just be me, but I never considered these terms derogatory, "Hispanic" or "Latino." When you talk about "Latino," aren't you talking about coming from a Latin American country? You are not talking about 
people who come from Central America, are you? Are you pro-Spanish? There seem to be all these countries and ideas going on...

Kali hedges at this point in her discourse, choosing to preface her statement with "It may just be me, but..." which will soften the criticisms she is about to offer. Kali may be hoping not to impinge upon Paulita's face wants while simultaneously offering a change in topic which is rather abrupt. Here Kali marks this change, and partially apologizes for it. Kali is willing to adopt a contingent identity of teacher/mentor here, doing so with some trepidation, as if the construction doesn't entirely fit. Likewise, Kali is communicating her desires not to impinge on Paulita's wants. As a result, Kali chooses a form of apology which indicates her reluctance. This choice allows Kali to construct the identity of a concerned, wiser peer, to appear as if she is not disagreeing with Paulita, while at the same time allowing her to contest Paulita's major premise and to hold a position of authority by virtue of this identity.

The hedging now accomplished, Kali goes on to claim, "I never considered these terms derogatory." Kali's decision to phrase this statement in this way rather than to say something like "'Latino' and 'Hispanic' are not derogatory names" may suggest that Kali has some sense that Paulita's frame of reference which she has brought to bear upon this situation is quite different from the one Kali brings, possibly due to differences within their cultural backgrounds. Kali's use of language here reveals that she senses this, though she does not articulate it as such at this point. Kali's choice to employ the past tense ("I never considered") rather than the present ("I do not consider") also makes Kali seem more distanced from her own perspective or interpretation, avoiding her further appearance as threatening Paulita's position and tentatively constructed identity.

The series of questions which Kali raises next are all aimed at ferreting out, from very different perspectives, why it is that Paulita is making the claim that she is making. She asks these round-about questions rather than simply going on record with the question, "Why are you making the claim you are making?" Kali once again invokes a combination of two negative politeness strategies, questioning and hedging. She continues to use these techniques to modify the force of her speech acts, and to evidence that she is not assuming very much about Paulita's face wants.

Kali's first question, "When you talk about 'Latino,' aren't you talking about coming from a Latin American country?" seems aimed at discovering in part whether she and Paulita both understand the term "Latino" to have been used as a way to categorize those who came from "Latin" countries, including Latin America, but not excluding others. Kali's utterance reveals that she wonders whether Paulita knows that the term "Latino" is often used to identify and designate 
peoples in addition to those who come directly from "Latin America." In effect, Kali is saying that when Paulita uses the word "Latino," she seems to be referring only to "Latin American" countries. According to Kali, this evidences a rather limited understanding of the word "Latino." However, Kali's use of language here is clever. She reveals her ability to both make a statement and to recast that statement as a question so as to avoid face threat.

Kali follows up the first query with a second question which is designed to approach Paulita and her identity construction from a slightly different angle. Kali states, "You are not talking about people who come from Central America, are you?" This allows Kali to suggest she knows the answer to this question while suspending the actual condition of claiming that she knows the answer. Again, Kali's language allows her to hedge, by seeming to ask a question, while at the same time quite clearly making a statement.

Kali's next question aims at yet another aspect of Paulita's perspective evidenced in the paper. By raising this next question, Kali puts aside her sense that "Latino" and "Hispanic" are not derogatory terms. Instead, she focuses elsewhere. If we are to believe Paulita's premise, that these terms are derogatory, why then does Paulita, in answer to the problem of "Latino" and "Hispanic," choose to advocate the term "Spanish-Americans" instead? For Kali, invoking this term implies that Paulita is only including those people originally from Spain who now live in America. This would mean that the term Paulita uses excludes many "Latin" peoples, people whom Paulita seemed earlier in her paper to want to include. Kali's question comes out bluntly, "Are you pro-Spanish?" She evidences both a desire to go on record and a desire to give Paulita an "out" by being slightly indirect (by using this question rather than offering a statement such as "You are pro-Spanish"). If Paulita's answer to this question is "yes," this may explain to Kali why Paulita chose to use that term of self-identification over another one, revealing that her construction of social identity may depend on the very kinds of exclusionary tactics she argues against. Curiously, it is the very issue of identity construction and naming that takes precedence at this point in the exchange. Indeed within the construction of their own identities here, the peer group participants seem to also challenge the use of specific terms to designate one's identity.

Kali then tries to end with a general comment which evidences her confusion, "There seem to be all these countries and ideas going on...." Here Kali uses a strategy of negative politeness designed to communicate Kali's desire not to impinge upon Paulita. She does this by employing the specific technique of impersonalizing both herself and Paulita in her last statement (not mentioning Paulita's paper). Through using this negative politeness strategy, Kali explains rather indirectly that she does not understand how Paulita's use of the term 
"Spanish-American" will include or exclude specific countries and cultures. Kali also makes clear that she is not sure which ideas Paulita means to make central to her paper.

III. Paulita: You have to...

They talk over each other.

While the two talk over each other, what Paulita does say here is an example of negative politeness designed to communicate Paulita's wants not to impinge upon Kali. Paulita, who has been a comparatively quiet member in the exchange about her paper until this point, is now willing to risk not minimizing the face threat to Kali. This overwhelming threat to Kali's face wants is what enables Kali to feel comfortable enough to talk over Paulita, and to reassert her authority. Paulita's relationship to the "you" she creates for Kali to inhabit here is rather abrupt and disdainful. Paulita chooses here, in essence, to speak to Kali as Kali has spoken to her up until this point, but with even more of a willingness to be direct rather than to question and hedge.

IV. Kali: But, at home we had Spanish-speaking people...

Kali changes the subject, avoiding unnecessary impositions on Paulita's face wants. Kali now tries to make her own frame of reference for understanding the terms "Latino" and "Hispanic" clearer to Paulita. She recognizes that their different cultural frames have not yet been exposed through the conversation as they have both engaged in it. Kali not only asserts a new cultural identity here, but also a new framework for putting pressure on the terms of American identity constructions. Kali, however, much like Paulita above, doesn't get a chance to finish.

\section{The Dispute Between Paulita and Kali}

Paulita: Where are you from?

Kali: Trinidad and Tobago. There are so many different cultures where I come from. We don't consider ourselves French or Spanish or anything like that. We, in Trinidad...

Paulita: Well... well... I'm not talking about people from Latin America or Spain or Europe. I'm talking about the people who were born here and have a Spanish background. Just like there are people born here, not in Africa, and we consider and call them African-American...

Kali: Yeah but... their foreparents came from Africa-from Africa directly? If that's the case, calling them by their location wouldn't be a derogatory manner, just like this - they came from a Latin American country, do you understand? their parents, their foreparents... You mean, you say, you were born here but your parents came from a Latin American country, you know? Or, from Spain? 


\section{Paulita: Where are you from?}

Paulita newly asserts a tentative identity of authority here. Paulita seems to assume that she is entitled to interrupt Kali because she has just been interrupted by Kali. The strategy Paulita uses is a typical negative politeness strategy, questioning. However, Paulita does not hedge or qualify her question. Instead she asks it rather directly. Paulita's question is also meant to reveal the fact that Kali has left out an important element of her speech, an explanation about where she comes from and therefore the kind of cultural frame she brings to bear upon the situation. In addition, Paulita's question undermines Kali's position as "teacher" or "authority" since Kali has neglected to reveal a very important piece of information, an unteacherly mistake. The assumption that Paulita also makes with this statement is that the place from which Kali comes, and the framework that she brings to bear upon the discourse situation as a result, are not applicable to the situation which Paulita herself is explaining, nor compatible with the frame through which Paulita understands her own paper's argument to be made. Differences in cultural frame and in apparent identity construction, then, are being used to refute the validity of claims made about the formal features of a text.

II. Kali: Trinidad and Tobago. There are so many different cultures where I come from. We don't consider ourselves French or Spanish or anything like that. We, in Trinidad...

As Kali stops her flow of thought to answer Paulita's question, Kali makes clear her socio-cultural identities and frameworks for making sense of the issues of "race" raised by Paulita's paper. For Paulita, Kali's choice to reveal her primary framework for intelligibility, Trinidad and Tobago, makes clear the difference of her frame from Paulita's, enabling Paulita to garner the evidence she needs in order to dismiss Kali's earlier assertions. Kali qualifies her statement with, "where I come from." Though Kali believes that these differences in their cultural frames for intelligibility do not cancel out the other formal questions she was asking earlier, Kali keeps these issues in the background now, choosing instead to foreground other concerns.

In addition, Kali adopts a use of "we" here which is no longer connected to the "group we" she asserted earlier, a "we" which was meant to refer to the peer group in opposition to the positions offered by Paulita. It is specifically dependent upon a cultural "we," including those people from Trinidad and Tobago. Even though Kali doesn't get to finish her statements about the position of someone like herself, or others in Trinidad and Tobago before being interrupted, she does have a chance to articulate a position which sounds very different from Paulita's. For Kali, to call oneself "French" or "Spanish" is an incidental identity marker since, as she writes reflectively elsewhere, "Everyone in Trinidad and Tobago is of different ethnic and racial origin. We 
are all mutts. Rather than claiming one ethnic or racial origin, we claim our status as citizens of Trinidad and Tobago first, and the geographical location of our ancestors only incidentally, if ever."

III. Paulita: Well... well... I'm not talking about people from Latin America or Spain or Europe. I'm talking about the people who were born here and have a Spanish background. Just like there are people born here, not in Africa, and we consider and call them African-American...

Before Paulita interrupts Kali, all that Paulita could've learned from Kali's last discourse exchange between them is that Kali's cultural frame of reference is different from her own. Therefore, this must be enough to suggest to Paulita that Kali's comments heretofore have been inappropriate since they have not been in keeping with the frame of reference to which all of the other peer group members ascribe (namely, they are "Americans" and have an American conception of the way "race" is constituted). The two "wells" at the beginning and the significant pauses between them seem to indicate Paulita's trepidation about going on record, and yet her desire to do so at this point. Paulita chooses to start to say something which might be viewed as a face threat, and instead abandons it, and leaves it hanging. Since Paulita thinks that Kali's frame of reference is inadequate to understanding the frame of reference in which Paulita's paper was created, Paulita appears to be empowered to say that Kali's frame is wrong when she propounds, "I'm not talking about people from Latin America or Spain or Europe."

Paulita then reasserts that Kali's frame is inadequate to judge the import of her paper by implying that most of Kali's comments must have been made with the inappropriate cultural frame. For Paulita, clearly, this also raises the question of whether any of Kali's earlier comments are at all relevant to Paulita's paper itself. Paulita states, "I'm talking about people who were born here and have a Spanish background." Paulita's comment leaves ambiguous whether these people have a "Spanish background," which is based simply in the Spanish language or traditions, and whether all of these people have lived in Spain.

Paulita then goes on to draw out the analogy she made earlier in her written paper: those people who were born in the United States but have a "Spanish background" are similar to people who were born in the United States "not in Africa, and we consider and call them African-American." The "we" she articulates here is meant to encompass the other group members, excluding Kali, as well as the other people who live in the United States. Paulita's use of "we" aims at avoiding impinging on Kali's wants. Still, by excluding Kali from this "we," Paulita threatens Kali's face severely. 
IV. Kali: Yeah but... their foreparents came from Africa-from Africa directly? If that's the case, calling them by their location wouldn't be a derogatory manner, just like this - they came from a Latin American country, do you understand? Their parents, their foreparents... You mean, you say, you were born here but your parents came from a Latin American country, you know? Or, from Spain?

Since Kali has evidenced an earlier problem with the analogy Paulita makes between "African-Americans" and "Spanish-Americans," it is not surprising that Kali takes exception to it here. Again, Kali qualifies herself. Kali may do this in order to avoid imposing too greatly upon Paulita's face wants with her change in topic. Kali seems to agree to what Paulita is saying with the "yeah," though this agreement is quickly followed by a qualifier. Again Kali asks questions seemingly in order to minimize face threat. However, like Kali's earlier questions, these function almost like statements. Her choice to repeat "from Africa" two times in the first sentence indicates that she is perhaps uncomfortable with proceeding to take on an identity of authority in the conversation since she has been told earlier by Paulita that her cultural frame is inappropriate to the situation. Kali tries to stick with the analogy that Paulita has made between the situation of "African-Americans" and "Latino-Americans." The label "AfricanAmerican" suggests that the people came from Africa, and "LatinoAmericans" implies that the people come from the many Latin American countries. Thus Kali is able to argue that if "Latino-American" is a derogatory term for those people, "African-American" should be for those other people.

After making these connections, Kali's language seems to literally fall apart. No longer comfortable assuming the identity as teacher, Kali appears to have been rearticulated as an "outsider" to the group, changing her own identity construction. As a result, the rest of her questions are aborted attempts at continuing the line of reasoning, and thus make little sense to the average listener or reader. Interestingly, it would seem that the other Basic Writers in the exchange have marginalized her precisely because of her cultural frame. One important thing to be learned from this part of the exchange is the way in which cultural frames for comprehending and conceiving of one's environment and identity are not only important for understanding each other's perspectives. A difference in cultural frames and social norms can easily be used against someone as a weapon to save face. Kali's language in this section was effectively dismissed because of this difference in cultural frames, and this by Paulita, a young Basic Writer whose paper purports to respect the integrity of cultural frames for herself and others. However, avoiding the risk to one's face wants is sometimes a greater concern than grappling with the other social issues raised by one's paper. 


\section{The Dispute Between John and Kali}

John: No, I don't think she's trying to say...

Kali and John talk over each other

John: She's saying that if you come from Africa or Nigeria, you should say, "I'm from Africa" or "I'm from Nigeria." But, if you are born here and you are black, you want to call yourself African-American because...

Kali and John talk over each other.

John: Yeah. Or, their grandparents were born in Africa... They fade away from saying they are "African."

Kali: I understand what you are saying - but you are American - you are American, but of a certain descent.

I. John: No, I don't think she's trying to say...

Kali and John talk over each other.

John intervenes at this point in the exchange which has, up until this point, largely been between Kali and Paulita. With his use of "No," John once again exposes his alliance with Paulita, this time by deciding to go on record. John asserts his identity here as allied with Paulita's, one in conjunction with his cultural identity as an African-American male. John qualifies his speech slightly so as to not completely impinge upon Kali's by saying, "I don't think she's trying to say. .." By asserting "I don't think" rather than "She's not," John speaks so as to offer this as his "opinion" or perspective rather than as a principle or rule. In this way, John takes responsibility for being the person who has this perspective rather than implying that because Kali's frame is different, she cannot judge (which would certainly have been a face threat). The fact that Kali interrupts John at this point indicates that Kali senses the on record nature of John's comment and wants to circumvent it, wants to respond to a potential threat to her own face.

II. John: She's saying that if you come from Africa or Nigeria, you should say, "I'm from Africa" "I'm from Nigeria." But, if you are born here and you are black, you want to call yourself African-American because...

Kali and John talk over each other.

In this piece of discourse, John is trying to tell Kali what he thinks Paulita is saying since he believes, given Kali's different frame of reference, that she might just have misunderstood Paulita. If this is the case, Kali was not threatening Paulita's face wants and John has been on the defensive for nothing. Utilizing the plural form of "you" so as not to threaten Kali's face wants, John impersonalizes both himself and Kali. Instead, by using "you" in this way, John is giving Kali the 
option to interpret it as applying to her rather than to the rest of the group members, if she so chooses.

It's interesting that John begins by giving examples of people who do not live in the United States and how they name themselves since he appears to be trying to convince Kali of the relevance of Paulita's argument. This is particularly important since Kali is not from the United States and will certainly identify herself with the first people whom John mentions. In other words, Kali might be less concerned with how her "race" was represented and much more with the fact that her country was represented, that she was from Trinidad and Tobago. John's use of "but" in the sentence "but, if you are born here and you are black" hedges the propositional content he is about to offer, and serves as an important way to shift the topic slightly. John's language here also brings an important immediacy to bear on the subject. The suggestion for people not from the United States is a "should" while the suggestion for the people of the United States is a "want to." By using these words here, John offers a very indirect imperative for what Kali should do (how Kali ought to name herself, the deterministic identity she ought to adopt) while only seeming to mirror the transparent and pre-existent "wants" of Blacks in the United States to call themselves "African-Americans." The first group appears to have little choice, the second, a great deal. John does this very subtly so as to avoid any risk of overtly threatening Kali's face wants.

III. John: Yeah. Or, their grandparents were born in Africa... They fade away from saying they are "African"

Here John claims a common ground by agreeing with Kali, suggesting that they share common points of view, opinions, attitudes, and knowledge. He leaves the implicit idea in the air, however, making the utterance somewhat incomplete. John's choice of the "they" is interesting since both he and Teketa, the most silent member of the group, consider themselves "African-Americans" and have at other moments in the course talked about "African relatives" or "African heritage." Here John chooses not to construct his own identity as raced in this way. He doesn't mark himself or Teketa as among "them." What this reveals, then, is John's willingness to ally himself with and ingratiate himself to Kali without overtly using a positive politeness strategy which might invoke comment and disillusionment from Paulita, his openly avowed ally. John seems to choose an identity construction more in alliance with Paulita and the peer group situation at this moment than in advocacy of his African-American identity specifically.

IV. Kali: I understand what you are saying... but... you are American you are American, but of a certain descent. 
Kali responds directly to John here. Her reference to "you," unlike John's, is aimed towards John himself rather than a "plural you." This first part of Kali's discourse participation employs a positive politeness strategy determined to claim a common ground with John so as to satisfy John's face wants. Kali claims here that she "understands" his point of view, opinions, and attitudes possibly in order to both seek agreement with him as well as to avoid disagreement which might threaten his face wants and erupt into a dispute. The "but," however, reveals Kali's reluctance to make that change in topic. The pause after the "but" would seem to imply that her reluctance is so strong, it may be causing her to re-evaluate whether she ought to change the topic after all. This notion bears out, of course, when Kali says awkwardly in the last part of the sentence, "but you are American - you are American, but of a certain descent." This seems to be a mere repetition of what John has said earlier. The only main difference between these two accounts is the way in which the two writers/speakers use language. The "you" Kali uses here, though it could well be meant to include other people who call themselves "African-Americans," seems to be directed very much at John as well. One is left wondering what change in topic Kali abandoned in favor of merely reiterating John's point, why she abandoned it, and whether her choice to abandon it was due to the fear that she could potentially threaten all members' face wants if she said it as she originally intended. Despite these students' own discussions about "raced" and "cultured" positions, their use of language reveals a whole host of other identity constructions which, at given moments, override them.

This section of discourse also seems to signal the demise of Kali's authority in the group as "teacher," facilitator, or advanced peer. Though Paulita's perspective earlier threatened Kali's face wants in major ways, it appears that through John's positive politeness strategies Kali became more convinced that she should abandon her earlier considerations. Her desire to be considered part of the group appears to have ended up being too strong in the face of John's positive politeness strategies to risk any more face threatening acts with the group. She therefore appears to momentarily abandon the earlier identity she adopted.

\section{The Intervention of Teketa}

Teketa: The thing I got out of it... They basically use Hispanic-American for census purposes. Then you talk about how other people name themselves - like "African-American." What else about the term "Hispanic" don't you like? What else bothers you? Okay, now that you have a sense of thattell us what other things. That way you can create a balance between the use 
of "African-American" and then why you don't like the other [the use of "Latino" and "Hispanic"].

Kali: Yeah. That's good.

Teketa: I think her transitions are very good.

Kali: Yeah... (pause)

\section{Teketa: Who is next?}

I. Teketa: The thing I got out of it... They basically use Hispanic-American for census purposes. Then you talk about how other people name themselves-like "African-American". What else about the term "Hispanic" don't you like? What else bothers you? Okay, now that you have a sense of thattell us what other things. That way you can create a balance between the use of "African-American" and then why you don't like the other [the use of "Latino" and "Hispanic"].

Teketa decides to enter this discussion only after the disputes between Paulita and Kali as well as John and Kali have ended; therefore, many of the major issues of authority and face saving have already erupted. Moreover, when she does speak, Teketa directs all of her commentary to Paulita, making her less likely to offend any group members' face wants. Lastly, Teketa chooses to speak at a juncture when, due to the limited time left in the peer group situation, the group must begin to move on to the next student paper.

Teketa begins with a statement, but leaves it unfinished. She follows this aborted statement up with a reiteration of a point that she heard in Paulita's paper, that the term "Hispanic-American" is insufficient for Paulita's purposes because it is not a term claimed by those people, but one given to them by the United States' government. After establishing a positive position vis-a-vis Paulita by repeating Paulita's own words, Teketa begins to ask a series of questions: "What else about the term 'Hispanic' don't you like? What else bothers you?" These questions seem to be designed to get Paulita thinking beyond the fact that the term was used for census purposes and on to other considerations. Here Teketa adopts the identity of facilitator.

Teketa's next decision is also very important. Rather than assuming a negative position in relation to Paulita after these questions, she presupposes a situation in which Paulita will be able to provide answers to these aforementioned concerns to Teketa's satisfaction by saying "Okay, now that you have a sense of that." This is a positive politeness strategy used to presuppose Paulita's success. Here Teketa assumes that Paulita will cooperate with her because it will be in their mutual and shared interest for her to do so. The next part of Teketa's statement, "tell us what other things," creates a new relationship between Paulita and the other Basic Writers in the group. It suggests that the "us," a relatively new construction of group identity, is repre- 
sented as interested in cooperating with Paulita and helping her to achieve what she should want to achieve with the paper. It also is sufficiently ambiguous as to not threaten Paulita's face wants.

In the actual exchange, Teketa states, "That way you can create a balance between the use of 'African American' and then why you don't like the other [the use of 'Latino' and 'Hispanic.']" Here Teketa uses yet another positive politeness strategy aimed at claiming a common ground between herself and Paulita, but also between Paulita and the entire peer group, it would seem. She accomplishes this through noticing or attending to Paulita's wants. Teketa recognizes that Paulita hopes to draw a connection between the plight of African-Americans in terms of naming and the Spanish-American population. Teketa realizes that this is Paulita's desire, approves of the desire, and, in this sentence, suggests how she can realize that desire. Interestingly, here Teketa appears to resist the very construction of her identity as static, as an African-American woman alone, in favor of helping Paulita to clarify the ideas in her paper.

\section{Kali: Yeah. That's good.}

Kali's reply to Teketa is also one further example of a positive politeness strategy, the expression of interest, approval, and sympathy with Teketa. By seeking agreement with Teketa, Kali does a very strategic thing. She not only allies herself with another member of the group (until now she is without overt allies). She also associates herself with someone whose positive politeness strategies are greatly affecting Paulita's relationship to the group (making this relationship seem more positive than it has heretofore), and with someone who is indicating that the entire group shares a common goal, to help Paulita realize her aims for the paper.

III. Teketa: (long pause) I think her transitions are very good.

The long pause in the discussion indicates that members are now at a loss with how to proceed. Identity constructions by individuals have been constructed provisionally so far. Now that a group identity has been constructed provisionally, members seem confused. All face wants seem to have been at least somewhat restored through Teketa's contribution to the group and Kali's seconding of Teketa's assertions. Though her comment is a very positive one (and aimed at extending the positive politeness strategies Teketa offered earlier), she no longer speaks to Paulita as "you." Instead she uses an impersonal reference, establishing a common ground with the other members of the group around Paulita and Paulita's paper.

IV. Kali: Yeah... (pause)

Kali's "Yeah" in response suggests that she may want to affirm 
Teketa's desire to establish this common ground with the other members of the group. Kali may be deciding to leave off here because 1) the problems that will come up now if she does threaten Paulita's face wants cannot be resolved in the remaining time left for her paper; 2) she doesn't want to break up the common ground of the group as established by Teketa; and 3) she isn't quite sure what else she might say about Paulita's paper that hasn't already been said. Kali's identity and assertion of it here appear to demand the subversion of that authority in favor of establishing the group's folk logics and values.

\section{Teketa: Who is next?}

The fact that Teketa responds next is very telling. Clearly the group members have run out of time to attend to Paulita's paper. However, in general, it has been Kali who has assumed the role of authority, and has acted as the group member who most clearly took up the position of authority in the group. Despite the disputes between Paulita and Kali as well as Kali and John over gaining the authority within the group, none of these members actually succeeded in gaining that authority for very long. Instead, by saying very little and resolving the group's problems at the end through positive politeness strategies, Teketa has been able to take up that identity rather easily. She dictates the next stage in the peer revision group with her on record question, "Who is next?"

Teketa's intervention reveals several things about how issues of authority are finally settled in Basic Writing peer groups: 1) Authority is often lost to two members of a dispute (in other words, neither one wins). One real trick to gaining authority in the Basic Writing peer group is to make your aims seem to be the other members' aims, your wants to be their wants. This allows one to say what one wants to say about the paper's goals, strengths, and weaknesses, but make all of these opinions seem to originate from the writer of the paper. In other words, positive politeness strategies could offer more ways to gain authority within a peer group than cultural positioning or other equally relevant identity markers alone could. 2) There are particular techniques which Teketa used which helped her to do this such as speaking personally to Paulita with a singular form of "you," seeking agreement between herself and Paulita, and being optimistic about Paulita's ability to revise the paper, and 3) Shifts in identity construction by group members occur constantly, especially when members are called to account or face threats are redressed. 


\section{Self-Performative Constructions of Student Identity: Implications for Future Basic Writing Scholarship}

Since this analysis is necessarily speculative in nature, I will now discuss some of the potentially useful questions it raises. First, what possible implications might this kind of analysis of our students' exchange have for future Basic Writing scholarship? Examining students' moment-to-moment interactions in this way can reveal not "who Basic Writers are" but how those who are labeled as such construct new identities, new senses of intersubjectivity, and new conceptions of the situations at hand. This may potentially elucidate how these contingently constructed identities enable them to grapple with larger social and political forces. Though student identity construction often involves self-characterizations according to race, class, and gender distinctions, the nature of the Basic Writers' interaction itself and the students' perceptions of it continually shape how they construct their identities. In many ways, then, it would appear that students themselves may indeed already momentarily resist rigid constructions of their identities through the very actions of their own interaction. This suggests that we cannot adequately understand our students' identities unless we look very closely at the interactions in which they construct them, a task which we have yet to fully undertake. Similarly, it would appear that political subversion of dominant discourses which produce student identities (institutional, societal, and scholarly) can occur at some level within students' verbal exchanges quite frequently. This possibility might cause us to re-examine our applications of politically-invested analytic lenses to their situations alone, then, since such applications may run the risk of denying the complexity of our students' own contingent creations of identity and politics through their interactions. Extended examinations of the Basic Writing students' peer interactions inside our classrooms also hold the potential to expose the various ways in which teachers, Basic Writing Programs, and college/ university administrations may assume relationships to Basic Writers which Basic Writers' language itself actually defies.

How might such an analytic, if only in a very preliminary way, help us to revise our construction of Basic Writers' student identities within our scholarship? First, those of us concerned about Basic Writers' social situations may want to look carefully at how we utilize the "conflict" metaphor. If this metaphoric allegiance can lead us to claim that Basic Writers exist on the "margins," as either victims or resistant entities, as discussed earlier, this may indeed prove limiting. As Maureen Hourigan's Literacy as Social Exchange: Intersections of Class, Gender, and Culture clarifies, a politics of difference based on "contact 
zone" pedagogy has the potential to be liberating for many Basic Writing students, but it can be equally disempowering to others - particularly, as Hourigan points out, our many Basic Writers who do not possess the luxury of "class assurance," and therefore the advantages often needed to challenge class privilege (51). Reading Basic Writers' situations as "subject to the system" or "disruptive to it," Basic Writing Programs as complicitous in student oppression or radically fighting against it, our roles as Basic Writing teachers as promoters of contact zone pedagogies or supporters of the status quo, inevitably masks the complex dynamics of our students' identity productions and the relationship of such identity productions to other variables. Ironically enough, then, the broad range of Basic Writers' situated identity reconstructions in face-to-face conversation, real-time computer communication, and through written composition are variables for which our Basic Writing scholarship has yet to fully account. Twenty years after the publication of Shaughnessy's landmark Errors and Expectations, this seems a crucial next leg of our journey in the now well mapped Basic Writing "frontier."

\section{Works Cited}

Bloom, Lynn Z. "A Name With A View." Journal of Basic Writing 14.1 (1995): 7-14.

Brown, Penelope and Stephen Levinson. Politeness: Some Universals in Language Usage. New York/London: Cambridge University Press, $1987 / 1978$.

Buttny, Richard. Social Accountability in Communication. London, Newbury Park: Sage Publications, 1993.

Gleason, Barbara et al. "Symposium on Basic Writing, Conflict and Struggle, and the Legacy of Mina Shaughnessy." College English 55 (1993): 879-901.

Harris, Joseph. "Negotiating the Contact Zone." Journal of Basic Writing 14.1 (1995): 27-43.

Helmers, Marguerite H. Writing Students : Composition Testimonials and Representations of Students. Albany: SUNY Press, 1994.

Hourigan, Maureen. Literacy as Social Exchange: Intersections of Class, Gender, and Culture. Albany: SUNY Press, 1994.

Laurence, Patricia. "The Vanishing Site of Mina Shaughnessy's Errors and Expectations." Journal of Basic Writing 12.2 (1993):18-28.

Lunsford, Andrea and Patricia A. Sullivan. "Who Are Basic Writers?" Research in Basic Writing: A Bibliographic Sourcebook. Eds. Michael G. Moran and Martin J. Jacobi. New York: Greenwood Press, 1990. Miller, Richard E. "Fault Lines in the Contact Zone." College English 56.4 (1994): 389-408. 
Pratt, Mary Louise. "Arts of the Contact Zone." Profession 91 (1991): 33-40.

Shaughnessy, Mina. Errors and Expectations: A Guide for the Teacher of Basic Writing. New York: Oxford University Press, 1977.

Sheridan-Rabideau, Mary P. and Gordon Brossell. "Finding Basic Writing's Place." Journal of Basic Writing 14.1 (1995): 21-26.

Sullivan, Francis. "Critical Theory and Systemic Linguistics: Textualizing the Contact Zone." Journal of Advanced Composition 15 (1995): 401-434.

"Summer Institute Center For Academic Achievement." Syracuse University. 1996.

Troyka, Lynn Quitman. "Defining Basic Writing in Context." A Sourcebook for Basic Writing Teachers. Ed. Theresa Enos. New York: Random House, 1987. 2-15. 
Morris Young

\section{NARRATIVES OF IDENTITY: THEORIZING THE WRITER AND THE NATION}

ABSTRACT: This paper explores the ways in which basic writers begin to theorize identities that locate them in our larger culture. As part of the composing process students need to first locate their own notions of the writer in a dominant culture that has often labeled them as "non-standard" and "at-risk." The author reads student texts for "theories" about writing and identity. The paper then moves to an examination of a student narrative which acts to construct both an individual identity and a cultural identity through the recuperation of language.

The truth is, however, that the oppressed are not "marginals," are not men living "outside" society. They have always been "inside" - inside the structure which made them "beings for others." The solution is not to "integrate" them into the structure of oppression, but to transform that structure so that they can become "beings for themselves."

Paulo Freire, Pedagogy of the Oppressed

\section{All I asking for is my body \\ Milton Murayama}

While the literacy debates of the 1980s grew into conflicts about culture and cultural values and polemics about common American heritage and multicultural identities, the very subjects who were supposed to benefit from this renewed interest in literacy education, the students, were often left in the shadows of the political rhetoric. Certainly students were active participants in the debates alongside more public and "authoritative" figures: individuals argued for expanding

Morris Young received his doctorate from the Joint Ph.D. Program in English and Education at The University of Michigan. He is currently Assistant Professor of English at Miami University of Ohio. His research interests include Asian American Literature, the politics of literacy, and composition theory. 
the curriculum to include works that represented the diversity of America (and the World); others argued for a "return" to "traditional" education. But in many ways Paulo Freire's "banking" concept of education played itself out as both dominant and emergent cultural economies acted in the production of "literate" citizens by "depositing" sanctioned "knowledge" into student subjects. Thus the public debate about the "literacy crisis" became a debate about national and cultural identity and how what was read and written or how texts were read and written shaped the Nation. ${ }^{1}$ What was seemingly ignored were the attempts to discuss a more complex understanding of student literacy practices. When the recent Oakland Public Schools policy statement asserting Ebonics as a separate language made news headlines, the same anxiety about language, literacy, and national identity emerged as critics ignored the emphasis on a new pedagogical philosophy and strategy and only saw a threat to the perceived unifying discourse of the Nation, standard English.

I want to suggest that there is a need to refocus our attention on the students who in many ways can and do create the terms for discussing literacy through the production of texts that engage their own literacy practices as well as the literacy practices and expectations of our larger culture. Talking about literacy is a complicated and often frustrating experience because the term "literacy" is just as ambiguous as it is powerful. When it is invoked, it is used to describe a standard in our larger society (perhaps most often manifested in our educational institutions), a standard that is never clearly defined and often relies heavily on "Western" assumptions and contexts and the modernity of nations. Literacy becomes a marker of membership, and those who can demonstrate this membership gain both access to and privilege in the dominant structures of power. Those without membership often face economic and political disadvantage, limiting their participation in the community in various ways. The implications of literacy, then, are greater than just acquiring reading and writing abilities that meet the community's standards: literacy often becomes the marker of citizenship and this assignment of legitimacy is often "required" to enjoy the full benefits of citizenship or even of basic human rights. Thus the incentive for students to be identified as "literate" is great; for students to question literacy is a great risk.

When Paulo Freire suggests the "oppressed" are not "marginal" because they are already located in dominant culture, he offers a space in the formulation of the Nation for an agency of the oppressed. The oppressed are already potentially active members of the community, capable of doing cultural work though this work may take different forms and represent diverse interests. The challenge, then, is to overcome the various systems of oppression that have maintained marginalized subjects and to dismantle those structures that act to keep 
cultural control either through simple dominance or through the more subtle hegemonic acts of educational and cultural production. While aspects of Freire's liberatory pedagogy are problematic because it does act in ways to maintain the dichotomy of "oppressed" and "liberated" and suggests that acquisition of state sanctioned discourses can be enough to provide access, I still find his move to have the oppressed become "beings for themselves" an important theorization of agency. In Freire's work I find a suggestion for the right to self-determination. The oppressed do not only lift themselves up from oppression but also determine their own course of action; and perhaps most important, determine their own identities located not simply in the dominant culture, nor in opposition to it, but as continually being constructed in the conflicts between dominant and emergent cultures. ${ }^{2}$ Like the title of Milton Murayama's novella about growing up in plantation Hawai' $i$, All I Asking for Is My Body, marginalized students are also seeking more agency to move within and beyond the institutional structures in which they find themselves.

The classroom becomes an important site to recognize and generate student self-determination. Too often the classroom has been constructed as a site for reproduction: students are trained in standard academic discourses; they deploy these discourses as part of required practice; they become participants in a community, often reproducing the practices of that community. The call by E. D. Hirsch, Allan Bloom, and William Bennett in the 1980s to "return" to a romantic conception of education as the discovery of Truth and Knowledge is explicit in its acceptance of a paradigm of domination; Truth and Knowledge necessarily connote a single cultural standard. Less explicit are moves by educational institutions to allow for limited change in curricular and pedagogical practices to provide an appearance of educational reform. However, this can be just a more subtle practice of student oppression as described by C. H. Knoblauch:

The kinds of change that the personal-growth argument recommends are, on the whole, socially tolerable because they are moderate in character: let students read enjoyable novels, instead of basal reader selections; let young women and young Hispanics find images of themselves in schoolwork, not just images of white males. Using the rhetoric of moral sincerity, the personal-growth argument speaks compassionately on behalf of the disadvantaged. Meanwhile, it avoids, for the most part, the suggestion of any fundamental restructuring of institutions, believing that the essential generosity and fairmindedness of American citizens will accommodate some liberalization of outmoded curricula and an improved quality of life for the less privileged as long as the fundamental political 
In many ways, nothing is changed except for a moderate expansion of the canon and limited recognition of the students as producers of personal identities but certainly not as full participants in public culture. There is a "compassionate" oppression at work in this model as students are allowed to "read enjoyable novels, instead of basal reader selections," are allowed to "find images of themselves in schoolwork, not just images of white males." Students are allowed to locate themselves in the culture within certain limits and are permitted to choose from the representations offered to them. While Knoblauch describes the hegemony of American educational institutions, his examples can be extended to illustrate the hegemony of American culture in general. While the school operates to contain cultural resistance by its students by offering limited recognition, American culture employs schooling both to maintain a population of workers as well as to contain larger cultural nationalisms that can disrupt the American Dream. The use of a rhetoric of "citizenship" is an attempt to both appease resistance as well as to offer inclusion, though that inclusion in reality may be very limited. Thus students are still trained to become "literate" citizens, perhaps with a bit more "choice" but still remain very much part of the reproduction of structural oppression. Students do not have full "citizenship" in their own classrooms as they learn to become "citizens" and are not allowed to be seen as already contributing members of the community. They can only exist as or become "citizens" if they meet the cultural requirements and standards as defined by the Nation, though the narrative of Nation always makes the possibility of citizenship seem to be an easily achieved reality.

A move toward student self-determination, then, is not a rejection or dismissal of teachers or "knowledge" or "skills." Rather, it is a recognition of the very existence of the students and the way in which they already construct themselves, construct culture, and place themselves within this culture. It is the reconceptualization of the classroom and its participants and dynamics. It is the recognition of what Mary Louise Pratt has called a "contact zone," those "social spaces where cultures meet, clash, and grapple with each other" (34). What is the role of the teacher? What is the role of the students? What role do they play together in the construction of a classroom culture that must account for its different types of members instead of dismissing them? There has already been much movement toward the inclusion of students as community members. In composition studies an early acknowledgment of the students' right to self-determination can be found in the 1974 statement by the Conference on College Composition and Communication on the "Students' Right to Their Own Language": 
We need to ask ourselves whether our rejection of students who do not adopt the dialect most familiar to us is based on any real merit in our dialect or whether we are actually rejecting the students themselves, rejecting them because of their racial, social, and cultural origins. (2)

This statement is an early recognition of the role educational institutions play in the reproduction of dominant culture and its effects on those students often defined as being outside this culture. The possibility that teachers (either consciously or unconsciously) may be "rejecting the students themselves, rejecting them because of their racial, social, and cultural origins" is especially disturbing because it means that students are once again not seen as already being members of society. Rather, they remain outside until they can prove that in spite of their race, class, gender, sexual orientation, or any other marker of marginality, they can at least through language participate in the community. Students are forced to prove that they belong and that they are worthy of being community members by acquiring a particular discourse that often operates more on the assignment of legitimacy given by the dominant culture than by its utility in specific discourse situations.

While much has changed since the CCCC statement, there is always a danger of student texts being lost. As Knoblauch again recognizes, these dangers can often come from those who appear to be supportive of students and their rights as "politicians and school officials quick to realize the ultimate gain in administrative control that comes from allowing such modest symbols of self-determination to release built-up pressures of dissatisfaction" (78). ${ }^{3}$ While this hegemonic control may appear to diffuse the power of students and their acts of selfdetermination, it is the continuing production of student texts which is their most effective act. Student texts may be "silenced" as teachers or other readers often reduce the power and subversiveness of these texts to comments in the margins about usage and effectiveness. But when we look past the marginalia and into what students write, we see that they write not only to meet their assignments but also to respond in various ways to their place in the world. In the basic writing classroom this is Tom Fox's redefinition of basic writing as cultural conflict. ${ }^{4}$ As the following student narratives illustrate, students are already theorizing and producing narratives of self and cultural identity.

\section{College Identities}

Writing a sentence, a poem, or a few lines in your diary makes 
you a writer.

Rose

A writer I think may be someone who's creative in writing and making stories come true to life.

Peter

Furthermore, we can't really state the social significance of writing because it affects people who have diverse beliefs and principles.

Nate

What is a writer? What is writing? Are you a writer? While reminiscent of the questions asked by Roland Barthes and Jean-Paul Sartre about the philosophy and nature of language, the questions just recited were put to my students on the first day of class at the University of Hawai' $i$ in the summer of 1992. The questions were asked as a prompt for a freewriting exercise that I hoped would give me some idea about the writers I had in class and what I needed to do in class to help them prepare for the types of academic writing expected of them in the university. However, I also asked the questions because of the subtext provided by Barthes and Sartre: their notions of writing and textuality allow for an exploration of the self as creator of texts and also of the self as a text. ${ }^{5}$ While I did not expect the students to be explicitly philosophical or theoretical in their discussion of writing and language, I did hope for responses that would suggest that the students had some understanding of their relationship to writing and what writing meant to them in terms of participating in the university. At worst I expected "traditional" definitions of "correct" usage and standard genres; at best I hoped for interesting pieces and interesting students.

What I received were responses that in fact were quite philosophical and theoretical as the students did not merely consider how language and literacy might change the material conditions of their lives (an often stated goal of education) but rather described very personal connections with writing and its power in helping them enter the world of public discourse. I began this section with quotes from three of my students who each display in their statements an awareness and understanding of writing that moves beyond the privileging of correctness of form and the reification of textual and authorial intent. Rose questions the authority of privileged genres and believes the writer is created by the act of writing. Peter asserts that the writer is someone who creates texts and makes those texts active in the world. And Nate suggests that the acts of writing and reading are socially constructed in a postmodern world. While the students are probably not familiar 
with the terminology I have used to frame their statements, their statements certainly suggest that they are familiar with a notion of writing that allows them to determine what is valuable and useful in their lives and are not concerned solely with meeting the expectations and requirements of an institution, an institution that can validate them and confer upon them a type of authority, or just as easily dismiss them.

In a sense these students have begun to define their sites of writing. They want to deprivilege "traditional" texts as autonomous and authoritative and emphasize acts of writing. They want to create something "true to life," or more precisely, something that is true to their lives. And they want to recognize not the single social significance of writing but the multiple significances opened up by the possibility of writing. But they also find themselves in the university. And while the university is not antithetical to the modes of action that the students have suggested, the reality is that a particular public discoursean institutional discourse - is utilized in order to participate in the community. The problem that is posed to these students, then, is whether the public identities they have already begun to create for themselves can exist within the public that the university will require them to participate in if they are to be "successful"?

The writing course I taught that summer at the University of Hawai'i was part of a summer program for incoming first-year students. The program identifies graduating high school seniors who are not traditionally admitted to the university (i.e., "high risk"), but who can be successful if provided with proper support:

[the program] is based on the belief that given a chance, individuals who are motivated and provided with new learning opportunities and support services will be able to succeed in their first year at the university, thus being able to mainstream with the regular student population and eventually earn a bachelor's degree. ${ }^{6}$

The program came into existence as part of the Honolulu Model Cities demonstration project of the early 1970s. The project reached into "Model" neighborhood areas that were traditionally working class and populated largely by ethnic groups who were underrepresented at the university. In 1973 the program was fully funded by the Hawai' $i$ State Legislature and became a University of Hawai'i program, marking the beginning of a state-supported program in higher education for the non-traditional/disadvantaged student. The program continues today and in 1992 accepted 125 students from over 400 applicants statewide. Of the 125 students accepted into the program in 1992 a majority were female, Native Hawai'ian or Filipino, and recent public high school graduates. ${ }^{7}$ 
The program sets certain writing requirements in order to model the composition requirements of the university, asking that the students write three formal papers (narrative, comparison/contrast, and argument). However, other than the three genre requirement, the instructors design their course as they see fit. Because of the student profile (i.e., high risk and probably underprepared) it seemed important to change the "traditional" conditions of the classroom. Rather than teaching strictly genre and form, I used the classroom to question existing notions of literacy and literature by having students read "literature" by writers from their community and by using both culture and language as themes throughout the course. The students were asked to write the three "formal" papers but they were provided the opportunity to develop their own subjects and were encouraged to consider their own experiences as textual material. In addition to the "formal" writing, students wrote daily in response to a variety of material (e.g., poems, essays, current events, or life experiences) in order to move beyond the limitations of an academic paper. These freewrites, though, often became the starting points for their papers.

Robert Scholes's strategy of teaching "textuality: textual knowledge and textual skills" was an important influence in my design of the course. In Textual Power: Literary Theory and the Teaching of English, Scholes writes:

We must help our students come into their own powers of textualization. We must help them to see that every poem, play, and story is a text related to others, both verbal pre-texts and social sub-texts, and all manner of post-texts including their own responses, whether in speech, writing, or action. The response to a text is itself always a text. Our knowledge is itself only a dim text that brightens as we express it. This is why expression, the making of new texts by students, must play a major role in the kind of course we are discussing. (20)

Thus the students were asked to produce a variety of texts. But in order to help them conceptualize their own texts as being "valid" textual material for the class they were presented with published works of writers from Hawai'i and from other "marginalized" groups (essays by Michelle Cliff, Richard Rodriguez, Ishmael Reed, and others). Before the students could begin to situate themselves as writers, I thought it important that they recognize that there are writers from their own community who are producing "literature." This further destabilizes the ideological and institutional structures that have privileged texts and experiences that are not necessarily meaningful to the students in my class. On a theoretical level, I wanted to emphasize that textual production could be thought of as an act of cultural pro- 
duction; that the activity of writing the students were engaged in should not be thought of as being a distinct academic activity, but rather as an already existing cultural practice. By first recognizing the production of culture through their own texts other cultural constructs such as literacy could be both contested and produced in terms that would be useful to them.

Another critical factor in emphasizing textuality and the unstable nature of texts was the need to negotiate the students' own use of language, and in particular, the use of Hawai'i Creole English (HCE) or pidgin (as it is widely known). The students come to the classroom with a variety of languages; for some English was a second language, for others HCE was their primary discourse. Often their use of written English was viewed as non-standard. ${ }^{8}$ However, rather than questioning the value of their language, or suggesting that standard academic discourse is a more valuable language, I hoped to show them in the class that these were merely different discourses that act within different communities. Instead of maintaining a separation of discourses, we used the classroom to discuss the differences and recognize that these discourses could inform each other in terms of content, rhetorical strategy, and creating identities within these texts. ${ }^{9}$ This also allowed for students to be more productive in creating texts. Though there was an implicit understanding that they would be using "standard" academic discourse, I thought it was more important to emphasize that they just write and that once their texts were produced they could then shape them to meet the conventions of various discourse communities. It seemed more important to work toward fluency and building confidence in writing and producing texts than it was to emphasize form and convention which would be reinforced in First-year composition. The course was in Scholes's term, the pre-text, an activity to help the students situate themselves before being asked to engage in the critical activities of writing and participation in the university. They needed the opportunity to situate themselves in their own texts and through their own texts before they could be asked to write about others' texts.

I also had to situate myself and consider my role in the textual and cultural production of the students. My multiple subject positions complicated my pedagogy because of the various interests I had in this writing class. As a local subject-Hawai'i resident, public school graduate, university alumnus, Asian/Pacific American - I shared many of the same experiences as my students who were just a few years younger than me. But I also found myself in a liminal position as a University of Michigan PhD student back for the summer to teach this course. My time away at graduate school provided me with the critical distance to think about issues of education and the teaching of writing in a place like Hawai' $i$, but I also wondered if I would lose sight of 
the very real political and material conditions that affect Hawai'i's students. My interest in this course was about more than teaching writing; it was about my students as well as myself being able to move beyond the ideology of standard English which in Hawai'i's history has been used in the discrimination against Hawai'i's non-white population and moving toward an examination of the politics of language and literacy in such an explicit "contact zone."

However, in pursuing this critique of a dominant cultural institution and challenging the traditional construction of the academy was I just replacing one ideology with another? In introducing "new" writing to these students was I "opening up the canon" to allow for limited representation of marginal cultures and ultimately reproduction of oppression? As a local subject now removed to an elite university, was I exercising a quiet paternalism under the guise of critical pedagogy to "help" students "liberate" themselves?10 The bottom line is probably yes. Program requirements and philosophy did not allow for the kind of radical restructuring needed to situate students in a more explicit position of self-determination. Students really were learning the "basics" to acculturate them to university life. And even the practice of a more radical pedagogy and awareness about situations like the "contact zone" can be problematic. ${ }^{11}$ However, by focusing on textual production as cultural production, the terms for discussing literacy could be generated in the classroom. The students' texts could become examples of literacy and of the cultural work that could provide the students at least the opportunity to conceptualize themselves as cultural workers but perhaps more important, as producers of culture, or even cultural critics, and certainly as writers.

\section{Writing/Writer Theory}

As I explained earlier, I asked the question "What is a writer?" as a writing prompt. Just as the question itself is full of possible answers, asking the question is also full of pedagogical as well as theoretical possibilities. On a very practical level, I wanted a writing sample from the students so I would know how to shape my pedagogy to address the needs of the students and their position as writers in the university. On another level I wanted to learn about the students, see how they viewed their relationship with texts, and find out how they placed themselves within our textual economy. And on another level, by asking them to define what a writer and writing is, I hoped to change the conditions of the classroom, to make it writer-centered instead of 
teacher-centered. Though ultimately I would still be evaluating their texts, I did hope to create a classroom environment where students felt comfortable enough to begin to evaluate their own work as well as to respond to (if not question) my comments.

When I read over the students' responses I was surprised by how many of them asserted their right to determine what is acceptable as writing and who can be a writer. Surprised not because they formulated a stance about writing and the writer, but surprised because of the risk these students were willing to take when in their backgrounds and in the history of Hawai'i such a risk has often been rewarded with humiliation, dismissal, or even physical punishment. ${ }^{12}$ A consistent theme in the responses was that an important part of writing and being a writer is the ability to be expressive and sincere in communicating experiences and ideas. This suggests that the students are privileging the imaginative writer, the writer of fiction and poetry. However, I believe it is also an indication that the students see the writer as making himself or herself through the texts, that the writer who is expressive and sincere has been successful in presenting himself or herself to the public to share experiences. The students that I will be discussing attempt through their texts to share experiences and ideas that are important to them and important in the construction of their identities.

The prompt, "What is a writer?" was actually asked at three points in term: the first day of class; after the first paper (narrative); and at the final meeting. This was done to provide some gauge on how the students' ideas changed over the term. It also provided me with some of the students' own "theories" about writing that informed my readings of their writings. The first piece that I want to look at is Rose's "What is a Writer? \#1":

Writing, to me, is just a way of expressing your feelings, but instead of doing it verbally, you write it all down. Anyone can be a writer. Writing a sentence, a poem, or a few lines in your diary makes you a writer. So anytime you express yourself or your feelings down on paper, etc., I feel that you are considered to be a writer.

Writers write about anything they can think of, such as angry feelings that cannot be held in anymore written in a letter to the despised person, or a small poem to a love one.

Right now I feel as though I have "writers block", but I don't because I am writing what I feel down on paper. Thinking about what to write can take a second or a lifetime. It is taking me a while to think about to write because I am not a good thinker, but once I get an idea in my head. I write until my 
fingers hurt. Also, I tend to babble. Which I feel is okay because I'm still expressing myself

Writing is an expression.

Rose begins her "definition" of writing by suggesting that there is no separation between oral and written expression and that they are both "just a way of expressing your feelings," with the exception that one is written down. This is followed by the declaration that "[a]nyone can be a writer." The juxtaposition of these two ideas creates a possibility for an expanded notion of what writing is and who can be a writer. This is especially important when the politics of HCE are considered because what has been considered a non-standard oral form is given equal status with a standard written form. The next two sentences question privileged genres, giving value to more personal discursive forms and then equating expressiveness with being a writer. In the second paragraph the idea of expressiveness is reinforced by describing two powerful emotions (anger and love) and suggesting that writing becomes a way to negotiate those emotions, serving a therapeutic function. The third paragraph is perhaps the most interesting because in it Rose actively constructs herself, displaying a selfreferentiality, and also performing a self-evaluation of herself as a writer. She uses writing as a heuristic, interacting with the text she produces as well acknowledging the dialectic and dialogic relationship that has been formed when she notes that even her "babbling" is a useful production.

Rose's second freewrite reinforces the ideas she introduced in her first piece:

A writer is a person who writes. Whatever you think about and write it down considers you to be a writer. Writing down your daily thoughts, jotting down a grocery list, or summarizing a book you just read, down on paper makes you a writer. What I am trying to say is that when you got any kinds of thoughts or ideas down considers you to be a writer.

Writing is important because it is a way of expressing yourself. If you don't express yourself, I think you're weird. Writing is an expression which when used properly will help you explore sides of you never existed.

In the first paragraph, Rose again questions privileged genres by privileging a "grocery list" as an important text. She also restates her belief that writing is an important way of expression and even makes the value judgment that "if you don't express yourself, I think you're weird." By making such a statement she clearly suggests that writing is a way to identify yourself, to reveal yourself, to make yourself pub- 
lic. And in the final sentence the idea of writing as heuristic and selfevaluation is reintroduced. Perhaps the most interesting thing about this second freewrite, though, is her movement in the first paragraph to describing writing in terms of thinking and producing ideas. Her first freewrite almost exclusively discussed writing in terms of expression except for the idea of writing as heuristic toward the end. In this second freewrite she emphasizes the "writing-as-thinking" aspect much earlier and places it before writing as expression which assumes a secondary place in the next paragraph. In James Berlin's terms, this is a move from subjective rhetoric to epistemic rhetoric which allows Rose to start to make connections through language between the personal and the public.

Rose's final freewrite, though the shortest of her "What is a writer?" pieces seems to me the most revealing in terms of constructing a public identity. Though in her first two freewrites she begins to tease out ideas about writing as a way of developing an identity, it is in her final piece where she expresses this idea without hesitation:

What I think about writing is that it is and will always be a form of expression just as art and music is. People throughout time wrote to express their feelings or themselves as a whole. When I write in school, it is usually forced upon me to do and I end up not writing well. I don't like to be graded on how well I express my feelings and thoughts. When I write on my own, my feelings are as free as the blowing breeze.

Rose's second sentence ("People throughout time wrote to express their feelings or themselves as a whole.") brings together two important themes that have recurred in her pieces. The importance of expression and her ability to express her feelings is present once again but now she makes the move to say that this way of writing allows the writer to become "whole." Previously she had only intimated that not expressing yourself was to not have an identity, or in her words, "weird." The next two sentences, however, are even more intriguing because she now directly challenges those who would deny her the right to construct herself. By naming the "school" as a place where she has had difficulty being, she questions the right of the institution to construct her. She objects to being "graded" not because she is resistant to the opportunities that she knows education can provide her but rather because she sees that "grading" as a judgment of her identity and of her right to be a part of the public where she believes she is already an active participant. Her final line is not a rejection of public life but rather an affirmation of her existence in a public that exists beyond institutional boundaries where the freedom of the "blowing breeze" allows her to write her own self. 
Nate's series of "What is a writer?" freewrites are shaped in a much more argumentative manner than Rose's pieces were. His first freewrite was among the lengthier ones in class as well as most ambitious in terms of rhetorical style:

What is a writer? Is he someone who has a college degree? Is he someone who has a sharp mind? Is he someone who carry a book or dictionary or a pencil and paper all the time? Is he someone who does all the paperwork in a business firm? Or just someone who jots down his thoughts and feelings as they come along?

I think a writer is someone who take the time to actually sit down and write whatever is in his mind. Writing about his inner thoughts and feelings I don't think it's fair to say that writers are the only people who actually get their works published in a book because I know that there are much better writer than those authors of books that we so oftentimes regard as bestsellers. I think that simply holding a pen and writing something that we are concerned about is already writing.

The thought of being a writer gives some people a feeling of intimidation because they think that people $\mathrm{w} /$ college degrees, professionals, and authors $\mathrm{w} /$ published books only have the right to be called writers. I think if a person feels this way he is insecured. Insecured $\mathrm{w} /$ the fact that he knows he's a writer but then he doesn't get known for being one like Shakespeare or Judith Krantz, maybe. I don't tolerate this idea because I think we are only degrading ourselves if we take the time to pity ourselves because we are unsung writers. Well, we don't have to be known to be a writer. Just plainly writing something that you can consider marvelous is already a triumph of both the mind and the heart because we know deep inside us that we have done something.

If you get discouraged because you can't write anything? I think being in this mood is a good time to actually write. How? It's very easy. You get discouraged because you can't write. Then, write about what you are feeling, then start from there. Soon you'll find a good paper out of what you've just done.

Writer. College degree? No! It's within a person.

Nate uses his first paragraph to dismantle institutional and cultural representations of writers. In the examples he provides there is a strong link between texts and writers, suggesting that too often the reification of texts and their assignment of value have created a culture that has been exclusionary. Nate follows up on this idea in his second and third paragraphs by deprivileging both popular and ca- 
nonical texts and the cultural capital assigned to them. He replaces these texts and their writers with the "unsung" writer, the person who becomes a writer by virtue of writing about something with which he or she is concerned. Unlike Rose who more subtly suggests that writing is a way of constructing identity, Nate is quite explicit and even polemical in his assertion. He totally dismisses the notion that a writer must be validated by another and is even more adamant in saying that writers should not even seek validation from others. For Nate, the construction of identity takes place in the act of writing and not in any form of validation.

We also find in the fourth paragraph an idea similar to the one Rose suggested in her freewrites. Nate also introduces the idea that writing can act as a heuristic, allowing writers to work out difficulties through producing texts. Underlying this use is the production of ideas and knowledge that in so many ways has been lost in the commodification of texts that Nate has earlier discussed. And in his final sentence he once again rejects commodification and asserts the individual's ability and right to be a writer. In his second freewrite, Nate reiterates the points made earlier:

A writer for me, is someone who jots down his thoughts and ideas. The whole idea of being a writer doesn't have anythings to do with best-selling authors. I think everyone can be a writer if they want to. Because writing is something that I do to make use of our time, I find to be interesting. Just sitting in front of my typewriter and type whatever I think of.

He much more explicitly points out in this piece that writing is related to thinking and ideas. However, he is less passionate in this piece and in fact almost seems to summarize the main points of his first freewrite. His final freewrite, however, moves toward a new conceptualization of writing :

I agree with what the author said. I think that the subject of writing doesn't only affect what is being written rather it also consider other factors that would contribute to the success of writing. Like many other things, writing has an origin and it links to other roots in the society. For instance, religion has different beliefs that are presented in different churches. As for writing, we consider screenplays, playwright, poems, books and other types of literature, archives and so forth.

Furthermore, we can't really state the social significance of writing because it affects people who have diverse beliefs and principles. What might be relevant for a mayor may not be relevant for a policeman, what might be relevant for a teacher 
In the first sentence Nate is responding to William Stafford's "A Way of Writing" (read for class) and Stafford's description of the process of writing as opposed to the skill of writing. Nate further develops this idea of "process" and moves toward a notion of social construction. In his first freewrite, Nate argued for the individual and what the individual alone could produce. However, in this final piece he returns writing to society, but still makes the important point that there should be no single standard of judgment or evaluation. His example of the many different churches and religions alludes to a constitutional right to freedom of expression. His expansion of what can be considered writing also is influenced by this right. And in his final paragraph, Nate makes the profoundly insightful comment: "Furthermore, we can't really state the social significance of writing because it affects people who have diverse beliefs and principles." He recognizes that the individual must exist in society and cannot be so isolated as he suggests in his first piece. What Nate constructs, then, is a public where writing does not act as a meta-narrative nor have a single social significance. Rather, writing is rhetorical, creating situations where people with diverse beliefs can meet in a textual public and not remain isolated. Though Nate indicates that these people with diverse beliefs and principles may have different interests, he does not dismiss the possibility of interaction among them. He simply acknowledges that context plays an important part in both the producing and reading of texts. Social significance becomes not a marker of value but a marker of connection and purpose and of the transformation of literacy within culture to meet the needs of individuals.

\section{Narrating a Nation}

While Rose and Nate theorize the role and identity of the individual writer underlying their constructions is an awareness of the writer in culture and how culture constructs the writer. Poet Eric Chock notes the specific problem of conceptualizing the writer in Hawai'i: "And we wonder why they have problems teaching our kids to read and write. The answer is the problem, obviously. If there is no such thing as a Hawai'i writer, how can you teach a Hawai'i kid to write" (8). Chock recognizes a problem of representation: Hawai'i writers have been represented as absent, as producers of colorful but non-literary texts; Hawai' $i$ students have been represented as non-literate and as not being able to represent themselves. The complexity of this situation requires a strategy where subjects can begin to create a new space for writing. 
While Homi Bhabha suggests that there is a certain ambivalence in the idea of the Nation, that the Nation becomes more of a transitional space than a stable history, he also recognizes the need to narrate the Nation (1). Narrating the Nation is an act of composing, perhaps ultimately rhetorical if the Nation is indeterminate, but important as a first step if one is to imagine oneself as part of a culture, and for my purposes, as a writer in that culture. While the Nation may often be a romantic narrative of progress and unity (perhaps like literacy), it provides for a space where individuals can write from or write against, where students can begin to locate themselves within the various spaces in which they find themselves.

The next text I would like to look at is a narrative written for the first formal paper assignment. The students were asked to write a narrative about an experience, either negative or positive, in which they learned something. The students wrote about a wide variety of things: leaving home for college; the death of a close family member; winning a state volleyball championship; graduating from high school. One student, however, chose to write about his lack of having a language. Peter is a Native Hawai'ian from the island of Maui. Because of current political activities concerning Native Hawai'ian sovereignty and the then upcoming observation on January 17, 1993 of the 100th anniversary of the overthrow of the Hawai'ian monarchy, Peter was very aware of his situation within the community. Peter uses his narrative to negotiate the confusion that he faces as a Native Hawai'ian in contemporary Hawai'i, concerned about preserving a cultural identity, but lacking what is often considered an essential marker and creator of identity, language.

\section{"Know Your Language"}

I don't know where I got the motivation to learn the Hawai'ian language but it started me off in a long term ambition and desire to learn my native tongue. The Hawai'ian language is so dear to me I would do anything to learn it. But the fact is, I do not know how to speak Hawai'ian, so that made me set some goals for the future.

It all started at home when my dad asked me, "What you going do when you grow up?" I really had nothing to say to him. I still had my mind set on learning the Hawai'ian language. Although my parents did not know how to speak Hawai'ian, they still encourage me to learn it. I was about eighth grade at this time and I couldn't wait to get to high school. It would give me some opportunity to learn the language while I was going to Lahainaluna.

Lahainaluna came and I was very disappointed to find out that Lahainaluna did not offer a course in Hawai' ian language. 
So I took Hawai'ian studies instead. I wasn't satisfied with the class, because I had my mind set on learning the language and not the history. So I decided to join the Hawai'iana club thinking that it would make a change. I must say that it was a lot of fun, because we would play Hawai'ian music, dance modern and ancient hula. In the chants we would have a pretty good understanding of what the song was about. But knowing what the song was about and knowing what each word in the chant meant was different. If you knew what each word meant in the song then you would get a different perspective of what the song meant. And it would provide a deeper meaning.

Towards the ending of every school year, counselors would pass out registration forms for requests on what courses you would like to be offered the following school year. I have registered Hawai'ian language as a possible elective to be offered the next school year. From my freshman to junior year, I have been making the same request, but it was never a guaranteed matter. Every year I had my hopes up, but to my disappointment they still did not offer the Hawai'ian language course.

During my senior year I figured I shouldn't make any requests, because they'll probably never offer it for the next school year anyway. I would have to wait for college to get the opportunity of learning the Hawai'ian language.

Now college is almost upon me and I'm afraid that I might be facing some more disappointment, due to the experience I had at Lahainaluna. Being that Lahainaluna the oldest Hawai'ian school, having an alma mater sung entirely in Hawai' ian, and not having a Hawai' ian language course. The first thing that comes to my mind is, what if I don't make it into the fall. And that would only cause more disappointment.

To me having the opportunity to learn the Hawai'ian language is not something that you have to go to college for. It is something that should be used on a daily basis for everyone who lives here in this state, no matter what race they are. To express my point all Japanese who come from Japan, speak Japanese. All Filipino who come from the Philippines, speak the Filipino language. But not all Hawai'ian can speak the Hawai'ian language. I feel you do not have to be of Hawai'ian ancestry to speak the Hawai'ian language, you only have to have it in your heart.

Peter begins his narrative by describing a sense of loss but balances this with a sense of hope and optimism. Though he does not know Hawai'ian, Peter sees it as an essential part of his identity, de- 
scribing it as his "native tongue" (as opposed to English, the language of the United States, where he was born). ${ }^{13}$ He describes a strong attachment to the language and yet he never fully explains what that attachment is which becomes even more complicated since he discusses no active engagement with Hawai'ian at all. In the second paragraph the problem of identity becomes even clearer when Peter describes his answer to his father's question about his future: "I really had nothing to say to him." The inability to answer his father adds to the identity problem that Peter has described up to this point. He could not answer his father because he either did not have the words to explain himself, or did not know what he wanted to do, or could not even imagine his life. He simply did not have the language to conceptualize himself.

When Peter describes his experiences in high school there is a change in tone. The very place where he thought he would be able to acquire his language and to begin the process of constructing an identity could not help him. The school does provide the opportunity to acquire other cultural practices that could contribute to his emerging yet still unshaped identity. And yet, Peter rejects some of these opportunities believing that these other practices are not the primary tools that he needs. He becomes almost obsessive in his privileging of the language and of a textuality that in his mind cannot be produced in any other form or practice. In the sixth paragraph, Peter becomes guarded in his desire for Hawai'ian. Perhaps to prevent himself from further disappointment, he lowers his expectations and prepares himself to be denied the opportunity once again. However, the guardedness may also act to prepare him for a disappointment that might occur once he does learn Hawai'ian. He will finally have the tool that he desired so much and the opportunity to construct an identity. But what if the language does not meet his expectations? What if it does not provide him with a way of answering his father's question and helping him to discover not only who he is but who he wants to become? What if his already existing cultural identity remains unchanged by his acquisition of Hawai'ian?

In a small way his final paragraph answers some of those concerns. Peter begins to deprivilege Hawai'ian, or at least the construct of Hawai'ian that he created. The first important move that he makes is to remove it from the university and other institutional structures. ${ }^{14}$ He recognizes that Hawai'ian, and probably texts in general, should not be assigned a value merely by being placed in the university. Peter wants to bring Hawai'ian back into the community, into a situation where it can further the construction of identity and of nationhood. In the final two sentences he notes that not all Hawai'ians can speak Hawai'ian but also that you do not have to be Hawai'ian to learn the language. In these words there is a call for nationhood, for the build- 
ing of a sovereign Hawai' $i$ that begins with the learning and activity of language. Peter has moved from his individual desire at the start of the piece to a community desire of citizenship within a new nation. The narrative has provided him with the possibility of narrating his life and discovering through a type of praxis the purpose for his learning Hawai'ian.

\section{Literate Lives}

What the texts of Rose, Nate, and Peter illustrate are an active participation between student writers and their texts. While the texts do have problems when evaluated in terms of standard academic discourse, they are very significant in revealing how students conceptualize their texts and the purposes of their texts. The activity of writing was often cited as a way of producing knowledge, acting as a heuristic in many cases. In other examples of student writing (not discussed here), there was an apparent therapeutic use of writing by the students who often reconciled feelings for relatives who had passed away or worked out confusing and angry situations like the sexual assault of a sister. But all of these writings were grounded in a purpose determined by the writers. Deborah Brandt sees this recognition of purpose and need as an important act of literacy:

The most successful readers and writers are grounded in an immediate and particular context of need, which gives purpose and direction to an act of reading or writing. Before skills or even background knowledge, literate people need a place to be literate-a place where they and others are asking the kinds of questions and doing the kinds of work that make reading and writing and text-based knowledge purposeful. (117)

She reconceives literacy as not grounded in texts but rather existing in the interaction between writer, reader, and text. And this interaction is also influenced by other factors which create the reading or writing situation, create the event which becomes a writer's subject, or create the context for reading a particular text in a particular way. When Rose, Nate, Peter, and the rest of the students write their texts, they write about their lives and their selves in order to create the context for their literacy. Certainly they will be influenced by the university and the larger American culture, but because they have begun to situate themselves within a knowledge that is purposeful to them they will be able to negotiate their identities and literate acts within the communities in which they find themselves.

For Henry Giroux, such a negotiation might be considered an act 
of citizenship:

The concept of citizenship must also be understood partly in pedagogical terms as a political process of meaning-making, as a process of moral regulation and cultural production, in which particular subjectivities are constructed around what it means to be a member of a nation state. (7)

However, while Giroux's statement critiques both historical and current pedagogical theories and practices, his notion of citizenship becomes an important conceptual as well as pedagogical tool. I tried to create in my classroom a destabilized site where the students would need to become responsible in shaping their educational agenda. Thus instead of subscribing to the existing cultural hegemony of meaningmaking, moral regulation, and cultural production, the classroom became a place to question these practices. Giroux accurately describes the dynamic of education which is so often lost in a conception of literacy as textual knowledge. The act of citizenship is a part of this dynamic. The students actively sought citizenship when they became aware of their role in shaping the public in which they were acting. They became citizen writers and one, Peter, even began to participate through his writing in the literal and metaphorical act of nation-building. Rose, Nate, and Peter have been able to create their own public identities. These identities will change as they experience different things, encounter new people, and live their lives both inside and outside the university. But they have begun to understand that to participate in public life and to use public language is not to lose a part of themselves. Instead they theorize their roles as writers and their place in the Nation because they recognize that they are cultural workers and already live literate lives. Our responsibility as teachers is to recognize this as well as to understand our own positions in culture. While I have discussed the theoretical, ideological, and rhetorical relationships between students, their writing, and culture, we cannot overlook the very real material effects on their lives. When we (students and teachers) write we begin the work of reading and writing our culture and moving toward a more complex understanding of literacy and education and what it means to be a citizen in America. What we cannot lose sight of is that there must be action which follows this understanding and that our work as both students and teachers of culture does shape our lives as well as the lives of others.

\section{Notes}

I would like to thank Anne Ruggles Gere for her careful reading and thoughtful comments. I would also like to thank the editors and 
consulting reviewers of $J B W$ for their comments. All student texts in this article appear unedited. In all cases written permission from the writers has been given. Pseudonyms have been used to maintain author anonymity.

1. See John Trimbur's essay, "Literacy and the Discourse of Crisis," for a discussion of the cultural anxieties involved in the construction of the "literacy crisis," perhaps most often illustrated by "drawing lines between standard English and popular vernaculars, 'masters' and 'servants'" (280).

2. See Gerald Graff's Beyond the Culture Wars for a discussion on the teaching of ideological conflicts as a more effective pedagogy for contemporary society.

3. See also Gary Tate's "Empty Pedagogical Space and Silent Students." Tate critiques the essays in the collection Left Margins: Cultural Studies and Composition Pedagogy for not making student texts central in a discussion of developing critical pedagogy in the classroom. While I am sympathetic with Tate's critique I also recognize that the authors in the collection are involved in their own critique of culture and focus on classroom practice not to ignore student texts but rather to emphasize the power of those sites of composing.

4. See Tom Fox's essay "Basic Writing as Cultural Conflict." Fox suggests that a "basic writing pedagogy ought to help students explore the cultural conflicts and continuities that attend their entrance into the university" (80-81).

\section{See Barthes's Writing Degree Zero and Sartre's What is Literature?}

\section{Mission statement from the program handbook.}

7. The profile of the summer program student is similar to the profile of the "underprepared" writer identified by the University of Hawai'i's Manoa Writing Program. In their study of 342 incoming students who were placed into remedial writing classes (as determined by a writing placement exam) between 1987-1989, the Manoa Writing Program found that many were from ethnic groups underrepresented at the university, primarily Native Hawai'ian or Filipino. The study also showed that many of the students identified as underprepared were from the neighbor islands (the Big Island, Maui, Molokai, Lanai, and Kauai) or from rural areas of Oahu, had SAT-verbal scores below 400, but maintained a B average in high school (Pagotto 119). The majority of my 26 students were either Native Hawai'ian or Filipino and from a neighbor island or some rural area of Oahu.

8. The Hawai'i State Board of Education drafted a policy in 1987 that mandated that "Standard English [would] be the mode of oral communication for students and staff in the classroom setting and all other school related settings except when the objectives cover[ed] native Hawai'ian or foreign language instruction and practice" (Sato 653). The policy was met with strong resistance from the community and the BOE adopted a much weaker version 
that simply "encouraged" the modeling of standard English. Also in 1987 a federal lawsuit was filed by two National Weather Service employees who charged that they were denied positions on the basis of race and national origin, specifically as reflected in their HCE accents (Sato 655).

9. I am thinking here of arguments made by Richard Rodriguez who rigidly defines public and private languages, and Lisa Delpit who critiques the notion that "authentic voices" are the only available discourses to "marginalized" peoples.

10. Lisa Delpit argues that sensitive and well-meaning educators do a disservice to students when they privilege "authentic voices" and argue that these voices do share equal status with the dominant discourse of standard English. Delpit's point is well taken and in my class I tried to actively and critically engage "authentic voices" and "institutional" discourses to see how both operate as well as destabilize notions of what can be "valuable" writing in the academy. The recent trend of academic autobiography, ethnography, and other blends of the personal and public suggests that there is a rethinking of scholarship and research.

11. See Janice Wolff's essay, "Teaching in the Contact Zone: The Myth of Safe Houses," for a discussion about the difficulties that can arise from a pedagogy based on critical awareness. Despite her use of contact zone theory, Wolff describes the resistance of her students and her realization that her own radical pedagogy in fact was a privileged discourse that excluded students.

12. See Lois-Ann Yamanaka's novel Wild Meat and the Bully Burgers for a fictionalized account of the humiliation and anxiety Hawai' i students face when their use of pidgin clashed with the school's demand for standard English. Another example of linguistic discrimination is the suppression of the indigenous Native Hawai'ian language. During the turn of the century and through much of the 20th century Native Hawai'ians who spoke Hawai'ian in the public schools were often punished physically. See Albert J. Schutz's The Voices of Eden: A History of Hawai'ian Language Studies for a discussion of the decline and revival of the Hawai'ian language. See also Vicki Viotti's "Native Tongue" for profiles of Native Hawai'ian speakers and the discrimination they faced.

13. It is interesting to note that both English and Hawai'ian are designated as official languages in Hawai'i's state constitution. The current Native Hawai'ian sovereignty movement has complicated the language situation in Hawai'i further. While not an official language (and lacking a standard orthography), HCE has had more of a presence than Hawai'ian and has played a role in defining "local" identity, the group identity of longtime Hawai'i residents. An interest in Hawai'ian language has grown considerably though and has played a significant role in the sovereignty movement. See Candace Fujikane's essay, "Between Nationalisms: Hawai'i's Local Nation and Its Troubled Racial Paradise," for a discussion of the competing ideologies of "Local" identity and Native Hawai'ian sovereignty. Also see Suzanne Romaine's "Hawai'i Creole English as a Literary Language," for a discussion of the status 
of HCE.

14. The role of the University of Hawai'i in the education of Native Hawai'ians has been very controversial. Native Hawai'ian sovereignty activist Haunani-Kay Trask, an associate professor of Hawai'ian Studies at the university, has discussed what she sees as the institutionalized racism of the university toward Native Hawai'ians. See her book, From a Native Daughter: Colonialism and Sovereignty in Hawai'i. See also Restructuring for Ethnic Peace: $A$ Public Debate at the University of Hawai' $i$, which recounts a public forum where the status of Native Hawai'ians in the university was the central issue.

\section{Works Cited}

Barthes, Roland. Writing Degree Zero. Trans. Annette Lavers and Colin Smith. New York: The Noonday Press, 1967.

Berlin, James A. Rhetoric and Reality: Writing Instruction in American Colleges, 1900-1985. Carbondale: Southern Illinois University Press, 1987.

Bhabha, Homi K. "Introduction: Narrating the Nation." In Nation and Narration. Ed. Homi K. Bhabha. London and New York: Routledge, 1990. 1-7.

Brandt, Deborah. Literacy as Involvement: The Acts of Writers, Readers, and Texts. Carbondale: Southern Illinois University Press, 1990.

Chock, Eric. "On Local Literature." In The Best of Bamboo Ridge: The Hawai'i Writers' Quarterly. Eds. Eric Chock and Darrell Lum. Honolulu: Bamboo Ridge Press, 196. 6-9.

Committee on CCCC Language Statement. "Students' Right to Their Own Language." College Composition and Communication 25.3 (Fall 1974): 1-18.

Delpit, Lisa. "Acquisition of Literate Discourse: Bowing Before the Master?" Theory Into Practice 31 (Autumn 1992): 296-302.

Fitts, Karen and Alan W. France, eds. Left Margins: Cultural Studies and Composition Pedagogy. Albany: SUNY Press, 1995.

Fox, Tom. "Basic Writing as Cultural Conflict." Journal of Education 172.1 (1990): 65-83.

Freire, Paulo. Pedagogy of the Oppressed. Trans. Myra Bergman Ramos. New York: The Seabury Press, 1970.

Fujikane, Candace. "Between Nationalisms: Hawai'i's Local Nation and Its Troubled Racial Paradise." Critical Mass: A Journal of Asian American Cultural Criticism 1.2 (Spring/Summer 1994): 23-57.

Giroux, Henry. Schooling and the Struggle for Public Life: Critical Pedagogy in the Modern Age. Minneapolis: University of Minnesota Press, 1988. 
Graff, Gerald. Beyond the Culture Wars: How Teaching the Conflicts Can Revitalize American Education. New York: W. W. Norton and Company, 1992.

Knoblauch, C. H. "Literacy and the Politics of Education." In The Right to Literacy. New York: Modern Language Association of America, 1990.

Murayama, Milton. All I Asking for Is My Body. 1959. San Francisco: Supa Press, 1975; rpt. Honolulu: University of Hawai'i Press, 1988. Pagotto, Louise, and Irena Levy. "Developing the Skills of Underprepared College Writers: Identification, Intervention and Instruction." In Academic Literacies in Multicultural Higher Education: Selected Essays. Eds. Thomas Hilgers, Marie Wunsch, Virgie Chattergy. Honolulu: Center for Studies of Multicultural Higher Education, 1992.

Pratt, Mary Louise. "Arts of the Contact Zone." Profession 91 (1991): 33-40.

Rodriguez, Richard. Hunger of Memory: The Education of Richard Rodriguez. New York: Bantam, 1982.

Romaine, Suzanne. "Hawai'i Creole English as a Literary Language." Language in Society 23.4 (1994): 527-554.

Sartre, Jean-Paul. What is Literature? Cambridge, MA: Harvard University Press, 1988.

Sato, Charlene J. "Sociolinguistic Variation and Language Attitudes in Hawai'i." In English Around the World. Ed. Jenny Chesire. Cambridge: Cambridge University Press, 1991. 647-663.

Scholes, Robert. Textual Power: Literary Theory and the Teaching of English. New Haven: Yale University Press, 1985.

Schutz, Albert J. The Voices of Eden: A History of Hawai'ian Language Studies. Honolulu: University of Hawai'i Press, 1994.

Tate, Gary. "Empty Pedagogical Space and Silent Students." In Left Margins: Cultural Studies and Composition Pedagogy. Eds. Karen Fitts and Alan W. France. Albany: SUNY Press, 1995. 269-282.

Tehranian, Majid, ed. Restructuring for Ethnic Peace: A Public Debate at the University of Hawai'i. Honolulu: Spark M. Matsunaga Institute for Peace, 1991.

Trask, Haunani-Kay. From A Native Daughter: Colonialism and Sovereignty in Hawai'i. Monroe, ME: Common Courage Press, 1993.

Trimbur, John. "Literacy and the Discourse of Crisis." In The Politics of Writing Instruction: Postsecondary. Eds. Richard Bullock and John Trimbur. Portsmouth, NH: Boynton/Cook Publishers, 1991. 277295. 
Viotti, Vicki. "Native Tongue." The Honolulu Advertiser. 8 December 1996. F-1, 14.

Yamanaka, Lois-Ann. Wild Meat and the Bully Burgers. New York: Farrar, Straus, and Giroux, 1996. 


\section{Rosemary Winslow and Monica Mische}

\section{THE HERO'S PERFORMANCE AND STUDENTS' QUESTS FOR MEANING AND IDENTITY: A HUMANITIES AND WRITING COURSE DESIGN}

ABSTRACT: This essay describes a seminar course for underprepared students which focuses on the study of the hero's quest and solves many of the difficulties inherent in the remedial writing course as it had been taught on our campus. An understanding of the individual as formed within culture and society but as having some power to choose her path informs the use of verbal and visual materials from several humanities fields to guide students through an examination of cultural and societal images of strong, courageous, and responsible individuals at selected points in time. Students' journeys through the materials are in themselves hero quests as they struggle through difficult but interesting and relevant reading and writing assignments, supported by intensive help in small group workshops and tutorials. The aim is to teach critical thinking, close critical reading, and critical and creative writing as these are necessary for making the journey of inquiry. As the theme necessitates a study of individuals making personal and moral decisions, learning goes beyond these critical skill areas into "critical wisdom."

At the Conference on Global Literacy that convened in Heidelberg last summer, Miep Geis gave an invited talk about her experiences sheltering Anne Frank and her family during the early years of World War Two. Near the end of an hour of moving reminiscence, she mentioned that people often remark to her that she is a hero. Always her reply, she stressed, is that she is not. Her reason? That anyone could have done what she did. In her view, to act with courage, to risk one's own life to help save another, is nothing special; it is something anyone can do. In "On Christian Heroism," an essay on the Jewish Holocaust, Cynthia Ozick argues another perspective - that anyone could have acted as Geis did, but only a few did, and this active re-

Rosemary (Gates) Winslow is Associate Professor of English and Director of Rhetoric and Composition at The Catholic University of America, where she has taught since 1979. She has published numerous articles and book chapters on American poetry, rhetoric, composition, and business and technical writing. At present she is at work on a study of rhetoric and poetics in a community near her home in Washington, D.C.

Monica Mische is a doctoral student at The Catholic University of America and is writing a dissertation on agency and temporality in critical theories and the teaching of literature and composition. In addition to her own study and teaching, she coordinates areas of the writing program, including this course. 
sponse despite significant difficulties is what constitutes heroism. Such action requires a sense of responsibility to others that overrides even fear for own's own safety, a sense which itself requires a transcendent valuing of something greater than the individual.

We have designed a course around the idea of the hero as one put into a position of difficulty and who must then decide whether to act to overcome obstacles, to establish a new position for himself in society, and perhaps to renew society in the process. Though the course was developed in our work with students who were identified as being at risk of not making the transition to college successfully, it would make an excellent course for any level of student, a direction we are now pursuing. With an interdisciplinary content study of the hero quest through visual and verbal texts, we sequence concepts, strategies, and skills in small steps and provide intensive help in writing. Because the preparation of sequenced materials and the intensive writing help require two and a half times the amount of instructor time as the usual course, at least initially, it is more costly and so is reserved for those most in need.

We developed the format over three summers in the special fourweek session for these students and expanded it two years ago to a full semester, six credit-hour course (three credits in literature, three in writing) to replace the remedial writing course for this group of students. The students not only liked the course, they wrote better at the end of the summer version than the groups in the previous two summers who had taken our usual version of remedial writing using a standard remedial writing textbook. All students from the hero quest course placed into regular composition by the end of four weeks, and, with overall grade point averages of around 2.5, they matched a control group of students who had some but not all indicators of being at risk. The average of first semester GPAs for students who took the new, full semester version in the fall of 1995 was 3.16. Their course load included philosophy, math, foreign language, and our course. Our course - in which the course average was 3.05 - pulled the overall average down slightly.

We have two main objectives here: to explain why we decided on the hero quest theme and to describe what we did. These comprise the two larger sections of this essay. A short final section draws implications from what we learned that are being used to restructure our first and second year writing and literature programs for all students. 


\section{Why the Hero?}

The students in our program have a wide spread of ability levels, at least insofar as they can be judged from such indicators as SAT scores, high school GPAs, and entrance application essays. Many of them are not sure they want to pursue college study. Some have low confidence, some a false confidence: they don't believe they can do college work, or they think they are already well prepared for the work. Most have an inaccurate view of what college study requires, either that it is easier or more difficult than it really is. Many have what we call a "damaged interest" in learning, resulting in low or misdirected motivation, which is a key factor: where there is little will to learn, there is likely to be little success. The majority, though not all, do not see the relevance of academic learning in their lives beyond long-term occupational goals. Some do not have even this goal. A few display anger at schooling, or at authority figures in general. In the first two summers, most openly expressed anger at being labeled "remedial" and blamed that for their current situation. Finally, like the vast majority of adolescents, many of these students have impoverished images and models of what their resources are, what they could be, and what strong, responsible adults in a democratic society are-and do. In addition, for whatever combination of reasons a student may have been placed in the program, all of them share lower high school GPAs. Though occasionally the critical factor was long-term illness, low high school achievement has left these students with inadequate learning in critical thinking, reading, and writing skills.

We speculated that a course which approached these skills through a focus on cultural and social construction of hero images might enable students to explore and develop a new perspective on society and their place in it, including their current, difficult situation as underprepared first year students. The course would open up critique but would go beyond critique to examine what strengths and resources cultural traditions and society offer and what ways strong individuals have responded to these constructions of self by struggling to overcome them. Through materials that ranged across time but focused in on a few specific points in time, past and present, students would explore the complexity of self - and social identity and responsiveness. The curriculum would be challenging - a struggle to be engaged inbut intensive help in skills would be provided in small group workshops and tutorials outside of class. In this way, the how of skills and strategies would be learned by way of the need to use them to delve into the inquiry. The why, when, and where of critical approaches 
and literacy skills would not be detached from sustained inquiry into a topic and neither would the in-class sessions need to concentrate on this learning. In short, the course itself would be a hero quest, complete with student choice and responsibility as well as social responsibility on our part to provide the "gifts" - the outer resources to complement the individual's inner resources - as assistance along the hero's journey. This focus would move through various literacies (linguistic, critical, cultural) to include the next developmental step, which we call "critical wisdom," that is, grounding critical thinking in both human circumstances and transcendent values, in which the individual is located and acts within something larger than the self. We hoped they would learn that intellectual study could become an important avenue in a search for identity, meaning, and purpose.

That small children are keen and curious learners is perhaps evidence enough that somehow relations to learning and its value have been disturbed through causes outside the learner. Though only the learner can attempt to repair effects of disturbance in himself, social entities can-indeed must - assist this work. Thus, part of our responsibility as educators is to assist such repair while working to repair disturbances in social institutions themselves.

But let us draw briefly from two theorists to expand on our rationale. In The Theory of Communicative Action, Jurgen Habermas theorizes the processes of individual action amid the interconnected individual, social, and cultural domains in which one lives. Socialization functions both to restrict and to provide resources. For the individual, "[a]ction, or mastery of situations, presents itself as a circular process in which the actor is at once the initiator of his accountable actions and the product of the traditions in which he stands, of the solidary groups to which he belongs, or socialization and learning processes to which he is exposed" (135). He both makes and is made by tradition. Identity is developed within an ordinary understanding of lifeworld, in which the individual forms a narrative that functions in the service of self-understanding by locating himself in time and across time with respect to traditions in the social space (136). Thus, narration as "communicative action serves the formation of personal identities" (137). Whether we like it or not, then, teachers of language and literature tacitly encourage and support either the reinforcing or the renewing of students' identities. Clearly, we think some renewal is in order, and we see in Habermas's explanation of disturbances in the lifeworld an explanation for the ways we understand underprepared students see themselves.

Habermas regards certain disturbances in the cultural reproduction of the lifeworld as "get[ting] manifested in a loss of meaning and lead[ing] to corresponding legitimation and orientation crises" (140). These three areas correspond respectively to the three major "domains" 
of reproduction processes of the lifeworld: "loss of meaning" to the cultural reproduction domain, "legitimation" of the order of interpersonal relationships to the domain of social integration, and "orientation crises" to the domain of the socialized personality. Habermas contends that "each of these reproduction processes contributes in maintaining all of the components of the lifeworld" (142). For example, when there is loss of meaning in the cultural domain, collective identity and breaks with tradition accompany it. These disturbances in the cultural domain further disturb the social and personal domains, and these features manifest: "withdrawal of motivation," "anomie," loss of "personal responsibility," alienation," and "crisis in orientation and education" (143).

Charles Taylor's analysis of ethics in modern democratic culture explains the problem in these three domains in terms of the loss of the "heroic dimension" to life. He sees individualism, for all its positive benefits, as one of three chief "malaises" of the modern era.

Modern freedom was won by our breaking loose from older moral horizons. People used to see themselves as part of a larger order. ... People were often locked into a given place, a role and station that was properly theirs and from which it was almost unthinkable to deviate. Modern freedom came about by the discrediting of such orders.

But at the same time as they restricted us, these orders gave meaning to the world and to the activities of social life. The things that surround us were not just potential raw materials or instruments for our projects, but they had the significance given them by their place in the chain of being. The eagle was not just another bird, but the king of a whole domain of animal life. By the same token, the rituals and norms of society had more than merely instrumental significance....

The worry has been repeatedly expressed that the individual lost something important along with the larger social and cosmic horizons of action. Some have written of this as the loss of a heroic dimension to life. People no longer have a sense of a higher purpose, of something worth dying for. $(3,4)$

And without a higher purpose deemed important enough to die for, it may be that there is not an important purpose worth living for beyond the pursuit of what is of "use." Taylor sees this as the second chief malaise - "the primacy of instrumental reason," which is one result of the "disenchantment of the world," the loss of the "heroic dimension" $(4,5)$. The present phase of democratic development has restricted the sense of "resonance, depth, and richness in our human surroundings" (6) as well as the choices open to individuals, who cannot 
act fully on their principles within a social structure that values the expedient and economic at the expense of other higher purposes (7). Taylor blames further loss of freedom on a third malaise: the segregation of people within their own private concerns and satisfactions, including the "heart" - a situation which harms political and moral action $(7,8)$. But while Taylor sees the reality of factors of cultural and social organization that make it difficult for the individual to act with greater degrees of responsible freedom, he does not despair of progress in this direction, as many do. He sees change needed on two fronts: both the individual and the institutional (8).

We concur with Taylor that all is not hopeless, that individuals are not totally already constructed by society or that individuals cannot make changes in themselves and society. Nor do we see the passing of the old order and its "heroic dimension" as all positive or all negative. Rather, we see the study of this dimension as a vital one for all students, but especially and crucially for those who are adrift in a sea of unexamined societal images and values, many of which appear to offer freedom but within a narrow field of action that is not encompassed by a sense of higher purpose. With Taylor too, and the many other thinkers who have contributed to social critiques on the repressive aspects of modern society, we view the situation in which students-at-risk find themselves to be largely not of their making. The complex interactions of life domains, in the disturbed forms that exist, require knowledge and wisdom to negotiate and renew. But each individual must be able to make that negotiation and renewal for his own and the social good.

\section{The Course Design: Theoretical Backgrounds for Approaches to Texts and Assignment Design}

While ideas such as Habermas's and Taylor's affirmed our decision to treat the theme of the hero, we needed other inspiration for designing a detailed curriculum. Though we drew from many theories, Mikhail Bakhtin's concept of the chronotope, as the intersection and working through of conflicting constructions of tradition, discourses, and identities, provided the pivot for selecting and approaching course materials. The chronotope of the "road" was particularly suggestive as the place where the various domains of the lifeworld come into visible contact so they can be seen and examined. In "Forms of Time and the Chronotope in the Novel," Bakhtin discusses the "road" as a place where "[p]eople who are normally kept separate by social and spatial difference can accidentally meet; any contrast may crop up, the most various fates may collide and interweave with one another" (Dialogic Imagination, 243). We viewed the hero's journey as such 
a road, as well as the course itself, as a place to bring together texts from past and present for a study of how they continue, contradict, and transform tradition. The course would be a "space" where students would encounter perspectives from various times put into contact with each other. The cultural basis of the lifeworld could be made present and relevant as students studied its impact on their lives. Bakhtin emphasizes this characteristic of the road as a "course" which is only made when time (past, present, future) encounters and enters into space: "Time, as it fuses with space and flows in it (forming the road); this is the course of the rich metaphorical expansion on the image of the road as a course: 'the course of life,' 'to set out on a new course,' 'the course of history,' and so on; varied and multi-leveled are the ways in which road is turned into metaphor, but its pivot is the flow of time" (Dialogic Imagination, 244). Students' journeys through our course would similarly proceed through time, encounter the various discourses of tradition, but would focus on the way a selection of heroes had met, grappled with, and responded to these discourses. The responses of the hero, together with the responses of authors and visual artists, would be analogous to the students' learning responses: they would be negotiations through the discourses, a traveling of their own course. As thinkers and writers, students would engage in a quest for a position and a voice to speak from that position.

Bakhtin writes about education as expanding awareness of the multi-voiced nature of social discourse, of bringing their languages out of their "different chambers" where they can "collide" and where a person must "attempt to coordinate them." Consciousness of the diversity of language and thought is what opens up choice, and makes choice not only possible but inevitable (Dialogic Imagination, 295). From the standpoint of awareness, students can decide where they will locate themselves, on what road they will travel, what images and languages they will align themselves with. To make this idea prominent, we extended Bakhtin's "road" into a chronotope that he does not discuss but that is related as a place where many different people and discourses encounter each other - the city. We sent students on "City Quests" to put academic learning into contact with everyday life, especially at points where tradition is remembered and set in the midst of the ongoing present and projected into the future. These quests, mostly to monuments, museums, and transportation centers, were effective in bringing the textual materials further into the personal dimensions, as students inevitably had strong emotional, spiritual, and sometimes physical responses that assisted their intellectual understanding.

Wolfgang Iser's recent work on literary anthropology added to Bakhtin's ideas by providing analytic tools for examining literary works as exposures of cultural, social, and literary realities as schemata, as testing their boundaries, and negotiating gaps between them through 
processes like "staging," "doubling," "envisioning potentialities," the "self-unfolding" of complex identity, and determining "goals of becoming." Martha Nussbaum's essays on literature and moral philosophy provided a way to set emotion in relation to the intellectual, spiritual, and moral domains. Her regard for literature as a necessary (because complex and specific) supplement to moral philosophy's abstract reasoning enabled a theoretical ground for including emotion and suggested analytic tools based on style. Research being conducted in our Psychology Department by James Youniss and Miranda Yates on adolescent moral development strengthened our commitment to the importance of integrating the emotional, intellectual, and moral dimensions. This work, now completed, indicates that adolescents who write about their emotional response to subjects they are studying are the ones who go on to show growth in moral reasoning. Youniss and Yates contend that students need to find a perspective on the various values and philosophies in and outside of the academy, and to do this in a responsible way requires moral thinking and development. To assist students in developing, distinguishing, and integrating the dimensions of self, we sequenced readings to move through the dimensions and assigned frequent free response writings. We also paired creative and academic writing assignments. We paired conceptual readings with literary reading, presenting several conceptual models of the hero so that students could see how even theories arise from perspectives. We hoped for, and witnessed, a growing sense of authorial privilege and stylistic inventiveness, the two key features David Bartholomae finds students need for entering academic discourse communities.

\section{Integrating the Learning Materials: Two Examples}

We'd like to take you through a description of two course modules, one from the second week and one from mid-semester, in order to show how the materials are presented and integrated. We begin with a study of archetypes of the hero. Initial readings include a conceptual book, a feminist re-vision of Jung's theory, Carol Pearson's The Hero Within: Six Archetypes We Live By, and Homer's Odyssey. Readings from other cultural traditions (Native American myths, stories from the Bible, etc.) enable comparison and contrast of heroic figures and actions. After students have studied these texts for two weeks, and written a myth of their own, we prepare them for their first field trip and major writing assignment - the "Aesthetic Quest" - with a twohour interactive slide presentation. The focus here is on applying conceptual thought to factual details and viewing examples of heroic images in different centuries. First, we show a slide reproduction of one of Paolo Uccello's "St. George and the Dragon" paintings (15th century 
Italy). The painting depicts a familiar triad: a fierce, fire-breathing dragon, a beautiful maiden, and an armored knight on horseback, what Pearson calls the villain/victim/hero paradigm. We ask students to "read" the picture by having them describe what they see and what's happening. They note the use of color, line, composition, elements of foreground and background, body positions, facial expressions, light, dark, narrative events depicted in and outside (before and after) the scene. Then we ask them to use the concepts Pearson presents to inquire into stages of the hero, male/female roles, motivations, and the artist's conception of the cultural and social roles the figures seem to embody. Students share and negotiate their findings, discovering and justifying interpretations with factual details from the painting. After a sometimes heated discussion, we introduce a modern American poem based on the painting, U.A. Fanthorpe's "Not My Best Side," and stage a dramatic reading so that students can hear all three of its voicesdragon, hero, and damsel-in-distress - and the perspectives they are representing. Not only do the students see how the contents of the paradigm have shifted, though not the paradigm itself, they recognize stereotypes of these figures in the paradigm from contemporary society and examine the poet's perspective behind the ironic take on both medieval and contemporary images of self. Helped by the archetypal theory studied, they see that each individual can embody or suppress one or more of these elements but that a full view incorporates all in each person. In this way, we pull the personal dimensions into relation with the cultural and social domains and also distinguish the kinds of thinking that will be needed for academic analytic and interpretive work.

In the second hour, a lecture with slides on images of the hero in Western culture from ancient Greece through 1900 in sculpture, architecture, and painting teaches historical material while demonstrating argument from evidence and "reading" visual forms of cultural expression. Several writing assignments derive from this. One is a creative piece in which students select a painting and create a prose or poetic narrative from the point-of-view of a character depicted in the painting. Students have fun with this assignment, but it also functions in other ways: to demonstrate and reinforce that details must carry the argument in both aesthetic and academic texts; to enable a response to the materials using emotion and intellect; and to stretch their stylistic repertoire. They imaginatively "throw" themselves into the painting and into the hearts, minds, and souls of the characters. They imagine past deeds or family histories, document inward emotional traumas, physical exertions, or spiritual unrest, or dramatically retell familiar historical events. The narratives are lyrical, tragic, and comic in tone. They get students creative juices flowing, and attune them to the textual details in art and literature that not only tell a story but evoke 
aesthetic and emotional responses and moral evaluations.

A second assignment is a longer thesis-driven paper with supporting arguments and specific visual and verbal textual evidence. Students make a trip to the National Gallery of Art in downtown Washington, D.C., and as they tour the museum, they choose an artwork (painting, sculpture, or print) that seems to embody one or more of the heroic archetypes Pearson describes (innocent, orphan, wanderer, warrior, martyr, magician). Students make careful notes and purchase a postcard of the artwork to show the class. In their essays, they first provide a working definition of the archetype as set forth in Pearson's framework, including a discussion of fears, goals, values, actions, and beliefs central to that particular archetypal mode of being. They then describe the artwork in vivid detail, using their newly acquired sensitivity to formal elements of visual art to explain the ways in which the artwork seems to illustrate Pearson's archetypes. Students may also include in their essays their aesthetic and emotional response to the artwork and their sense of what the artwork, and the artist behind it, seem to be saying - what theme, message, or insights are revealed about human nature, heroic action, or stages of the life journey. The focus here is on strategies for interpretation from details within a given conceptual framework, thesis formation and support, and organizing ideas as necessary tools for pursuing inquiry into the topic and writing about one's findings.

The gallery visit also provides the basis for a third piece of writing, as students take notes comparing and contrasting the two buildings of the Gallery, one built around 1940 on classical (Graeco-Roman) principles of design (architect John Russell Pope), as presented in the Greek temples in the slide lecture, and the other modern in design (architect I. M. Pei). Giving a set of varied but related assignments at the same time demonstrates that inquiry can be multi-faceted, that research can take place outside of the university, and that it can be interesting, enjoyable, and relevant to personal interests.

The assignments are drafted and taken to writing workshop for one or two revisions. During this first set of assignments, students' writing improves dramatically from first to last draft. Descriptive powers are enhanced, language becomes more concrete. Students' ideas are elaborate, often daring. Their papers display, if not a standard academic "thesis statement," then at least an implicit focus or organizing principle. Perhaps more importantly, students manage to incorporate and "flesh out" an author's theory without losing their own voice or subordinating their own interpretations and ideas. We encounter few of the labored, near-plagiarized summaries and paraphrases so often found in basic writing. Students have learned very quickly to take an interpretive position and support it with a wealth of textualverbal and visual-evidence. Students have been quickly launched 
into finding a position from which to say something of their own while using the others' (textual) voices to locate their own ideas and voices.

At mid-semester, we settle into an integrated study of slavery in nineteenth-century America and the Jewish Holocaust before, during and after World War II. Students read autobiographies: Elie Weisel's Night, depicting his internment in a concentration camp during his adolescence, and Narrative of the Life of Frederick Douglass. They do library research on both topics; compare filmic representations of events to written versions; read the first chapter of W.E.B. DuBois's The Souls of Black Folk, ideal for its naming of slavery as a holocaust and its recognition of the problems of identity and double consciousness; read Cynthia Ozick's essay, "On Christian Heroism," a taxonomy of types of people during the Jewish Holocaust-hero, victim, murderer, bystander - that revises the Pearson paradigm and asks readers to contemplate their own capacities for heroic action. They also read poems by nineteenth century American slaves and World War II concentration camp prisoners and visit the National Holocaust Memorial Museum and the Frederick Douglass Historic Site (his last home, overlooking Washington) - the "History Quest." After these texts, students read Octavia Butler's Kindred, a contemporary science fiction narrative of emancipation in which the heroine compares slavery to the Jewish Holocaust as part of her attempts to understand her identity in terms of present conditions as affected by the past. Butler uses time travel as a device for exploring connections, for understanding Douglass's life and writings from an experiential perspective, and for contrasting nineteenth and twentieth century social conditions and conditioning of modes of thought and perspectives. These materials take students deeply into the complex issues of the individual's struggle for identity and meaning amid oppressive social forces and cultural realities vs. stated ideals.

Having recorded their intellectual, emotional, often spiritual and physical reactions to these readings and experiences, students compose a comparative essay that links researched facts, authorial perspectives, witness perspectives, and reader experience. Students focus on particular exhibits and narratives that depict what life was like during both of these periods of history. Calling attention first to the particular structural details that make these remembered events and stories resonate so powerfully, students then interpret the larger vision and moral imperatives that the authors, architects, film makers, and curators convey -ideas about the construction of history, community, and identity, about the horrors, consequences, roots and possible forms of resistance to such injustices. Finally, in class discussion, and in their writing, students consider how the knowledge they have learned about these past events might illuminate current social and political situations (in the former Yugoslavia, in the Middle East, on 
the streets of Washington, D.C.) and current racial, religious, and ideological tensions, thereby helping us to understand better our own selves and communities, helping us to shape and transform our future world.

The remainder of the semester's study comprises books, poems, films, and essays selected to give a view of the complexity of human thought and action in all three domains of the lifeworld and several dimensions of the personal domain. Lectures by professors of religious studies, mythography, film studies, semiotics, history, and psychology supplement knowledge. Additional "City Quest" field trips include war and police memorials for a unit on remembrance, and a theatre production or a film students have selected together to study. We, and our students, have liked Toni Morrison's Song of Solomon and her Nobel lecture, in which she expresses a vision of the role of language and literature for the renewal of individuals in community. Eudora Welty's short story collection, The Golden Apples, involves interconnected, mythically-based hero quests for love and beauty in the world by characters who never quite fit into society and are never quite successful in their searches. Most of Welty's characters live what, on the surface, appear to be quiet, unremarkable lives, but their inner lives are profoundly rich-sometimes hopeful, sometimes tragic. Treating themes of time and timelessness, self and community, Welty traces the inward journeys of her characters and their moments of realization, which illuminate the depth and complexity of human experience. Like Pearson, Welty shows that our journeys are spiral in shape - they take us through time, allowing us to revisit the past, reassess the present, and imagine the future.

Either T.S. Eliot's The Waste Land or The Four Quartets affords focused study of the spiritual quest interrelated with concomitant effects on and influence from lifeworld domains and personal dimensions. Hermann Hesse's novel of a young man's spiritual quest, Siddartha, provides yet another perspective, and Cormac McCarthy's All the Pretty Horses, magnificently and beautifully treats a sixteen year old boy's transition to manhood through a quest that is difficult in all dimensions of life, throwing contrast on American tradition and society when the young hero journeys into Mexico for adventure. The boy's experience of initiation teaches him to respond differently with head and heart, eventuating a new spiritual and moral positioning with respect to American society, to which he returns and in which he no longer fits. The book highlights the difficulty of discovering and living out high moral principles and hard-won vision within a society that does not value the hero's knowledge. Throughout the semester, news, magazine, and journal articles as well as short poems help to expand perspectives on the topic into current situations.

In addition to providing a range of perspectives on these issues materials must, to meet various instructional needs, include a range of 
easy to difficult, literary writing to workhorse prose, young men's and young women's viewpoints, perspectives academic, non-academic, and multicultural.

\section{At the End of the Course}

The glimmer of future possibilities, of self and social transformation, echoes in student papers throughout the course, but particularly in the culminating essay - an open-ended assignment, reflective and synthetic in nature. Although we never explicitly ask students to consider their personal experience or situations, here many elect to write about their own "quest" - where they are now, where they've come from, where they hope to go as they make their journeys in life-and connections they see between their own values and systems of belief and wider historical and social realities. Students find clear parallels between their own lives and the lives of the people in the texts we read. Many express deep appreciation of the knowledge they have acquired about paths the hero may take, the limitations imposed on human beings, but especially the power individuals do have to choose to act and direct their lives at moments in time. By the end of the semester, students write of the profound affect and deep personal meanings and self-redirection the course has assisted them in achieving. The repositioning of self with respect to school, society, and culture is evident in the strong voices in the writing (a sign that they have seized authorial privilege), in the varied organizations of papers that incorporate rhetorical modes and stylistic features flexibly and appropriately, and in the demonstrated depth of understanding of the subject matter.

To illustrate what students say they have learned, we offer a few excerpts of from the final papers.

- I am now beginning to see how reading can affect you as an individual. I am starting to understand how the use of propaganda works. When people read, the information is absorbed into their subconscious whether they want it to or not. College has changed me a great deal. I admit the amount I read now is far heavier than the way I read a year ago. Lately I have read books on all subjects, some on philosophy and others on social and political issues. I also feel more comfortable in starting a conversation with someone because I an not in fear of being intimidated because of lack of knowledge on the subject. I now feel as many do that reading is fundamental.

-... the texts we have read this semester have ... given me a new perspective of looking at problems and occurrences in 
everyday life. I was shocked to know that many of the ideas and feelings I had in this class were also shared by other class members .... Douglass [who may be my relative] showed me never to let your spirit die. He showed this through his entire life. He was put down, and he got up.... I should always try to believe that if something doesn't work the first time, don't quit, maybe it was just done the wrong way. I won't just call Douglass a role model but I will call him a guide to live by.

-For these authors [Butler, Douglass, and Weisel], identity is the only thing a person can hang onto. ... People strive to know who they are because once an individual knows his/herself then they can move on with their life, and know exactly where they are headed.

- Until this year I have never read so many pieces of literature that have crept so far into my soul as to pierce my heart and run into my consciousness. . . . no other written works have touched me so deeply as Elie Weisel's Night and The Narrative of the Life of Frederick Douglass. . . . These two works have opened my eyes to the unexplainable terror that one man can bring upon another man for no apparent reason but the color of his skin and the affiliation of his beliefs.

-College has helped me start my journey but the rest lies on my shoulders. I am not sure what my life will become but I do know that I want to make an impact on the world for the good. First I must come to terms with myself. There are things about me that I must change before I will be able to help the world. -Viewing or visiting something rather than only reading about it gives us a feeling of actually taking part in the journey. Although I had heard about the people and events we studied, I could not fully grasp or imagine what the experiences were like until I went on my own personal journey and visited the places where the events took place.... I was able to be affected first hand because I could almost put myself in:the characters' positions.

\section{Organizational Structure}

To give students daily support as they work with these challenging materials and assignments and to give them experience in the various learning environments at the university, we use a tripartite organizational structure-seminar, large group lecture, and small group workshop plus tutorial. Seminar sections are limited to 15 students and meet for two two-hour sessions per week. Instructors inquire regularly about progress in other classes and about general difficulties stu- 
dents may be experiencing as they adjust to college. Twice-weekly writing workshops of four or five students and individual tutorials not only provide crucial, intensive help with writing but maintain continual contact and support. Bi-weekly large group lectures and fieldtrips into the city reinforce note-taking skills and help students find relevant connections among disciplines and between academic study and their lives. Lectures and field trips act as pivots for the relational learning: weekly work is preparatory to them, and major writing assignments ask students to consider daily readings in connection with them.

To make this design work in a flexible way, ongoing collaboration among the various instructors is crucial; and flexibility is key if students' needs are to be met. The writing director has responsibility for general planning, scheduling, and oversight. A coordinator has responsibility for weekly staff meetings and day-to-day communication. Instructors for the seminars and the workshop/tutorials maintain close daily contact (by written notes, e-mail, or telephone) and attend weekly staff meetings on curricula, strategies, and assignments and evaluate individual students' progress and academic needs. Student writings or verbal statements are shared anecdotally and serve to generate new assignments, projects, and teaching strategies that can in turn better match, challenge, and deepen students' knowledge, abilities, and interests. Grades on all papers, quizzes, and tests, are assigned by seminar leaders; these measures comprise $75 \%$ of the final grade. The remaining $25 \%$ is assigned by the workshop/tutorial instructors and is based on preparation of drafts and peer response group participation as these give evidence of learning.

\section{Implications: Our Learning and Program Changes}

Teaching this course for three summers and two semesters demonstrated several things that are translating into changes in other courses.

1. The focus on a single theme that was explicitly and immediately relevant and interesting to everyone (students and instructors) motivated inquiry and made the teaching of modes, strategies, close reading, research methods, style, and mechanics easier and more complete. Most of the writing instructors and some of the literature instructors have developed their own themes for first year courses for all students, and find similar results.

2. Because the course considered material from a fuller range of perspectives, everyone in the class was able to contribute to discussions. Since these students varied widely in language competence, all were challenged to learn new ways to read, think, and write; thus old 
ideas of who was better at what were leveled. In addition, each student could work toward her potential, which is much more difficult to do in skills or modes based classes. By the end of the term, the basic writers are ready for the required first year rhetoric and composition course. Others who were not basic writers to begin with make large gains in writing as they are making important adjustments to college in other areas. These have a head start on the rhetoric and composition course, and ten to fifteen percent of these place into honors composition at the end of the course.

3. Since we conceived this course as a summer replacement for remedial writing, we initially planned that students would take rhetoric and composition or honors composition following it. But since all students did not take this summer course, we kept the previous version of remedial writing for the fall semester until last year. Because the growth in students' writing performance was so great, we decided to eliminate the remedial writing course altogether and offer workshop/tutorials as part of the rhetoric and composition course for those students who would have been placed in the remedial course. If evaluations in the next two semesters match those of last fall, we plan (budget permitting) to offer the workshop/ tutorial to all students in the fall of 1998.

4. A comparison of skill level of end-of-semester papers from the Hero Quest course and from both groups of students in rhetoric and composition, workshopped and not, revealed that all three groups overall displayed the same range of competence. Because we had wanted to do certain kinds of writing in the Hero Quest course, we did not include argumentation nor a sustained piece of researched argumentative writing. Thus, we have up to this point required that students take rhetoric and composition in addition to the Hero Quest course. For next fall, we plan to incorporate this kind of writing into the course and list it as special sections of the rhetoric and composition course. However, as successful as this course has been and as committed as those who have taught it are to continuing, we do not plan to change the entire program over to it. We do not believe it is the only way to teach well, nor do we believe in placing instructors in the position of using an instructional model they do not want to use. To do so would undercut the aims of the course and our aims for teachers.

5. The exploratory and creative assignments have appeared to have spurred the deeper learning through building connections among the various personal dimensions and between the personal and the academic. We think this deeper learning may, in turn, be responsible for the growth in voice and style that student writing in this course displays. Accordingly, we have made changes in other courses to accommodate such learning. After the first summer, we began to change the requirements of two courses - rhetoric and composition and com- 
position and literature - to accommodate more such assignments. The development of curriculum around a theme was encouraged, with instructors designing courses that made use of their areas of greatest interest and expertise. Several instructors incorporate field trips as a way of teaching, through museum exhibits and monument design, how knowledge is constructed. Maximum enrollment in the composition and literature course was cut (at the suggestion of the dean's office) from 25 to 18, the same as the rhetoric and composition course, to allow for more frequent writing. At the sophomore level, we are making plans to develop literature courses that work in the ways this course does. The first such course, to be offered in the fall, will be an extension of the study of quest literature.

We never expected to learn so much, nor for the course to impact our entire first year program so pervasively. We have our students to thank for teaching us so much, for writing so well and for expressing so frequently and cogently what they were learning and valuing along the way. We have one final comment, one our students made over and over again: the work is hard, challenging, and there is a lot of it. But that is a great part of the success. Students are amazed that they can read these books, and so many of them, and write and speak so well about them. They find they have accomplished something they didn't think they could do, they like it, they value it, and their confidence soars. It is a well-grounded confidence, for indeed they have achieved everything we believed they could.

\section{Notes}

Previous versions of this essay were presented at the Conference on Global Literacy in Heidelberg, August 1996, and at the Conference of the Modern Language Association in December 1996.

We wish to acknowledge our debt to all those who contributed to the success of this course design: the students, who worked so assiduously and expressed so frequently and enthusiastically what they were learning along the way; and the instructors who also worked with devotion to teach and support students in their work. We would especially like to thank Lisa Robeson, whose ideas helped formulate the initial design, and Felicia Pattison, who gave much precious time to the expansion of the course to a full semester. 


\section{Works Cited}

Bakhtin, Mikhail M. The Dialogic Imagination. Trans. Caryl Emerson and Michael Holquist. Ed. Holquist. Austin: University of Texas Press, 1981.

Bartholomae, David. "Inventing the University." In When a Writer Can't Write: Studies in Writer's Block and Other Composing Problems. Ed. Mike Rose. New York: Guilford Press, 1985. 135-64.

Butler, Octavia E. Kindred. Boston: Beacon Press, 1979.

Douglass, Frederick. Narrative of the Life of Frederick Douglass, An American Slave. [U.S.] Antislavery Office, 1845; rpt. New York: Viking Penguin, 1986.

DuBois, W.E.B. The Souls of Black Folk: Essays and Sketches. Chicago: McClurg, 1903; rpt. Crest Paperback, 1961.

Eliot, T.S. Four Quartets. New York: Harcourt Brace Jovanovich, 1943. The Waste Land and Other Poems. New York: Harcourt, Brace \& World, 1934.

Fanthorpe, U.A. "Not My Best Side." In Western Wind: An Introduction to Poetry. Third Edition. Ed. John Frederick Nims. New York: McGraw-Hill, 1992. 314, 315.

Habermas, Jurgen. The Theory of Communicative Action. Volume 2: Lifeworld and System: A Critique of Functionalist Reason. Trans. Thomas McCarthy. Boston: Beacon Press, 1987.

Hansen, Miriam Bratu. "Schindler's List Is Not Shoah: The Second Commandment, Popular Modernism, and Public Memory." Critical Inquiry 22.2 (Winter 1996): 292-312.

Iser, Wolfgang. The Fictive and the Imaginary: Charting Literary Anthropology. Baltimore: Johns Hopkins University Press, 1993.

McCarthy, Cormac. All the Pretty Horses. New York: Vintage Books, 1992.

Morrison, Toni. "The Nobel Lecture: 1993." Artes Vol. 1 (1994): 7-13. Song of Solomon. New York: Alfred Knopf, 1977.

Nussbaum, Martha. Love's Knowledge: Essays on Philosophy and Literature. Oxford: Oxford University Press, 1990.

Ozick, Cynthia. "On Christian Heroism." Partisan Review 59 (June 1992); rpt. in Major Modern Essayists. 2nd Edition. Ed. Gilbert Muller. Englewood Cliffs, N.J.: Prentice Hall, 1994.

Taylor, Charles. The Ethics of Authenticity. Cambridge, Massachusetts and London, England: Harvard University Press, 1991. 
Weisel, Elie. Night. New York: Bantam, 1960.

Welty, Eudora. The Golden Apples. New York: Harcourt Brace and Company, 1956.

Youniss, James, and Yates, Miranda. Community Service and Social Responsibility in Youth: Theory and Policy. Chicago: University of Chicago Press, forthcoming 1997. 


\section{Jim Cody}

\section{THE IMPORTANCE OF \\ EXPRESSIVE LANGUAGE IN \\ PREPARING BASIC WRITERS FOR COLLEGE WRITING}

ABSTRACT: The workshop format-a format that supplements traditional writing class instruction with group work and individual instruction that emphasize the power of expressive language--is essential to basic writers for their development as writers. Writing workshops generate conversations and discussions that encourage social, political, and economic awareness to help basic writers discover who they are and where they are in society, so that they do not sacrifice personal voice for acceptance and recognition. Writing should be taught as an act of invention and expression in every step of the writing process to help basic writers become prepared writers, so they can be part of the mechanism that determines the way our written language develops and the way that written words signify meanings.

Intrigued by the concept of including students' texts as part of "contact zone rhetorical strategies" (Bizzell "'Contact Zones"' 168), I realize how valuable and unique my teaching experience was five years ago when I taught Basic Composition and Freshman Composition writing workshops for the EducationalOpportunity Fund Department (E.O.F.) at Montclair State University. Since most of the time the students attended different writing classes, one-on-one tutoring time for feedback on specific class-required papers became an integral part of their time with me. As a result of these small group workshops and one-on-one tutorial sessions, I had a unique opportunity to study the deeply personal process of acculturation that basic writers confront when they enter college. I was offered a look into what composition instruction produces when "students experiment with attending to suppressed aspects of their own history as part of establishing their writerly personae" (Bizzell "'Contact Zones'" 168). From this experience, I am convinced that the thoughts and feelings of basic writers captured in expressive language can be developed into linear modes of writing, preparing basic writers to write academic discourse without feeling betrayal and deprivation.

I am aware, however, that for many basic writers academic writ-

Jim Cody is a full-time instructor in the Writing Department at Brookdale Community College in Lincroft, New Jersey. He teaches Basic Composition, Freshman Composition, Research Writing, and Short Story classes. He still continues to work for Montclair State's English department teaching Basic Composition courses during the summer months for incoming E.O.F. students. 
ing has meant deprivation and betrayal. When writing is presented as a foreign language that requires imitation or conformity, it becomes disassociated from the everyday lives of students. Writing then serves to distance basic writers. Academic discourse is seen as a language that basic writers cannot call their own, a language that may even involve erasing the past to eliminate any traces of their marginalized or under-privileged conditions. When basic writers think that the only way to produce academic discourse is to deny themselves and their readers access to the language that expresses and informs their past, basic writers are then restrained, and traces of the pain and hardships caused by the dominance of academic discourse are hidden, as well. Ironically, they are deprived of the stories or scenes from their past that have the power to allow them to enter and contribute to the discourse of academia without being effaced by it.

Academic writing for many basic writers entails an element of betrayal: when this is unacknowledged, students may become passive. Min-zhan $\mathrm{Lu}$ is concerned about basic writers's passive response to academic discourse. Students who are not made aware of the changes that often accompany "mastery of academic discourse" can develop an irreparable sense of betrayal to their home life and language, and not realize their power to shape language ("Redefining" 34-35). In studying the link between oral and written expression of African American Students in her class, Arnetha F. Ball notes that her students risked failure in the academic arena when writing and "being labeled 'lame' within their informal vernacular speaking discourse communities" (34). Although failure and betrayal have their personal and social price tags, success may also be costly for basic writers. As Patricia Laurence writes about her students at City College, "Those students who make it in the college undergo rapid and difficult psychological, educational, and cultural change compressed in the space of one generation" (731). Basic writers who are deprived of their familiar discourses may feel powerless when they are advised to uncritically imitate academic discourse. Deprived of the familiar, they are given few if any opportunities to reshape academic discourse into a language that can resist the trappings of political, social, and economic dominance. Settings where basic writers are encouraged to speak and write for each other in familiar discourses may help to reduce the feeling of powerlessness and in fact increase their political, social, and economic awareness while developing their ability to question and change academic discourse.

In an effort to illustrate the degree and complexity of the alienation caused by the acculturation process that basic writers confront, I will describe three students who met with varying success in entering the academic discourse community. The first student, Maika, was one of seven students in a workshop I taught for incoming freshmen taking a Basic Composition course through the E.O.F. six-week precollege 
summer program. One of the pre-writing activities we used was Peter Elbow's "loop writing," which prompts thirteen "directed freewritings" to unlock students' ideas from the stranglehold that enforced topics often inflict on writers. Some of these exercises include generating stories, scenes, and portraits from the topic (Power 59-77). Since I was aware that students would be viewing Frederick Wiseman's film High School, I thought loop writing would be a good way to have students relate to the topic by keying on their high school experiences.

Maika is a Latina ESL student, who despite hard work in the class remained unable to connect her familiar, personal, and expressive language to her academic discourse. For the loop writing assignment preparing students to see the film, Maika wrote the following responses:

Under "Instant Version":

High school for me was the most beautiful experience in my life. Those four years were of bad and good times but I really enjoyed.

Under "Narrative Description":

I felt sad the last two weeks of my high school life, because I was leaving all my good memories good teachers and most of all my friends.

Under "Scenes":

When I first entered as a freshman

When I got lost like for five minutes

The bell ringing every 40 minutes

The fire alarm

When I get mad with my math teacher because he wasn't fair with me

Under "Portraits":

My algebra teacher because she explain the class like it suppose to be and because she was a nice person. The vice principal she was always in a bad mood and she suspend you for nothing

Under "Vary the Time":

John F. Kennedy H.S. in twenty years in the future will be a very old school and people won't be able to attend there no more, is not that is in a bad condition but ...

I was excited over Maika' reaction to the loop writing because I thought that she had generated enough material to help her respond to a more formal writing assignment, a reaction paper to the film. In the paper, however, there was no evidence at all of her high school being "the most beautiful experience in [her] life," and no mention of 
the specific experiences offered in the "Scenes" response. She remained unable to connect her high school experiences to her reaction to the film.

While there may be many possible reasons why Maika reacted the way she did to the assignment, I sensed that she was reluctant to share the experiences that she offered in her loop writing. It may be that the assignment--to write a reaction paper to the film--simply may not have prompted Maika to write about these experiences; in fact, overall she seemed to be concerned about the appropriateness of revealing personal details in a formal essay assignment. Unfortunately, Maika did not pass her summer course; she failed Basic Composition again in the fall, and struggled with the course again the following semester. The last writing I saw from Maika continued to show few signs of inviting the reader to share her experiences. I think she continued to have great difficulty because she did not trust the idea that her experiences expressed in written form were appropriate for college writing nor that they would result in the acceptance that she strives for in college.

Maika's lack of trust may result from years of compounded alienation experienced when confronting written assignments. Maika's failure illustrates the complex disassociation basic writers may experience when trying to fulfill written requirements in college. As Bizzell proposes, the difficulties of basic writers must be addressed by recognizing differences in dialects, discourse conventions, and ways of thinking ("What Happens" 297). The resistance that basic writers exhibit may be caused by their "feel[ing] that they are being asked to abandon their less prestigious, less socially powerful world views in favor of the academic" ("What Happens" 299). Awareness of why they find themselves resisting change gives basic writers more chances to survive in college. Bizzell sees that those who are aware are "sufficiently familiar" with the power behind the academic world view to influence society (299). Basic writers need to develop an understanding of why they write the way they do and of how their voices are their power and their unique contribution to academic discourse.

Let me share writing from another student in the group, Lydia, who was able to use expressive language in her academic discourse (avoiding betrayal and deprivation), and become aware of the reasons why she wrote as she did during the same six-week summer basic skills program that Maika attended, which included regular basic composition instruction supplemented by my basic composition writing workshops. Unlike Maika, Lydia's associative or expressive language was so integral to her personality that she could not exclude it when she wrote. At the end of our first session together, Lydia wrote about her writing in response to the following instructions: 
Briefly describe your writing experiences at this point in your life. Feel free to be as informal as you like. What do you like about writing? What stinks about it? What do you do when you write? What kind of writing do you enjoy doing? What kind of process do you go through when you write? How has writing made you feel over the years? What works for you? What doesn't? You don't have to answer all of these questions. Just relax and describe how you and writing have gotten along.

She wrote,

I feel my writing techniques aren't that very good. I want to improve my vocabulary words now. I like writing what's on my mind and what I know about the subject I'm writing on. What stinks is I don't concentrate enough on the facts, my mind wanders off. I have the radio playing low, I try to get all my facts together, but it seems that my mind likes to wander. Writing on subjects as sex, cultural events, and racism.

No process I just write and if it looks ok at that time find with me. Writing has made me feel that the way I represent myself on paper is the way I am in person. Getting an A+ works for me in my writing assignments, but how can I get an A+ when my facts and general ideas aren't in tact. Getting a C or D doesn't work for me. Because when I was in High School I rarely got a $\mathrm{C}$. I never got a $\mathrm{D}$ in my work.

Much of what Lydia wrote was in response to each question presented, so it is unfair to approach her writing as an organized essay. In addition, the assignment called for freewriting. Lydia, however, pinpoints some of her writing shortcomings and areas of concern. She refers to a lack of concentration, wandering off, and an inability to stick to and collect facts--perhaps referring to things she's been told about her writing. But she comes to a startling observation near the end, "the way I represent myself on paper is the way I am in person." Connected to this awareness of her lack of concentration in writing is her sense that her writing is parallel to the way she expresses her person or personality. Lydia saw writing as a means of mirroring or reflecting her personality. While writing, she expressed who she was, and this perhaps disheartened her as it included the disorganization that surrounded her life. The associations, the inferences, the metaphors that accompanied her thought process surfaced whenever she wrote. However, she was also aware that in writing, ideas must be linked together one at a time in a linear fashion, and that words are used in writing in conventional ways and are expected to express specific pre- 
determined meanings.

At the same time, Lydia also included in her writing the expressive discourse that made writing seem more natural to her--a discourse that basic writers often feel forced to reject when they write to fulfill the academic writing assignments. James Kinneavy sees the aim of all expressive discourse as being "to enable a new social personality to achieve self-determination" (410). I believe for basic writers expressive language is not the result of randomness, carelessness, or lack of organizational skills. It is "logical" in the sense that it is the result of an event or set of circumstances already experienced by the expressive language user. I believe that the "valued goal" for Lydia was to express her identity . Assuming this goal, she began using expressive language to "[work] towards its achievement." Or as Kinneavy might say that, by preserving expressive discourse in response to academic discourse, she aimed to "enable [her] new social personality to achieve self-determination" (410).

The problem with Lydia's response at this point in her writing experience was that she was unaware of the power of expressive language to achieve her goal of retaining her identity in writing. She lacked an awareness of the logic behind her expressive language. As a result, her expressive language often seemed to clash with what was required of her in academic writing. She needed to give a purpose to her expressive language that explored and questioned the reasons behind her distance from academic discourse. Without an awareness of the power of her expressive language to confront the dominating forces of academic discourse, Lydia was trapped, unable to reject writing due to her desire to be accepted in college, unable to conform to academic writing due to the political, social, and economic influences behind the controlling power of her own identity.

Linda Nelson, Professor of Writing at Stockton State College in southern New Jersey, tries to make her students aware of the power of using expressive language as a social force. She recalls how she herself, as a writer, succumbed to "the jacket voice" and had tried to erase any hint of her mother's Jamaican English which for Nelson had lowerclass associations (172). She had learned to avoid her natural voice in order to gain recognition and acceptance. She had determined that the discourse required of success dictated that she become something that she was not. "The jacket voice" (172) resulted in good grades throughout elementary school and high school, but she was aware of what she was leaving behind and wondered what irreparable damage she was doing to her ability to express herself.

But I was keenly aware of other voices. Like an intimate longing, there was the voice of my father, a Mississippi sharecropper, who spoke to us sparingly in meandering folktales of 
talkin'alligators in swamps, of culled boys making they way through grave yards at dusk, and of my great grandfather, a runaway slave who 'nare one heard tell of sense.' My father's voice was more like the voices of the parents, aunts, and uncles of my friends, as it spoke to me through the chords of his blues songs, from a cheap acoustic guitar and a small, metal harmonica. This was a rich, deep, tonal voice, a voice that was more metaphoric than literal, more hyperbolic than precise.

Her awareness of what she was sacrificing enabled her to strike out against the standards of the academy. She no longer sought power in her words only, as her mother did, to "talk to white people and make them listen" (172), but instead she grabbed hold of the unconventional voice of her father, as she began to see herself as part of a social force. Writing was no longer "an act of conformity." Rather it became what Nelson defines as "an act of invention, which mirror[s] the truth of her experience" (173). As part of a marginal group that did not know it was being marginalized--that did not know it could be or should be a social force, she kept voices like her father's in check (174). She blames this on the ways that marginal groups often overzealously try to fulfill requirements in order to gain acceptance (174).

I believe that the writing that Maika produced when responding to her reaction paper assignment and the "jacket voice" used by Nelson are written discourses chosen by these writers to hide the evidence of the oppression, marginalization, betrayal, deprivation, and suppression that surrounds their lives. When expressive discourses like Maika's loop writing and Nelson's unconventional use of her father's voice in her writing are given space in academic writing they expose the malevolent trappings that control academic writing. Expressive discourse must be encouraged among basic writers in every stage of their writing processes, so that the dominant discourse does not dominate but simply resonates when other voices are purposely and strategically silenced for the benefit of the audience or reader used to or expecting the dominant discourse.

Basic writers often write with anger, but part of their underpreparedness is grounded in the fact that they cannot see the logic of their anger; and, like the young Nelson, they often feel compelled to hide this anger, unaware of the significance behind its force. Like Lydia, they are caught between the pressure to acquiesce to college standards for acceptance and their own personal commitment to familiar discourses. As Lu says, the audience that basic writers write to in college and the discourse they struggle to use are "strangers both in the political sense and linguistic sense"-- the world they are challenged to enter and respond to is a "world which has traditionally ex- 
cluded people like the writer and his parents" ("Redefining" 32). But their thoughts, reported or recorded in writing without concerns about "how to sound 'right'" or the "anxiety to reproduce the conventions of 'educated' English " (Lu "Professing" 446), have the power to compete with the dominance of academic discourse, so that their expressive language need not be lost.

I think Lydia's writing changed as a result of a growing awareness of the power behind her marginality. She brought this newly found awareness of the political, social and economical reasons for her marginality to help her explain why she had been unable to enter the world of academic discourse before. In her final paper for the summer session, she included the following scenes:

When I was fourteen years old I terminated my first pregnancy. On June 13, 1988, at United Hospital in Newark, NJ. It was a mistake (the baby). I didn't know much about the facts of life, and when I wanted to know, my mother would reply her answers to my questions with absurd remarks. Remarks that I didn't want nor need to hear.

My biological father left me when I was three years old. I haven't seen him since. I always see pictures of him and I know I resemble him a lot.

Later in the paper she grapples to make sense of these experiences:

All the things she wanted to achieve in life that has failed her is now in my hands. I'm repeating all the mistakes she's made when she was my age. My mother conceived her first baby at the age of fourteen and in 1988 that's when I got pregnant. I guess she thought I was following in her footsteps, that I was going to be nothing like she is now. But she is totally wrong. My first baby was a mistake. Her first baby was a plan to use in order to get out of school faster and just stay home and do nothing. All she wanted to do is sit around and collect Welfare (Public Assistance).

I guess the reason why that my mother and I can't get along is because of my "father." All the pain and trauma he has caused her. It can also possibly be the fact that I look exactly like him. This makes her boil. Every time she looks at me she see a part of him, and that upsets her all over again.

In her concluding remarks, Lydia offered a solution and gave advice to her readers, showing that she could not only make sense of these scenes for herself in writing but could also take on the social 
responsibility of informing others about the ill effects of her social and political conditions:

In summary, I would like to acknowledge to all youths that whenever they feel down or deeply depressed about a family dispute, seek professional counseling, or talk to someone who is willing to listen to you. Because the stress and lack of self-confidence could damn near kill them. I know because I traveled along that path many times.

This conclusion is a marked contrast to a conclusion from a paper that she offered earlier in the summer. Note below the reliance on the language of generalizations and cliches that she used to express her social awareness of how differently brothers and sisters are raised. Lydia was very happy with this paper at the time, but the struggle with having to make sense of her experiences is evident:

In summary, I feel there is not only a difference, but I do feel that there is a BIG difference in the way brothers and sisters are being treated. Whether the brother is older than his sister or the sister is older than the brother, whatever the case may be. Parents are more lenient with boys. The girls are sometimes looked on as "Ms. Likes". As the old saying goes; "boys will be Boys", and One, Twice, three times a lady."

Although she is aware of the social differences between brothers and sisters, this exposure of her awareness seems to have intimidated her into using cliches, a safer expressive language that hides the anger of being raised without the same privileges that her brother received, and that defies academic discourse by its lack of explanation.

She may have relied on this kind of language because she was struggling with her predicament. Instead of screaming out her rage on paper where she might reveal her vulnerability, she used language that offered little or no insight into her social identity. In a sense, she, too, succumbed to a kind of "jacket voice" - one that hides behind words rather than uses them for the more powerful purposes of illustration or explanation. Unlike Nelson, however, her "jacket voice" is associational and metaphorical. The discourse she uses is expressive under Kinneavy's definition - "with people we know well we do not have to fill in the background" (169), and it reflects an associative language more akin to discourses reserved for thinking and intimate speaking. Her mention of the "Big Difference" triggered off associations to "Ms. Likes," "Boys will be Boys," and "Once, Twice, Three times a lady," all intimate shorthand for an expressive language that does not reveal to the uninitiated. Her academic discourse reveals only partially, indi- 
cating that she may be either reluctant or too intimidated to expose herself for fear of "betrayal" (Lu "Redefining" 35).

In this writing, Lydia reminds me of the boy that Mike Rose refers to in Lives on the Boundary (127-28). The boy was obsessed with the song, "My Boyfriend's Back" - he would play it over and over again, and sing the words with delight. Rose later learned that the boy's brother had disappeared to become a member of a street gang. The bits of the song that had phrases like, "My boyfriend's back and you're gonna be in trouble," represented a powerful expression for the boy, who perhaps lacked the self-awareness to express his deep sadness over the loss of the one guiding figure in his life. Like Lydia, the boy latched on to phrases that defined his conditions on the surface. Unlike Lydia later on, the boy could not at the time see the meanings behind his expressions, and, as a result, he could not yet enter into a discourse that expressed an awareness of his identity or an understanding of his social position. But Lydia was bringing discourses that she was already familiar with to her writing. She was beginning to entertain the idea that she could write in the way that she thinks. Her reliance on cliches and fragmented pieces of phrases and titles to express meaning signified that she believed writing could offer her the chance to express herself in an inventive way that reflected the intimacy of casual conversation among close friends. This step, taken to confront academic discourse, accompanied by her growing social awareness, demonstrated her willingness to take on academic writing rather than continue to be marginalized by it or have her expressive instincts consumed by it.

Without familiarity with the idioms associated with expressions and cliches, some basic writers can't even express themselves in this "safer" language within academia. The term "idiomaticity" is defined by Marion Okawa Sonomura as "what makes the expressions in a language sound appropriate and natural in that language" (1). Sonomura describes the "writings of unskilled writers as conspicuously unidiomatic" (2). Lydia used her familiarity with popular expressions to dare to write as if her academic audience would know what she meant. This took courage--the same courage it took to express the experiences with her abortion and the relationship with her mother. She used expressions and cliches in place of conventional idiomatic forms. By doing this, she could approach the intimacy that she needed from her writing audience. For someone struggling to use writing as a means of understanding her identity, this was a pivotal moment for her writing. It was important for her to believe that "they" - her audiencewould know what she meant through the casual use of these fragmented pieces of language. Lydia's story is an affirmation of Lu's call to acknowledge that student writers have the same "political need and right of real writers to experiment with 'style'" (Lu "Professing" 446). 
I would like to turn to another example of a basic writer whose discovery of the power of using expressive language in writing nurtured a social, political, and economic awareness that not only prepared him to use academic discourse but also taught him how to participate in shaping it to create a language that he felt comfortable calling his own. Anthony was introduced to me in a workshop I ran for the Legal Studies Division of the E.O.F. at Montclair State. In his last semester, he was anxiously anticipating graduation in the spring. It had taken him seven years to reach this point, and he took great pride in his ability to survive, overcoming the pain, temptation, and danger that go with being raised in the inner city. In our first session together, he spoke of many friends who had wasted away - the results of drug addiction and criminal activities. Anthony's voice spoke clearly as he related these personal stories - the scenes were vivid and painful to him, but he was eased by the pride he exuded from having avoided crime and drugs. Anthony was in my workshop with a clear purpose. His legal studies professor had given him a generous extension of a deadline for a paper on Malcolm X. He was given the opportunity to work on it the whole semester with me and to submit it in time to pass the class for graduation. He showed me the term paper that he had handed in last semester, and I had him do some freewriting on his writing process.

Since Anthony was a senior, I had assumed too much. Having heard him speak with confidence, I was convinced that his written expression would be powerful. I was mistaken. Anthony's writing was cramped and lifeless. He wrote in risk-free, short sentences, in a very deliberate and rehearsed fashion. He did not build up any argument nor develop nor extend any thought. He wrote, it seemed, only to state conclusions, not reach them.

His conclusions, however, lacked any impact because he did not allow any room for evidence, reasons, analogies, or illustrations to persuade his reader that his conclusions were verifiable. When he did cite authorities, he did not explain their relevance. In addition, he spewed propositions and claims that were not necessarily off-base or illogical (though many were) but primarily lacked justification. For example, in his second paragraph, he referred to the poor conditions of the schools and the lack of "transportation to and from school," but did not include enough detail to support his position in favor of Affirmative Action - the details he had articulated in our discussion about his background. Anthony's writing had no connection to "natural thinking" or habitual thinking" as described by Elbow. There was no effort to make associations or analogies to the vivid scenes he had described orally to me in our meeting. His writing, instead, reflected what Elbow would call a nervous voice, "flat, gravelly, monotone, and evacuated" ("Reflections" 147). It reflected an anxiety--perhaps caused 
by a sudden feeling of being distanced from his conversational tone during our talk.

When I read his paper I could not picture the twinkle in his eye when he was relating his stories about inner city survival. Where did it go? Would I see it in the freewritten exercise I had just given him, I wondered, when I shook hands with him telling him how much I looked forward to our next meeting? As it turned out, his freewriting was as lifeless as the term paper:

Up to this point in my life, I find my writing skills to be somewhat awkward. Improvement could be made in some areas of my writing. One of the problems fall in the ability to develop my paragraphs and pages. I tend to develop writer's block whenever a writing assignment is given to me.

Anthony was a cramped writer. Unlike Lydia, he had not internalized the idea that he could bring his speaking or thinking habits to writing. Given the term paper deadline, I struggled with how I would have the time to present idea generating, prewriting exercises to him to help him summon the rich resources that seemed to be only given an outlet when he expressed himself orally.

Fortunately, at the same time that Anthony was attending my workshop he was also taking a nonfiction prose writing class, taught by Lee Khanna, a professor dedicated to using freewriting techniques. While I provided suggestions on how to address the subject of his term paper on Malcolm X, he was bringing in freewritings from his prose class about his job, the New York Giants, and getting a parking ticket. He wrote about what he liked to talk about. He began capturing the scenes from his life that meant the most to him, and he learned how to narrate; he began including details that built up suspense, developed connections between his ideas, and extended his meaning. His group work activities in the prose class also impressed upon him the need for a clear sense of purpose and audience.

My frustration was in seeing these marvelous gems develop while he ignored the Malcolm X topic. I kept asking for drafts of the term paper, but instead he kept bringing in papers from his prose class that he could not wait to read to me. As I read them I could understand why he exuded such excitement. One, entitled "Unnecessary Search" demonstrated not only the comfortable modes of expression for him, but in it he also began to "pay more attention to 'things out there' - to facts or logical, casual or chronological relations," as Kinneavy would call them (169). There was a thoroughness to his narrative, an effectiveness to his dialogue, and an ability to suspend information for a more powerful impact on his reader. This can be illustrated by the line, "Unfortunately, the officer did find something and it wasn't pretty." 
Anthony ended the paper by describing his social awareness of being a victimized African American male:

I personally felt violated and angered. He claimed that his only reason for stopping me is that the rear license plate was crooked. I felt it was his chance to add another AfricanAmerican male to the long list of drug dealers looking to make a deal. Fortunately, I don't use drugs nor deal with and I was clean.

What I failed to see initially in my frustration as the semester began to pass was how happy Anthony was to share his writing with me. I attribute this delight to the influence of his prose class. For the first time, Anthony was experiencing the pleasure of having his papers read by readers who listened carefully to his writing. Perhaps he was feeling the same pleasure he experienced when my attention was fixed on him as he spoke to me about his inner city experiences. He had earned what Brannon calls the reader's "assumption of the authority" behind the writer (158). And so Anthony was given inspiration to write, and to write about things he was an authority on - his life experiences. Brannon writes:

The incentive to write derives from an assumption that people will listen respectfully and either assent to or earnestly consider the ideas expressed. And ordinarily readers will make an honest effort to understand a writer's text provided that its ideas matter to them and provided that the writer's authority is sufficient to compel their attention. (158)

I am convinced that these essays, which offered him the chance to write academic discourse that include the expressive language with which he was familiar, worked as prewriting activities for his Malcolm $\mathrm{X}$ term paper. Anthony was learning to converse in writing. This conversational approach to writing released him from the restrictions that prevented him from expressing himself as fluently and cogently in writing as he did in casual conversation. To my delight, he entered my workshop in our next to last session with a term paper on Malcolm $X$. He was anxious to read it to me, the twinkle back in his eye as he retold me the stories (in writing this time) of his inner city experiences and how they related to the life of Malcolm X. I do not have a copy of Anthony's paper to reproduce--after he read it he rushed out with it to tie up the loose ends to prepare for his graduation. I learned later that Anthony received an A for his efforts on the paper, and that he did graduate.

By the time he graduated, Anthony did not feel as distanced 
from writing as he had at the beginning of the semester. Writing was no longer disassociated from his everyday life. The writing he did that semester enabled Anthony to find a way to express his own voice and still write academic discourse. Empowered with the confidence to use the language that expressed and informed his past, he combined this with more traditional academic discourse to make sense of the political, social, and economic influences on his life, and to relate them to the subject at hand. He used his language and his experiences, instead of mimicry or imitation, to respond to an academic assignment.

How can composition classes allow basic writers the chance to achieve the preparedness for academic discourse that Lydia and Anthony apparently achieved? I believe that part of the goal can be reached if we accept expressive discourse in every stage of the basic writer's writing process. Gary R. Cobine explains the value of expressive language in writing:

As a writer confronts a topic, collects and recollects material, puts material into incipient forms, recognizes patterns of ideas and details, and reworks the material in various ways, the writer's expository modes are complemented and invigorated by the expressive mode. (2)

Such comprehensive acceptance of expressive language in the basic writer's writing process only can be achieved, however, when "politics of linguistic innocence" (Lu "Redefining" 27) and pedagogies of imitation are set aside for the freewheeling pedagogy of workshopping whereby students are encouraged to speak to and write for each other in discourses that are familiar to them. Such pedagogy rejects betrayal and deprivation as the unavoidable consequences of the basic writer's response to academic discourse. It is a pedagogy that strives to reshape academic writing into a discourse so that more and more writers like Maika, Lydia, and Anthony can choose to participate "in the context of the history, culture, and society in which they live" (Lu "Professing" 458).

Initially, for these basic writers, writing was an unfamiliar territory whereas thinking and speaking were known experiences. These students were distanced from academic discourse because it competes with the ways they are used to communicating their ideas to establish their identities. The writing workshop setting, however, made writing an essential factor for successfully communicating ideas and thoughts. It moved academia away from agendas that exist for the purpose of preserving a discipline (Rose 197) to conversations, interactions, and discussions that focus on students' intellectual development.

Workshops then invite basic writers to experience writing in a 
context that mirrors how thought and speech develop. Writing is relied on to express what Elbow calls the "commonality of our hopes and fears and joys and sorrows, which we share as human beings" ("Example"). Relied on as such, writing can be trusted by basic writers to provide a discourse that is not just, as Sondra Perl puts it, a "cosmetic process where concern for correct form supersedes development of ideas" (436). This process involves a germination whereby basic writers begin to make sense of their expressive language leading to social identity and self-awareness moving the basic writer toward preparedness in writing. The causes and effects of their situations become more obvious, and writing becomes a way to make sense of and expose the conditions that have left them underprepared. Writing becomes not an act of conformity but a method of helping students empower themselves to enter into a discourse that once pushed them into the margins. The more basic writers become prepared writers who eschew the temptation to conform and imitate for acceptance, the greater chance our language has of becoming more sensitive to multicultural concerns and more openly accountable for the damage caused from academia's privileging of dominant discourses.

As I think back to my valuable and unique teaching experiences with Maika, Lydia, and Anthony, I also recall a "Diversity Day Workshop" I attended at Brookdale Community College about four years ago. The keynote speaker was Dr. David Abalos, Professor of Religious Studies and Sociology at Seton Hall University. I remember being riveted to every word during his lecture, "The Four Faces of Multicultural and Women's Scholarship from a Perspective of a Theory of Transformation," because what I heard him say about marginalized communities spoke to the lives of the basic writers I have encountered. Abalos talked about how minorities are afraid to reveal weaknesses in a world of power. They have to live lives of repression. Minorities, according to Abalos, often get over their inferiority in the face of powerful forces by assimilating - stripping themselves of uniqueness. But Abalos called for a "vomiting out" of the "poison" learned from the stories of patriarchy that conditions the powerless to repress their stories. Abalos advises instructors to assist students to tell their stories, so that students can recover from the traumas caused by physical abuse, mental abuse, and desertion.

Writing workshops enable my students to tell their stories in a discourse that has its roots in a language they can call their own, a language that survives when the entire process of writing is complete. The language that is closest to their own is the language of their thoughts and their intimate conversations with friends and family. Expressive language, therefore, must be encouraged when teaching basic writers if they are to see that writing is a form of communication that has space for their intimate thoughts and ideas to take shape. When ideas can 
take shape, conversations and discussions can take place that encourage self-awareness. The discovery of who they are and where they find themselves in society needs to be significant enough to convince basic writers not to sacrifice awareness of their political, social, and economic conditions for acceptance and recognition. This is not easy, and it is a battle that I believe rages with every class that I teach. By making writing an act of invention and expression throughout every step of the writing process for basic writers, I give my students a chance to become prepared writers. And when basic writers are no longer distinguishable from prepared writers they can become part of the mechanism that determines the way our written language develops and the way that written words signify meanings.

\section{Works Cited}

Abalos, David. "The Four Faces of Multicultural and Women's Scholarship from a Perspective of a Theory of Transformation." Diversity Day Program. Brookdale Community College. New Jersey. May 11, 1994.

Ball, Arnetha F. "Expository Writing Patterns of African American Students." English Journal 85 (1996): 27-36.

Bizzell, Patricia. "'Contact Zones' and English Studies." College English 56 (1994):163-169.

---. "What Happens When Basic Writers Come to College?" College Composition and Communication 37 (1986): 294-301.

Brannon, Lil, and C.H. Knoblach. "On Students' Rights to Their Own Texts: A Model of Teacher Response." College Composition and Communication 33 (1982): 157-166.

Cobrine, Gary R. "Teaching Expressive Writing." ERIC Digest. ED 396 338 (1996): 2-3

Elbow, Peter. "Reflections on Academic Discourse: How It Relates to Freshman and Colleagues." College English 53 (1991): 135-155.

---. Writing with Power: Techniques for Mastering the Writing Process. New York: Oxford University Press, 1981.

--. "Example of Contract System for Course Grades." Unpublished Essay. 1990.

Kinneavy, James. A Theory of Discourse. Englewood Cliffs, NJ: Prentice Hall, Inc., 1971.

Laurence, Patricia. "Patricia Laurence Responds." College English 57 (1995): 731-733.

Lu, Min-zhan. "Redefining the Legacy of Mina Shaughnessy: A Critique of the Politics of Linguistic Innocence." Journal of Basic Writing 10 (1991): 26-40.

---. "Professing Multiculturalism: The Politics of Style in the Contact 
Zone." College Composition and Communication 45 (1994): 442-458. Montclair State University. "Application for Undergraduate Admission." 1994.

Nelson, Linda Williamson. "On Writing My Way Home: Finding My Authentic Self Within the Academy." Writer's Craft, Teacher's Art: Teaching What We Know. Ed. Mimi Schwartz. Upper Montclair, NJ: Boynton/Cook. 1991. 171-177.

Perl, Sondra. "The Composing Processes of Unskilled College Writers." Research in the Teaching of English. 13 (1979): 317-36. Rpt. in A Sourcebook for BasicWriting Teachers. Ed. Theresa Enos. New York: Random House. 1987. 417-439.

Rose, Mike. Lives on the Boundary: A Moving Account of the Struggles and Achievements of America's Educational Underclass. New York: Penguin Books, 1989.

Sonomura, Marion Okawa. Idiomaticity in the Basic Writing of American English: Formulas and Idioms in the Writing of Multilingual and Creole-Speaking Community College Students in Hawaii. New York: Peter Lang Publishing, 1996. 


\section{Ann Kirch}

\section{A BASIC WRITER'S TOPOI FOR TIMED ESSAY TESTS}

ABSTRACT: This article describes the problems the author's basic writing students have had in generating ideas for writing in response to timed essay tests. Since many of the common pedagogical approaches for helping students generate or create ideas for writing are ineffective, the author proposes an alternate technique based on the classical notion of the topoi. This ideological system enables students to generate ideas for timed writing tests and equips them for participation in the social and political dialogues that they encounter in higher education.

Last summer, after studying and practicing various "pre-writing" strategies, one of my students, Virginia, asked me what I would do if I had to come up with ideas in response to a timed essay test. She made it clear that the creativity techniques - free-writing, brainstorming, and clustering - simply had not worked for her. Every time she faced a timed essay assignment, her mind simply went "blank," and she could not think of anything to write. Even though she understood how to "cluster" for a textbook clustering assignment, she came up with nothing but empty bubbles when she had to get ideas for a timed essay. The rest of the students in the class sat quietly, waiting expectantly for my answer; Virginia, a "displaced homemaker," evidently represented many in this community college class when she asked this question. I suggested that they try a technique I use: When you get the essay topic, think about what other people might say in response to it. For example, if the topic deals with censoring rap song ly rics, imagine what friends, acquaintances, and others who have differing view points might say about the topic, write all these ideas down, and then sort them out.

The students were excited by the technique, and because it worked so well for me, I was certain that it could help them. However, when they tried it, they had only limited success: they had great difficulty imagining what these differing viewpoints could be. The method I

Ann Kirch is an instructor in the Developmental Studies Division at Grayson County College in Denison, Texas. She has presented at state and national developmental educators' conferences on a variety of issues concerning basic writers, including the design of collaborative team activities and the retention of under-prepared college students. She is a doctoral student in the College Teaching of English program at Texas A\&M University--Commerce. Her recent research has focused on applications of postmodern theory for basic reading and writing pedagosy. 
suggested, similar to the ones in their textbook, took for granted that the ideas for writing were "there" in the students' minds in some form or another if they could only use the proper "creativity" techniques to tap into them, bring them to the surface, and organize them into coherent written form. However, my students needed something more than instruction about what to do first and how to organize the clustering bubbles: they needed a ready source of ideas from which to write. Therefore, I had to rethink my suggestion to determine why it worked for me and not for my students. By examining various approaches to teaching students to generate ideas, I have discovered what I believe is a missing element in my basic writing pedagogy. From this discovery, I have developed a new approach for teaching students how to invent ideas for timed essay tests. In the paragraphs that follow, I will describe this method and suggest classroom activities that have helped my students improve their writing.

Before Virginia and her classmates asked me what I would do to get ideas for timed essays, we had already spent a considerable amount of time discussing the writing process and "pre-writing" strategies. "Pre-writing" suggests that writers take steps before they write, presumably to get ideas about what to write, and is clearly a helpful concept for those students who do not realize that good writing arises as a result of a process. Indeed, some basic writing students mistakenly believe that good writers are people capable of thinking up a perfect paper as fast as it can be written down. While this knowledge of a process is helpful, for basic writers, it is not enough because they often interpret this as advice to mimic the textbook formula of the process. Then, when following the process does not work, basic writers respond with complaints such as, "I don't know anything about this topic, so I can't even get started." For students thinking about the timed writing test itself, their question is often, "How am I supposed to complete all those steps in an hour?"

James Berlin points out that this process pedagogy arises as a result of what he calls the "objective" (139) approach to writing instruction. He explains that this objective approach is based on a positivistic, behavioral epistemology that focuses on steps in processes and descriptions of external reality (140-5). With the attitude of a scientist, the writer's task is to carefully observe external reality and record observations as clearly as possible. For a basic writing student facing a timed essay test, the problem with this instructional approach is that it skips over their first problem with the essay test situation: for Virginia, knowing that she is to "pre-write" before she writes does nothing to fill her blank mind with ideas.

Virginia and her classmates had also practiced several creativity techniques in the pre-writing chapter designed to help them get ideas for writing: brainstorming, free-writing, clustering, and keeping a jour- 
nal. These strategies are supposed to help students tap into some internal creative wellspring and then organize this gusher of ideas for writing. For some students, these strategies can be very effective. Certainly the textbook authors are generous in encouraging students to believe that they, too, are creative, and those who profit from these techniques seem to gain self-confidence as their writing skills improve over the course of the semester.

Berlin categorizes these creativity techniques as "subjective" (139), or expressionist, writing pedagogy. In this instructional approach, reality is located "within the individual, the lone agent acting apart from the material or social realms" (139). Individual insight and creative impulses are the reasons for writing, and the best ideas are original and unique, gathered through a meditative examination of one's inner nature, and carefully logged in a journal (146). These subjective creativity techniques encourage students to believe, rather egocentrically, that the only topics worth writing about are those that concern them personally. To my basic writing students concerned with making their pick-up payments, lining up a date for next weekend, or getting the laundry done, the range of topics that interest them is often personal and narrow. Because of the emphasis on egocentrism, students trained to look at writing subjectively often respond to failing timed writing tests with a flippant attitude: "I just didn't have anything to say about that subject" and "Who thinks up those silly topics, anyway?" The problem with this subjective approach is that since it does not address the issue of how to handle topics other than those that are interesting, it fails to help basic writers respond effectively to many topics found on timed-writing tests. Further, for many of my basic writing students, training them to depend on their private responses alone may lead them to think that they completely lack creativity. Equating creativity with imagination as so many people do (Jagla 32), they believe that their imagination is inadequate for the challenge of a timed essay test.

Since neither the objective nor the subjective pedagogical responses have proven sufficient for basic writing students facing timed writing tests, an approach that fills this gap by providing a source of ideas is needed: Berlin's "transactional" (155) approach seems to fill this gap and thus provides a theoretical basis for the topoi technique I developed. In the transactional approach, meaning resides not just in concrete reality nor in the student's creative ability, but, instead, in the rhetorical interplay among "material reality, writer, audience, and language" (155). Pedagogy based on this transactional approach helps students connect the objective reality, their own unique insights, and the ideas and concerns of the larger society. From this pedagogical perspective, ideas arise from the students' social awareness and from the writer's ability to locate connections between him- or herself, soci- 
ety, and the topic. What is missing from Berlin's "transactional" approach is a strategy for expanding basic writers' private worlds so that they become interested in the concerns of the society beyond our campus. Since the lack of ideas for writing timed essays often contributes to their earning the label "deficient" and places them outside the college level classes, helping the students gain this social awareness has the potential not only to give them a means of passing the writing test, but also for establishing the information base that can help make them a part of the mainstream in higher education.

Some critics of modern students see an obvious answer to my students' egocentrism and apathy about the concerns of the larger society: make these students culturally literate. Instructional material has been developed to help fill adult learners' minds with facts on every "literate" topic. However, filling students' heads with various facts seems to rely as much on chance for students who face a timed writing test as does brainstorming. No matter how many facts students learn, the ultimate applicability of these facts to a particular timed essay topic is as impossible to predict as the students' ability to apply facts they memorize outside of a meaningful context. The future benefit of knowing various tidbits of information is also questionable, for the cultural literacy answer ignores the fact that "the problem for basic learners, in short, is not the absence of knowledge, but the absence of knowledge that lends itself to further or broader learning" (Spellmeyer 126). In my experience, the knowledge that expands the learner's ability to learn gives basic writers an ability to respond effectively to any writing situation, including the timed essay test.

How a writing instructor goes about providing the type of knowledge that leads to broader learning presents a clear problem for designing an effective pedagogical approach. Patricia Bizzell, sensitive to the problem that basic writers often embrace outsider perspectives on topics they must write about, suggests that we teachers "present ... our political credentials" to our students (58). Our students might thus learn some carefully crafted insider positions to take on important issues and would not need to create their own views for a timed essay test. However, as Bill Bolin points out, "our adoption of such an approach might well obstruct our students' progress as developing writers and thinkers. Such an approach might very well also marginalize several of these same students" (78). Students might not learn to evaluate ideas and perspectives; moreover, they risk being unable to respond to an unknown essay test topic.

Where the ideas of the cultural literacy proponents may not provide basic writing students with knowledge flexible and generative enough for a timed essay test, rhetorical invention satisfies the need. Karen Burke LeFevre explains that "invention is... understood as a social act, in which an individual who is at the same time a social being 
interacts in a distinctive way with society and culture to create something" (1). Most importantly, invention involves an "internal dialogue with an imagined other or a construct of audience that supplies premises or structures of belief guiding the inventor" (34). Thus, through this internal or mental dialogue, invention provides a framework for organizing social awareness and understanding and, critical for students whose minds go blank, for generating additional ideas.

Such generative frameworks were common in the pedagogy of ancient Greek rhetoric teachers who taught invention as the first canon of rhetoric. According to Sharon Crowley, these invention frameworks, or topoi, were "an intellectual source or region harboring proof that could be inserted into any discourse where appropriate" (49). While Crowley's definition of topoi clearly captures the technique's generative usefulness for students, to enable us modern teachers to understand topoi more completely, we also need to understand that these "intellectual sources" or "harboring proof" (49) consisted of collections of thought patterns typical of Greek politics and valued by Greek society. Ancient rhetoric students memorized these collections and learned to think through them to invent ideas for their speeches. Thus, since the topoi were extracted from "the issues that concerned the community" (50) and were organized systematically, topoi can be more completely defined as a systematic arrangement of ideologies that allows students to draw from it to generate ideas for writing. When students become aware of the range of ideas of a community, they gain the ability to invent arguments along the lines of the community's concerns and values. Modern life makes our community equivalent to our nation; therefore, to create a topoi with significant heuristic potential, students must become familiar with the range of political ideology in the larger American society.

The topoi technique that I have developed to teach my students to respond more effectively to timed writing test topics combines the internal mental dialogue mentioned by LeFevre and the topoi described by Crowley into a generative framework of people and ideas. The advice I gave to Virginia and her classmates - to imagine other points of view that disagreed with their own-had not worked for them because they had no one with whom to conduct a mental dialogue and little understanding of the range of viewpoints possible in American society. However, when students engage in a structured internal dialogue with an audience representing various points on the American ideological spectrum, they discover content for their essays from their mental connections with others in our society. From there, students can investigate features of the ideas and responses and evaluate their appropriateness for the particular essay being written.

In order to teach students this invention technique, I have them work in teams that read much about and by various people who repre- 
sent particular political stances and positions on social issues. Their reading and reporting generates a mass of information, perspectives, and thought processes on topics and issues that I help them arrange into a system. Since the students hear and read terms such as "left," "right," "conservative," "liberal," "moderate," etc., from political commentators, I begin this activity by showing my students how this political vocabulary creates a system of political perspectives. This overview provides students with the basic framework upon which they can begin attaching the material they will be studying. The people whose work we read become reference points on this political framework, and the students learn to move mentally around this framework to invent a range of responses to issues.

Since the students in my basic writing classes frequently demonstrate various reading problems, I have designed the assignment as a team project. Students are assigned to one of four teams, each of which becomes responsible for reading and reporting on the material of a particular political or social writer. The teams read, discuss, and list the topics of concern and the perspectives of the person they are investigating. Each student on the team reads material that covers different topics of concern to their writing so that each student will have some new information to provide the group. After each team has read and discussed the work of their particular author, the class builds the topoi system by presenting and discussing the works of each team's writer. Each team becomes the expert on its own writer's ideology, but the goal is for each student in the class to become familiar with all the ideologies presented by the various groups so that each student can use the invention system. When a student uses this system, he or she responds to the topic of a writing assignment by thinking through how the various writers would respond to the topic, lists these ideas and then responds to them with his or her own ideas, judging the arguments and audience and discriminating among the various perspectives and ideas appropriate for the particular writing situation.

In order for this topoi invention system to be useful to the students when they write essays in a timed situation, the class must study people with diverse ideologies. Thus, I assist the students in choosing writers who have different perspectives from the ones that other groups are working on and from the perspectives of most people in the region. In Texas, Oklahoma, and Louisiana, the home states of most of my students, people's social and political perspectives tend to be in the conservative to moderate range. To challenge these points of view, students are reading Camille Paglia, Dick Gregory, Ralph Reed, and Marian Wright Edelman this semester. These four writers espouse political and social viewpoints markedly different from those held by most of my students and local people; these divergent perspectives help the students become more familiar with national perspectives, 
thus creating a wider experience base from which the students can respond.

In addition to assisting in the selection of authors, the teacher must actively participate in the reading stage of the assignment. For lower-level writing students, the teacher needs to select brief, easy-toread passages and circulate through the classroom to explain the difficult material. For higher-level students, the teacher can select longer passages and whole chapters for the students' reading, but he or she still needs to be present and ready to assist when the students begin to realize how much the viewpoints they are reading differ from their own. Their initial response is almost certain to be a strong emotional rejection of the ideas they are reading, regardless of their reading level. They are quite likely to express their discomfort with these new ideas by stating flatly, "I can't read this." At this critical point, the teacher needs to remind the students that they are not required to accept uncritically the viewpoints of the authors and that their own viewpoints are also valid. The students do, however, need to continue reading the material so they can report, as objectively as possible, the content to their groups and the class. After they report what they have read, they will be given a chance to share their reactions to the reading assignments.

This initial emotional rejection of divergent ideas, although uncomfortable for teacher and students alike, is an essential event in the process of building the topoi. This "conflict and tension" (Mutnick 148) between the students' ideologies and those of the authors they read indicate the students' increasing awareness of a broader range of social ideologies. As Bakhtin points out in his concept of dialogism, society's range of ideologies is based on a variety of intersecting "socioideological contradictions" (qtd. in Mutnick: 148). Thus, for students to systematize our society's ideologies, they must understand not only that the conflicts exist, but also that these conflicts actually comprise the system's framework.

Further, challenging the students' existing ideologies and helping them learn from the conflicts allow the students to engage in a. process that can form their individualities. According to Bakhtin, this formation of individuality occurs as two types of discourse, "externally authoritative and internally persuasive" (Mutnick 149), conflict. The reading assignments carry externally authoritative weight - both by being assigned by the teacher and by being published texts; the students' current viewpoints, belief systems, and experiences combine to form the internally persuasive discourse. When the students interpret the reading assignment as a command to believe what they read, they have recognized the authority of the discourse. Once I explain to them that they need not accept uncritically the viewpoints they read in their assignments, they begin to recognize the value of their own per- 
spectives, and their own internal discourse persuades them to move further into the conflict. However, after they have internally reaffirmed the value of their own perspectives, many of the students begin to discount the viewpoints in the reading they have been assigned. For students, the most comfortable way to deal with divergent viewpoints is to reject them; therefore, the teacher must help them balance, or establish a tension, between the externally authoritative discourse and the internally persuasive discourse. The teacher can do this by reminding them that the goal of the assignment is to understand and organize a broad range of issues from a broad range of perspectives; to do this, the students must read the material in a way that allows them to understand it well enough to accurately and unemotionally report to their group and the class.

Once the students have completed this challenging reading, they help teach the class about the person whose ideas they have been investigating and contribute to the shaping of the topoi system. Each writer, Paglia, Edelman, Gregory, and Reed, becomes a topos in the range of political ideas that the class assembles. After writing notes to prepare their own presentations, the students also write the points from the other teams' presentations. I help the students focus on various issues and concerns that make up each ideology by keeping a summary list on the chalkboard, and we discuss the points of conflict and the pertinent issues of each political position. Often, the students make connections between the viewpoints of their assigned writers and the viewpoints of other people they are familiar with from television, radio, relatives, or friends. These connections are extremely useful in helping them realize that they already are familiar with at least some of what they have studied and, thereby, in helping them gain a better understanding of the range of perspectives presented in class. In addition, some of my classes have enjoyed a role-playing debate in which they compare the perspectives on topics among the writers' various ideologies. During these debates, it often becomes clear that the unpopular liberal perspectives represented by Edelman and Gregory are either shared or have been accepted by some students; since Edelman criticizes welfare reform, her authority allows a generally unpopular viewpoint to be heard and recognized as a valid position.

To help the students learn to use this range of perspectives and political stances to generate ideas, I distribute a summary of each of their groups' presentations. Then, I bring in various practice timed essay topics. The students write down what Camille Paglia, Marian Edelman, Dick Gregory, and Ralph Reed might say in response to the topics and then discuss with other students what they believe these authors would say; thus, the students improve their ability to use the technique. Rather than being concerned that the students have correctly determined the response from each writer's ideology, I advise 
them to apply their understanding of each political perspective to the topics and then to engage in a mental dialogue by responding to topoi people in order to select ideas.

This invention technique has several advantages that seem to benefit students like the ones in our basic writing program. The students in my classes range in age from eighteen to forty-two and have diverse academic interests: general studies athletic scholarship students planning to transfer to four-year institutions, students attempting to be accepted into nursing or medical technology programs, and students with work experience returning to college to improve their opportunity to be promoted on the job. Our community college has an open admissions policy with a local placement test in math, writing, and reading. Students must also take the official state placement test (Texas Academic Skills Program) in their first or second semester in college. The majority of our students have been admitted to the college based on having graduated from high school, but about one-fourth of the students in basic writing dropped out of high school and were admitted based on having passed the GED. Most students attending our college reside in rural areas or small to mid-sized towns in Texas or Oklahoma and have been raised by families with very few, if any, college graduates; thus, they tend to have extremely limited perspectives on current social issues and political positions. Because of their limited perspectives on social issues, they are inexperienced in dealing with a range of issues like the ones they encounter on timed writing tests and often fail to recognize the social significance of the test topics.

The topoi invention technique helps students to gain a social awareness of topics and the perspective that any topic someone in society is concerned about is a topic worth thinking and writing about. For example, Lynn, a student from a small town in Oklahoma, failed the initial placement test because she was not interested in the topic of her essay, the dangers of pesticides. Since we have begun working on the topoi invention technique, Lynn has recently become very curious about the person her group is studying, Marian Edelman. She obtained information about Edelman from the internet and has told me that she is looking forward to the other groups' presentations. Lynn's response to Edelman's position reveals how the topoi technique is working for her because on the first day of their reading assignment, Lynn declared that she would be unable to complete the activity since Edelman's view of welfare and black families seemed so contrary to her own views. While Lynn has clearly not changed her own perspective on the question of welfare reform, she has become intrigued by Edelman's views and has talked to me several times about the mental dialogue she has been carrying on with Edelman.

Another major idea-generating benefit of the topoi invention tech- 
nique is that it seems useful in helping students in the difficult task of inventing alternative viewpoints. My students often find it impossible to accept or even work with perspectives that differ too much from theirs or their families'. However, these divergent views become easier to contemplate if they are associated with someone studied in the topoi system. The experience of one of my students, Lonnie, provides a helpful illustration. Before we began the invention technique, Lonnie complained that he could not believe that anyone could possibly understand both sides of an issue without being completely "confused." During our class discussion of the topoi system, the students responded in writing to whether liquor companies should be allowed to advertise on television. Lonnie, against the idea of advertising hard liquor on television, wrote that Camille Paglia would say banning alcohol products on the air would lead not just to hard liquor being banned, but also to products like mouthwash and perfume being banned because of their alcohol content. Lonnie wrote that he would respond to Paglia's argument by pointing out that alcohol products differ in the dangers they pose to society when they are abused. Thus, it makes sense for alcohol products to be banned because they are dangerous, but it makes little sense to ban unharmful products. Lonnie's mental discussion with Camille Paglia had helped him to find the argument of the other side, and, therefore, to formulate a response to it. This topoi technique helps students like Lonnie overcome the notion that being able to generate a particular idea is equivalent to believing it. Thus, students are able to generate enough ideas to evaluate and then to select the ones they find most appropriate for responding to a timed writing test.

The topoi technique also helps familiarize the students with reasoning patterns associated with the various authors they studied. In addition to the Camille Paglia "slippery slope" pattern that Lonnie worked with above, my students learn to associate Dick Gregory's work with a historical perspective. When students who have little historical understanding of events as recent as Watergate become familiar with Gregory's tendency to draw upon examples from history, they may experiment with this approach in their own writing. One timed essay topic that my students wrote in class after working on the invention strategy required them to write a letter to the local school board arguing whether to ban several classic American books from the library. Even though the students wrote their essays independently, thus simulating the timed essay testing condition, several students argued that these books should not be banned from the library because they have contributed historically to our culture, and that historical contribution should outweigh the judgment of a few parents. Although I have used this particular timed essay topic several times in the past, never before adopting the topoi technique have I noticed students arguing to keep 
books in a library because of the books' historical importance. Students explained that Dick Gregory's historical approach to issues had influenced their writing.

Finally, the topoi invention technique benefits students because they learn a system for examining a range of responses to topics and issues. As a result, they feel they can immediately begin writing rather than experiencing the stress of the blank mind. One of my students, Mitchell, mentioned that during timed essay tests his mind used to "start wandering." His mind wandered so much that his initial placement essay received a score of 5 out of 12 possible points. Students must receive a minimum score of 7 to pass the local placement essay, and in his retest, Mitchell told me that he used the invention system to focus his thoughts. Even when his mind did wander, the system enabled him to quickly return to the writing so he could complete his essay. His retest essay received a passing score of 8 . While many of the other class activities he had participated in undoubtedly helped him improve his writing, the knowledge that he had a system to rely on provided him with the confidence required to write a passing essay.

Comparing students' local placement test essays with their first full essays written after working on the invention technique further demonstrates how invention can help students discover content for their essays. One of my current students, David, received a score of 6 on his placement essay, one point below that required to pass. In this 330-word essay, he took a position against land in our county being sold to other states to be used as garbage storage areas. David provided two reasons for his position in the following topic sentences: "With the chemical waste in their back yards, countless numbers of children could develop brain tumors, cancer, or new diseases" and "Another major problem that will be caused by the waste is the oder." The scorers indicated that the essay's development was weak enough to be a major factor in the essay's receiving a failing score. In addition to a lack of reasons to support his view, David also failed to develop the two reasons. In the first body paragraph, David wrote about how the land should be valued and how it is important for children to learn to treat the land with respect. In the second body paragraph, after mentioning the problem with the odor of the waste storage, he repeated his point about how the land would become useless. In contrast, after learning the invention technique, David's first timed essay included 550 words with three body paragraphs explaining his opposition to funding tests for automobile safety devices for senior citizens. He developed his reasons based on those held by the topoi people we had been studying. His first body paragraph explained that "One excellent way of using the money would be to promote education. The young people of this great nation are in need of higher and better edu- 
cations. The senior citizens have been taught, paid their dues to this country. They have put all they had into making American great. But now it is time to help the people that are going to be taking over this great nation." In his next paragraph, David explained that "Another way the money from the test funding could be used is to help the needy people of this nation. Thousands of men, women, and children are left homeless every year... The money from the funding of such tests could be use to help needy and willing people to get back on their feet ... It is the responsibility of the government and the responsibility of every American to try and help those people . . . help themselves." David's last body paragraph explained that "A third way the money for the funding of the tests could be used is to improve our nations police force. With crime as high as it is, the officers are outnumbered. With help from the goverment, we would be able to increase the number of officers on the streets." David's ideas about where government money should go came up in class presentations about Paglia's, Edelman's, and Gregory's ideas.

The primary benefit of the topoi invention technique is that it strengthens students' social and political awareness. While my basic writing students are not initially excited by having to read the material by their topoi authors, once they start their work, engage in the conflicts, and understand how they will be able to invent better ideas for the timed essay test, they very willingly persevere through the reading and tension and demonstrate remarkable expansions in thinking, understanding, and writing. Since the technique both honors their existing perspectives while challenging them to understand others, the students become curious enough about political issues, perspectives, and priorities to extend their work outside the classroom. Many become participants in the ideological process: recently, several of my students voluntarily watched the President's State of the Union Address and wanted to talk about how the ideas in the speech connected to what they had been reading and discussing in our class. Thus, their preliminary, in-class discussion of political and social issues, values, and perspectives provided them with the ability to gradually build a broader and more profound awareness of the "topoi" of arguments prevalent today. They were increasingly able to determine how what they initially thought of as "silly" timed essay topics could connect to issues they and others in society believe to be important. By reading a wide range of writers in the larger American society. and discussing and debating various topics and ideas with classmates, the students began to become conversant on a wide range of issues and quite willing to depart from their writing textbook's reliance on inner creativity.

Enabling students to discover the political and social topoi within our larger society completely repositions the timed writing tests themselves. By training students to invent ideas for writing rather than to 
pre-write or create ideas through brainstorming and related techniques, the students contextualize the tests by creatively and rationally considering divergent points of view. Since timed writing tests are likely to remain in higher education for some time, it is important that basic writing teachers adopt pedagogical approaches that allow students to perform successfully on these assignments. By taking a broader perspective on the concept of generating ideas and developing a philosophy of idea invention, we can teach students to develop an ability that pushes them beyond the timed essay tests. They can use this information as a framework on which to begin fitting future material so that their ideological awareness can continue growing and they can continue as participants in the ideological dialogue. Thus, they become not the deficient outsiders so often pushed to the fringes of higher education, but competent insiders with the tools to connect writing with social and political understanding and experience.

\section{Note}

Student writing in this essay appears without corrections.

\section{Works Cited}

Berlin, James A. Rhetoric and Reality: Writing Instruction in American Colleges, 1900-1985. Carbondale: Southern Illinois University Press, 1987.

Bizzell, Patricia. "Power, Authority, and Critical Pedagogy." Journal of Basic Writing 10 (Fall 1991): 54-70.

Bolin, Bill. "Encouraging Students to (Continue to) Share Authority in the Classroom: A Response to Patricia Bizzell." Journal of Basic Writing 12 (Fall 1993): 77-85.

Crowley, Sharon. Ancient Rhetorics for Contemporary Students. New York: Macmillan, 1994.

Jagla, Virginia M. Teacher's Everyday Use of Imagination and Intuition: In Pursuit of the Elusive Image. Albany: SUNY Press, 1994.

LeFevre, Karen Burke. Invention as a Social Act. Carbondale: Southern Illinois University Press, 1987.

Mutnick, Deborah. Writing in an Alien World: Basic Writing and the Struggle for Equality in Higher Education. Portsmouth, NH: Boynton, 1996.

Spellmeyer, Kurt. Common Ground: Dialogue, Understanding, and the Teaching of Composition. Englewood Cliffs, NJ: Prentice Hall, 1993. 


\section{News and Announcements}

June 1-4, 1997: Literature and Literacy in an Age of Technology: Implications for Classroom Practice is the theme for the Summer Institute for Teachers of Literature at Myrtle Beach, South Carolina. Literature teachers have begun to develop new practices in response to technological possibilities including interactive CD-ROMs and the World Wide Web (WWW). The Ocean Creek Institute focuses this year on the problems and possibilities that emerge as literature instruction responds to technological change. The seminar leaders are John Slatin, Karen Swan, and William Costanzo. Enrollment is limited to 180 persons. Contact 1-800-369-NCTE, ext. 251 to get more information about the conference.

June 26-28, 1997: Expanding the Conversation on Reflection: Innovative Practices, New Understandings, Current Challenges will be held in Montreal, Canada. This conference is part of NCTE's Professional Development Services programs. Contact 1-800-369-NCTE and ask for Professional Development Services to get more information about the conference.

June 17-20, 1997: The 25th Wyoming Conference on English, "Really Useful Knowledge": Reading, Writing, and Resistance. The invited speakers include: Joseph Harris, Sara R. Horowitz, and Ira Shor. For more information about the conference contact Kathy Evertz at (307)766-6486 or KEVERTZ@UWYO.EDU. Conference information and updates may also be obtained from the WWW site at: http:// www.uwyo.edu/a\&s/engl (click on 1997 Wyoming Conference on English).

July 6-9, 1997: The 15th Annual Penn State Conference on Rhetoric and Composition to be held at State College, Pennsylvania will have as its theme: Rhetorical Bodies: Toward a Material Rhetoric. Some of the speakers include: Lester Faigley, Cheryl Glenn, Christina Haas, and Victor Villanueva. Visit the WWW site at: http:// www.cde.psu.edu/rhet\&comp/ For more information or call 1-800PSU-TODAY to receive a brochure about the conference.

January 7-10, 1998: CCCC Winter Workshop on Teaching Composition to Undergraduates: Constant Change and Perennial Wisdom in the Teaching of Writing will be held at the Sheraton Sand Key Resort, Clearwater Beach, FL. The workshop is designed to offer pro- 
fessional development opportunities to teachers in two- and four-year colleges through a three-strand workshop program: Technology and Writing, Basic Writers and ESL Students, and Diverse Contexts for Writing. Program co-chairs are Lillian Bridwell-Bowles and Ben Wiley. Information 1-800-369-NCTE, ext. 205.

CALL FOR PAPERS: Imagery and Composition: Classrooms, Curriculum, and Lives. Co-editors Kristie Fleckenstein, Linda Calendrillo, and Demetrice Worley solicit essays that investigate mental imagery in contexts that impinge on the teaching of writing and reading. The goal of the collection is to redress the imbalance across composition studies that has occurred because mental imagery has been marginalized and neglected. Submitters are urged to focus their essays on the intersection of theory and teaching. Submit 3 copies of a $3,000-5,000$ word essay (15-20 pages, including bibliography) in MLA format by June 30, 1997 to: Linda T. Calendrillo, Department of English, Eastern Illinois University, Charleston, IL 61920.

CALL FOR PAPERS: Journal for the Assembly for Expanded Perspectives on Learning (JAEPL) is soliciting manuscripts for the fourth annual edition; the theme is "Mind, Body, Spirit: Teachers Making Connections." Possible areas for consideration include: schema theory as body based, poststructuralist textualities, ecofeminism, writing as healing, silence, and ethics. Send 4 copies of 12-15 page manuscripts (APA style) by January 31, 1998 to Linda Calendrillo, Co-Editor of JAEPL, Department of English, 600 Lincoln Ave., Eastern Illinois University, Charleston, IL 61920, email jaepl@cctr.umkc.edu. Inquiries Kristie S. Fleckenstein, Co-Editor of JAEPL, University of MissouriKansas City, Kansas City, MO 64110-24999.

CALL FOR PAPERS: CAWS (CUNY Association of Writing Supervisors) Conference (to be held October 24, 1997 at Borough of Manhattan Community College); theme: That Thing We Do: Writing in CUNY. Send your abstract (a couple of paragraphs and a working title) to George Otte, Director of Writing Programs, Baruch College, CUNY, 17 Lexington Avenue, NY, NY 10010. Deadline: 1 July 1997. 


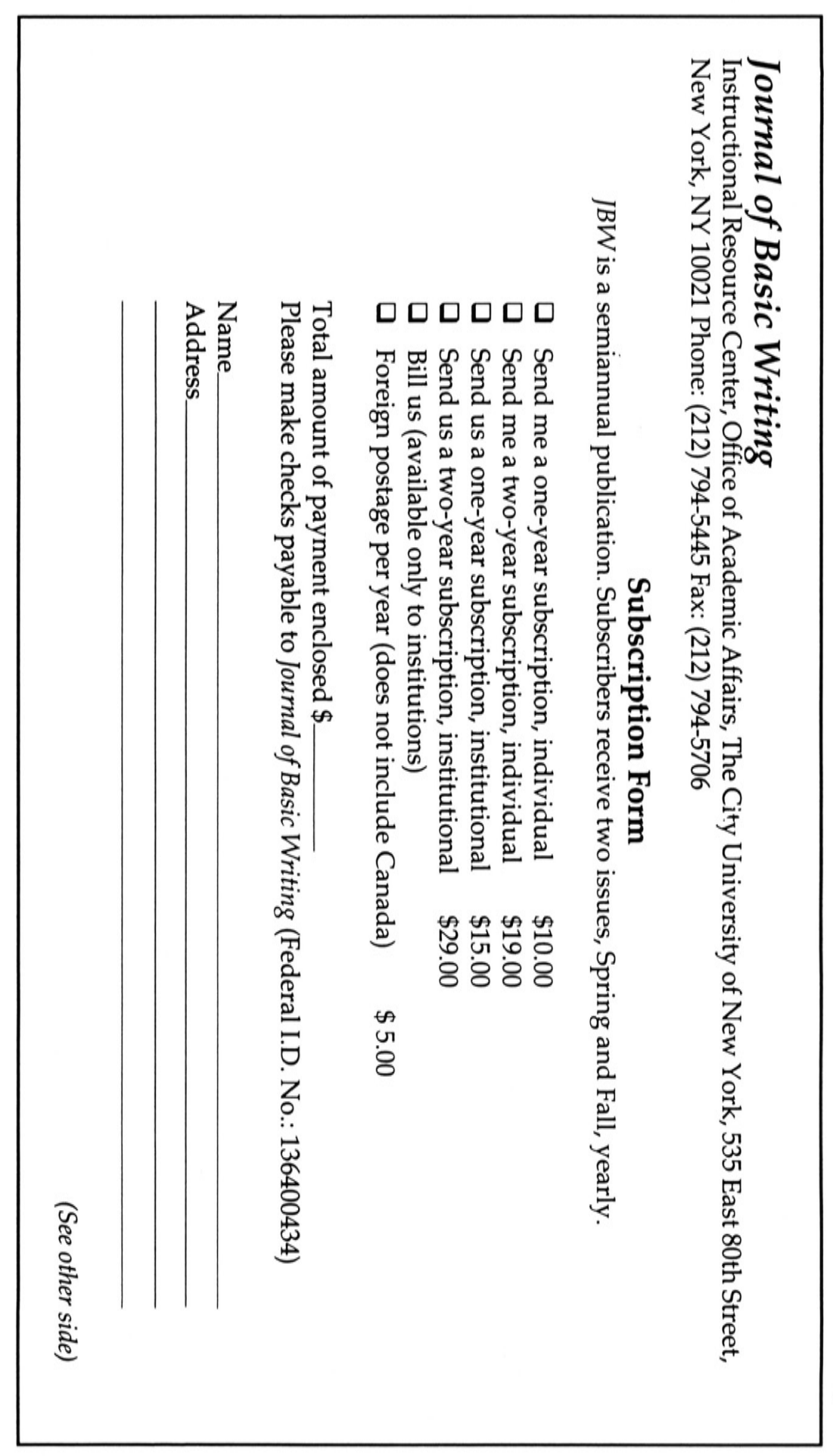




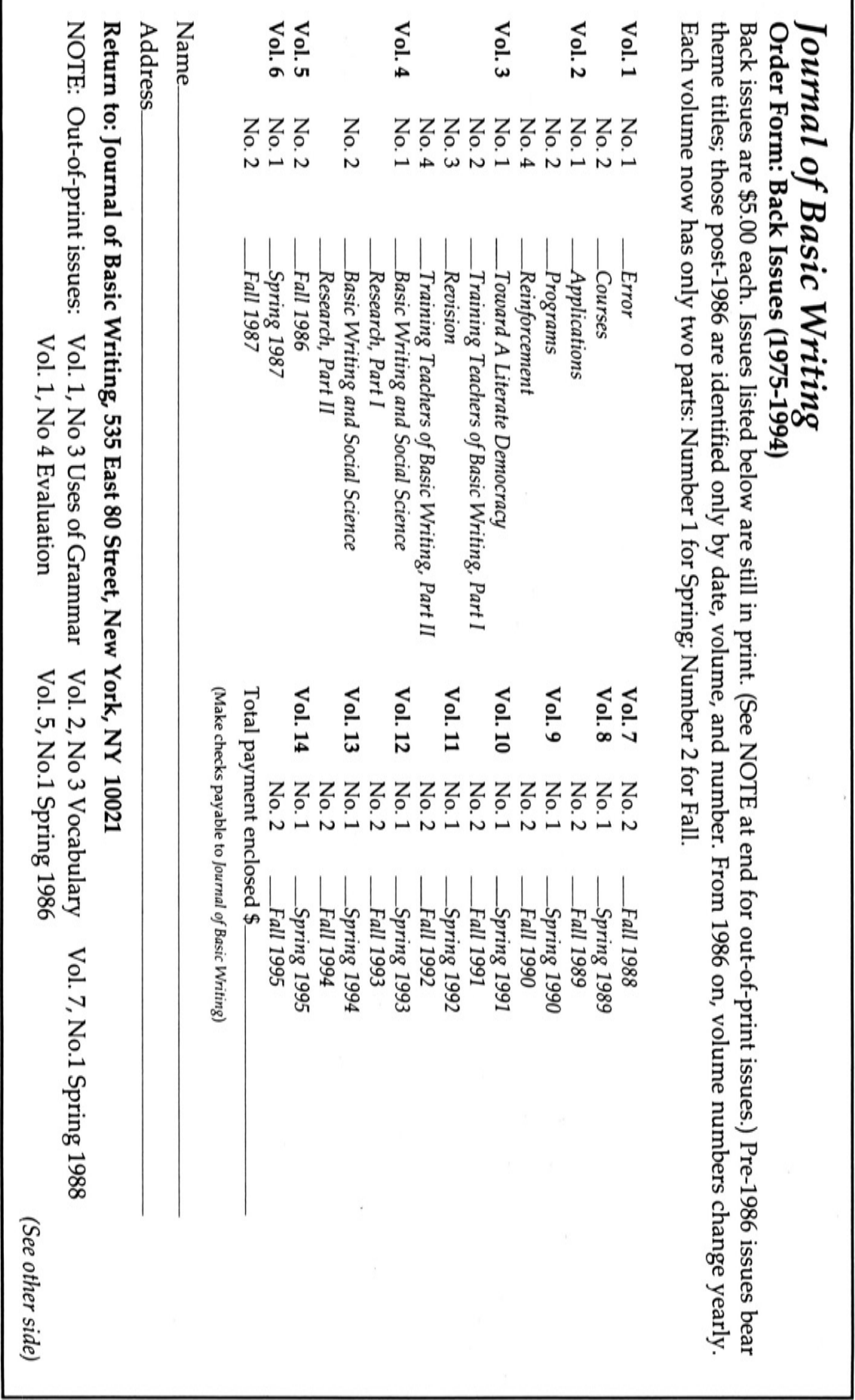




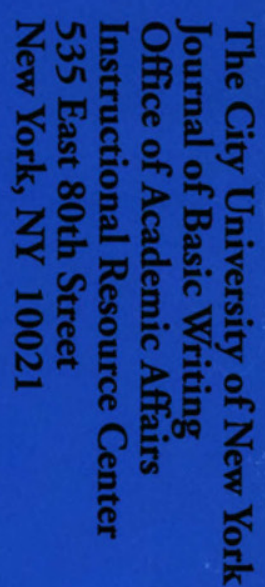

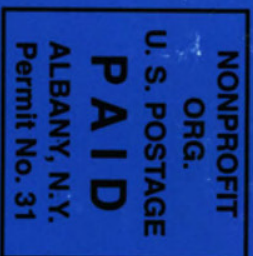

